Cochrane Database of Systematic Reviews

\title{
Mosquito repellents for malaria prevention (Review)
}

Maia MF, Kliner M, Richardson M, Lengeler C, Moore SJ

Maia MF, Kliner M, Richardson M, Lengeler C, Moore SJ.

Mosquito repellents for malaria prevention.

Cochrane Database of Systematic Reviews 2018, Issue 2. Art. No.: CD011595.

DOI: 10.1002/14651858.CD011595.pub2. 
TABLE OF CONTENTS

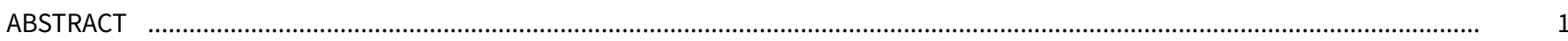

PLAIN LANGUAGE SUMMARY

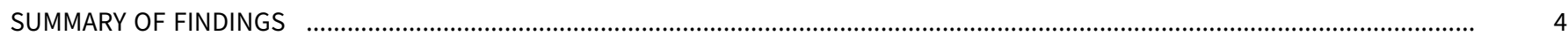

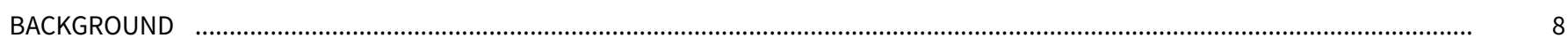

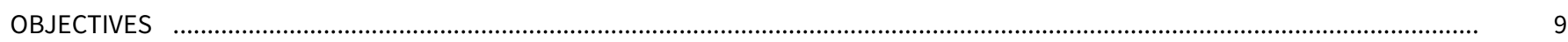

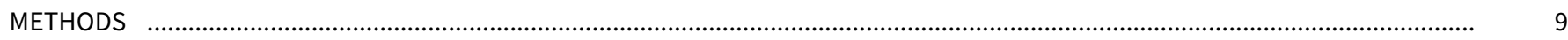

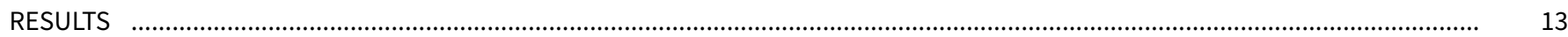

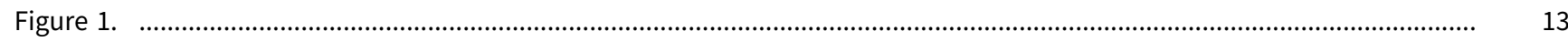

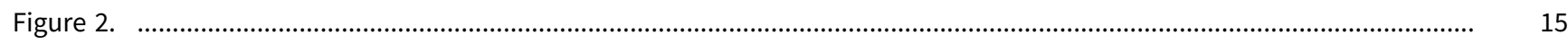

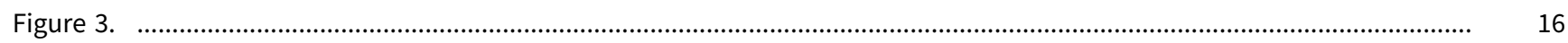

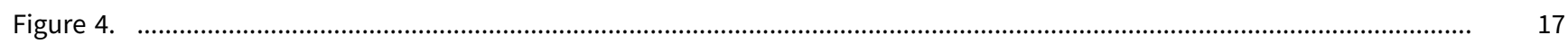

Figure 5.

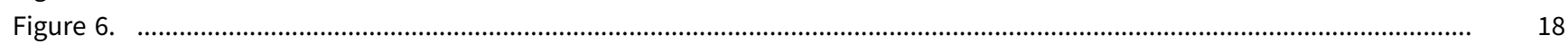

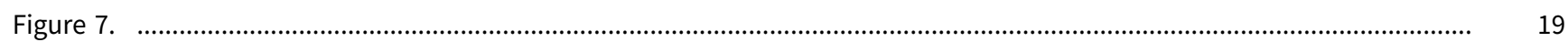

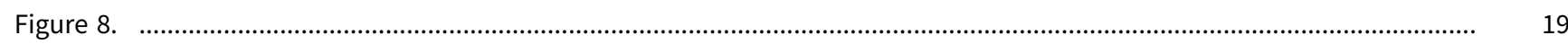

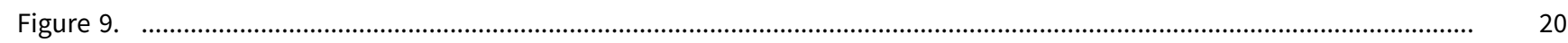

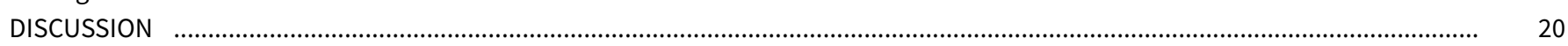

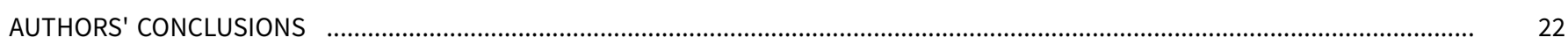

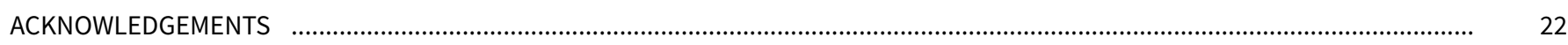

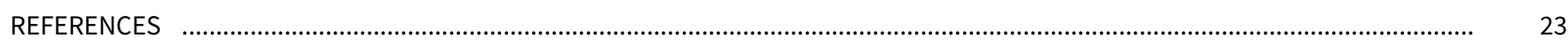

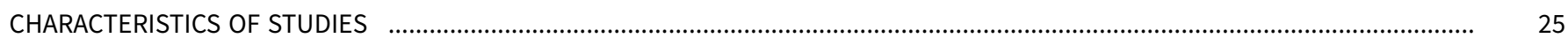

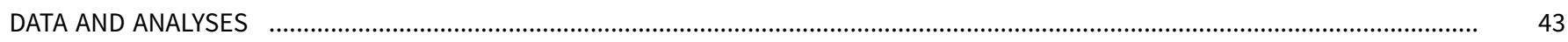

Analysis 1.1. Comparison 1 Topical repellent compared to placebo or no treatment, Outcome 1 Clinical malaria caused by 44 Plasmodium falciparum.

Analysis 1.2. Comparison 1 Topical repellent compared to placebo or no treatment, Outcome 2 Plasmodium falciparum parasitaemia.

Analysis 1.3. Comparison 1 Topical repellent compared to placebo or no treatment, Outcome 3 Clinical malaria caused by Plasmodium vivax.

Analysis 1.4. Comparison 1 Topical repellent compared to placebo or no treatment, Outcome 4 Plasmodium vivax parasitaemia.

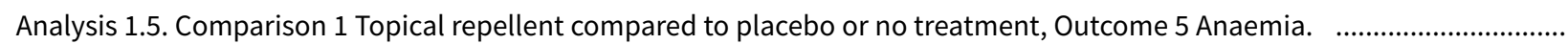

Analysis 1.6. Comparison 1 Topical repellent compared to placebo or no treatment, Outcome 6 All-cause fever. ....................

Analysis 1.7. Comparison 1 Topical repellent compared to placebo or no treatment, Outcome 7 Adherence to the intervention.

Analysis 1.8. Comparison 1 Topical repellent compared to placebo or no treatment, Outcome 8 Adverse events. ...................

Analysis 2.1. Comparison 2 ITC compared to placebo or no treatment, Outcome 1 Clinical malaria caused by Plasmodium falciparum.

Analysis 2.2. Comparison 2 ITC compared to placebo or no treatment, Outcome 2 Clinical malaria caused by Plasmodium vivax.

Analysis 2.3. Comparison 2 ITC compared to placebo or no treatment, Outcome 3 Adverse events.

Analysis 3.1. Comparison 3 Spatial repellents compared to placebo or no treatment, Outcome 1 Plasmodium spp. parasitaemia.

Analysis 3.2. Comparison 3 Spatial repellents compared to placebo or no treatment, Outcome 2 Adherence to the intervention.

Analysis 3.3. Comparison 3 Spatial repellents compared to placebo or no treatment, Outcome 3 Reduction in mosquito bites. .

Analysis 3.4. Comparison 3 Spatial repellents compared to placebo or no treatment, Outcome 4 Adverse events.

ADDITIONAL TABLES

APPENDICES

CONTRIBUTIONS OF AUTHORS

DECLARATIONS OF INTEREST

SOURCES OF SUPPORT

DIFFERENCES BETWEEN PROTOCOL AND REVIEW

INDEX TERMS 
[Intervention Review]

\section{Mosquito repellents for malaria prevention}

Marta F Maia1,2, Merav Kliner ${ }^{3}$, Marty Richardson4, Christian Lengeler ${ }^{1}$, Sarah J Moore ${ }^{1}$

1Public Health and Epidemiology, Swiss Tropical and Public Health Institute, Basel, Switzerland. 2Department of Biosciences, Kenya Medical Research Institute - Wellcome Trust Programme, Kilifi, Kenya. ${ }^{3}$ Health Protection Team, Public Health England North West, Manchester, UK. ${ }^{4}$ Cochrane Infectious Diseases Group, Liverpool School of Tropical Medicine, Liverpool, UK

Contact: Marta F Maia, Public Health and Epidemiology, Swiss Tropical and Public Health Institute, Socinstrasse 57, Basel, CH-4051, Switzerland.marta.maia@swisstph.ch,mmaia@kemri-wellcome.org.

Editorial group: Cochrane Infectious Diseases Group.

Publication status and date: Unchanged, published in Issue 2, 2018.

Citation: Maia MF, Kliner M, Richardson M, Lengeler C, Moore SJ. Mosquito repellents for malaria prevention. Cochrane Database of Systematic Reviews 2018, Issue 2. Art. No.: CD011595. DOI: 10.1002/14651858.CD011595.pub2.

Copyright ( 2018 The Authors. Cochrane Database of Systematic Reviews published by John Wiley \& Sons, Ltd. on behalf of The Cochrane Collaboration. This is an open access article under the terms of the Creative Commons Attribution-Non-Commercial Licence, which permits use, distribution and reproduction in any medium, provided the original work is properly cited and is not used for commercial purposes.

\section{A B S T R A C T}

\section{Background}

Malaria is an important cause of illness and death across endemic regions. Considerable success against malaria has been achieved within the past decade mainly through long-lasting insecticide-treated nets (LLINs). However, elimination of the disease is proving difficult as current control methods do not protect against mosquitoes biting outdoors and when people are active. Repellents may provide a personal protection solution during these times.

\section{Objectives}

To assess the impact of topical repellents, insecticide-treated clothing, and spatial repellents on malaria transmission.

\section{Search methods}

We searched the following databases up to 26 June 2017: the Cochrane Infectious Diseases Group Specialized Register; the Central Register of Controlled Trials (CENTRAL), published in the Cochrane Library; MEDLINE; Embase; US AFPMB; CAB Abstracts; and LILACS. We also searched trial registration platforms and conference proceedings; and contacted organizations and companies for ongoing and unpublished trials.

\section{Selection criteria}

We included randomized controlled trials (RCTs) and cluster-randomized controlled trials of topical repellents proven to repel mosquitoes; permethrin-treated clothing; and spatial repellents such as mosquito coils. We included trials that investigated the use of repellents with or without LLINs, referred to as insecticide-treated nets.

\section{Data collection and analysis}

Two review authors independently reviewed trials for inclusion, extracted the data, and assessed the risk of bias. A third review author resolved any discrepancies. We analysed data by conducting meta-analysis and stratified by whether the trials had included LLINs. We combined results from CRCTs with individually RCTs by adjusting for clustering and presented results using forest plots. We used GRADE to assess the certainty of the evidence. 


\section{Main results}

Eight CRCTs and two RCTs met the inclusion criteria. Six trials investigated topical repellents, two trials investigated insecticide-treated clothing, and two trials investigated spatial repellents.

\section{Topical repellents}

Six RCTS, five of them cluster-randomized, investigated topical repellents involving residents of malaria-endemic regions. Four trials used topical repellents in combination with nets, but two trials undertaken in displaced populations used topical repellents alone. It is unclear if topical repellents can prevent clinical malaria ( $\mathrm{RR} 0.65,95 \% \mathrm{Cl} 0.4$ to 1.07 , very low certainty evidence) or malaria infection (RR $0.84,95 \% \mathrm{Cl}$ 0.64 to 1.12 , low-certainty evidence) caused by $P$. falciparum. It is also unclear if there is any protection against clinical cases of $P$. vivax (RR $1.32,95 \% \mathrm{Cl} 0.99$ to 1.76 , low-certainty evidence) or incidence of infections (RR $1.07,95 \% \mathrm{Cl} 0.80$ to 1.41 , low-certainty evidence). Subgroup analysis of trials including insecticide-treated nets did not show a protective effect of topical repellents against malaria. Only two studies did not include insecticide-treated nets, and they measured different outcomes; one reported a protective effect against clinical cases of $P$. falciparum (RR $0.40,95 \% \mathrm{Cl} 0.23$ to 0.71 ); but the other study measured no protective effect against malaria infection incidence caused by either $P$. falciparum or $P$. vivax.

\section{Insecticide-treated clothing}

Insecticide-treated clothing were investigated in trials conducted in refugee camps in Pakistan and amongst military based in the Colombian Amazon. Neither study provided participants with insecticide-treated nets. In the absence of nets, treated clothing may reduce the incidence of clinical malaria caused by P. falciparum by approximately $50 \%$ (RR $0.49,95 \% \mathrm{Cl} 0.29$ to 0.83 , low-certainty evidence) and P. vivax (RR $0.64,95 \% \mathrm{Cl} 0.40$ to 1.01 , low-certainty evidence).

\section{Spatial repellents}

Two cluster-randomized RCTs investigated mosquito coils for malaria prevention. We do not know the effect of spatial repellents on malaria prevention (RR $0.24,95 \% \mathrm{Cl} 0.03$ to 1.72 , very low certainty evidence). There was large heterogeneity between studies and one study had high risk of bias.

\section{Authors' conclusions}

There is insufficient evidence to conclude topical or spatial repellents can prevent malaria. There is a need for better designed trials to generate higher certainty of evidence before well-informed recommendations can be made. Adherence to daily compliance remains a major limitation. Insecticide-treated clothing may reduce risk of malaria infection in the absence of insecticide-treated nets; further studies on insecticide-treated clothing in the general population should be done to broaden the applicability of the results.

2 April 2019

Up to date

All studies incorporated from most recent search

All eligible published studies found in the last search (26 Jun, 2017) were included and four ongoing studies have been identified (see 'Characteristics of ongoing studies' section)

\section{PLAIN LANGUAGE SUMMARY}

\section{Mosquito repellents for malaria prevention}

\section{What was the aim of this review?}

The aim of this Cochrane Review was to find out if mosquito repellents - topical repellents (applied to the skin); insecticide-treated clothing; or spatial repellents such as mosquito coils - can prevent malaria. We collected and analysed the results of all relevant studies to answer this question and found data from ten trials: six on topical repellents, two on insecticide-treated clothing, and two on spatial repellents.

\section{Key messages}

We do not know if the use of repellent lotions or burning of mosquito coils can provide protection from malaria to communities living in endemic regions. In situations where long-lasting insecticide-treated bed nets (LLINs) cannot be rolled out, such as after a natural disaster or amongst displaced populations, the use of insecticide-treated clothing may reduce the risk of malaria infection by $50 \%$. Most studies included in our analysis were poorly designed and had high risk of bias. In order to draw well-informed conclusions, further high-quality studies must be conducted to improve the certainty of the evidence. However, it is questionable if topical repellents can be used for malaria prevention in the general population as daily compliance and poor standardization (amount of repellent used, surface area applied, time of application, and period between repeated applications) are major limitations of this intervention. 


\section{What was studied in this review}

Mosquito repellents provide protection from mosquito bites. There are three different types of repellents: topical repellents, which can be applied on the skin; insecticide-treated clothing, through impregnation of clothing with repellent compounds; and spatial repellents, such as mosquito coils. Malaria has decreased in many countries because people have been given highly effective LLINs. However people are still being bitten before they go to bed. There is a need to find a way to offer protection from malaria during these hours. Mosquito repellents may address this gap.

\section{What are the main results of the review?}

A total of six trials investigated the use of topical repellents for malaria prevention. The trials took place in different malaria-endemic regions across South America, Asia, and sub-Saharan Africa. The topical repellents tested included lotions, treated soap, and local cosmetics. We analysed the studies in groups according to LLIN inclusion. Most studies rolled out LLINs to the population and investigated topical repellents as a complementary intervention to the treated bed-nets. The poor design of the included studies provided low to very low certainty evidence, consequently we do not know if there is a benefit of using topical repellents in addition to LLINs to prevent malaria. The compliance of participants to adhere to the daily application of repellents remains a challenge to further research.

Insecticide-treated clothing was investigated in two trials conducted with refugees in Pakistan and military deployed in the Amazon; neither study rolled out or reported the use of bed-nets. In the absence of LLINs, there is some evidence that insecticide-treated clothing may reduce the risk of malaria infection by $50 \%$. Given that the findings relate to special populations living in particularly harsh conditions it is unclear if the results are applicable to the general population. Further studies involving civilian populations should be done to improve the certainty of these findings.

Two studies investigated the practice of burning mosquito coils to reduce malaria infections. One study was conducted in China and the other in Indonesia. The study designs were substantially different and one study had high risk of bias leading to very low certainty evidence. We do not know if mosquito coils offer protection against malaria. The findings underline the need for further research.

\section{How up to date is this review?}

The review authors searched for studies that had been published up to 26 June 2017. 


\section{SUMMARY OF FINDINGS}

\section{Summary of findings for the main comparison. Topical repellents compared to placebo or no treatment for malaria prevention}

Topical repellents compared to placebo or no treatment for malaria prevention

Patient or population: malaria prevention

Setting: malaria-endemic regions

Intervention: topical repellents

Comparison: placebo or no treatment

\begin{tabular}{|c|c|c|c|c|c|c|}
\hline \multirow[t]{2}{*}{ Outcomes } & \multicolumn{2}{|c|}{$\begin{array}{l}\text { Anticipated absolute effects }{ }^{*} \\
(95 \% \mathrm{Cl})\end{array}$} & \multirow[t]{2}{*}{$\begin{array}{l}\text { Relative effect } \\
(95 \% \mathrm{Cl})\end{array}$} & \multirow{2}{*}{$\begin{array}{l}\text { Number of par- } \\
\text { ticipants } \\
\text { (studies) }\end{array}$} & \multirow{2}{*}{$\begin{array}{l}\text { Certainty of the } \\
\text { evidence } \\
\text { (GRADE) }\end{array}$} & \multirow[t]{2}{*}{ Comments } \\
\hline & $\begin{array}{l}\text { Risk with } \\
\text { Placebo or no } \\
\text { treatment }\end{array}$ & $\begin{array}{l}\text { Risk with Topi- } \\
\text { cal repellents }\end{array}$ & & & & \\
\hline $\begin{array}{l}\text { Clinical malaria: } \\
\text { P. falciparum }\end{array}$ & 39 per 1000 & $\begin{array}{l}\mathbf{2 5} \text { per } \mathbf{1 0 0 0} \\
(15 \text { to } 41)\end{array}$ & $\begin{array}{l}\text { RR } 0.65 \\
(0.40 \text { to } 1.07)\end{array}$ & $\begin{array}{l}4450 \\
\text { (3 studies) }\end{array}$ & $\begin{array}{l}\oplus \ominus \ominus \ominus \\
\text { VERY LOW1,2,3 } \\
\text { Due to risk of } \\
\text { bias, inconsisten- } \\
\text { cy and impreci- } \\
\text { sion }\end{array}$ & $\begin{array}{l}\text { We do not know if topical repellents have an effect on } \\
\text { malaria cases caused by } P \text {. falciparum. We have very } \\
\text { little confidence in the effect estimate. The true effect } \\
\text { is likely to be substantially different from the estimate } \\
\text { of effect. }\end{array}$ \\
\hline $\begin{array}{l}\text { Parasitaemia: } P \text {. } \\
\text { falciparum }\end{array}$ & 15 per 1000 & $\begin{array}{l}12 \text { per } 1000 \\
(9 \text { to } 17)\end{array}$ & $\begin{array}{l}\text { RR } \mathbf{0 . 8 4} \\
\text { (0.64 to } 1.12)\end{array}$ & $\begin{array}{l}13,310 \\
\text { (4 studies) }\end{array}$ & $\begin{array}{l}\oplus \oplus \odot \odot \\
\mathrm{LOW} 4,5 \\
\text { Due to risk of bias } \\
\text { and imprecision }\end{array}$ & $\begin{array}{l}\text { Topical repellents may or may not have a protective } \\
\text { effect against } P \text {. falciparum parasitaemia. Our confi- } \\
\text { dence in the effect estimate is limited. The true effect } \\
\text { may be substantially different from the estimation of } \\
\text { the effect. }\end{array}$ \\
\hline $\begin{array}{l}\text { Clinical malaria: } \\
\text { P. vivax }\end{array}$ & 36 per 1000 & $\begin{array}{l}\mathbf{4 8} \text { per } 1000 \\
(36 \text { to } 64)\end{array}$ & $\begin{array}{l}\text { RR } 1.32 \\
\text { (0.99 to } 1.76)\end{array}$ & $\begin{array}{l}3996 \\
\text { (2 studies) }\end{array}$ & $\begin{array}{l}\oplus \oplus \odot \odot \\
\text { LOW6,7 } \\
\text { Due to risk of bias } \\
\text { and imprecision }\end{array}$ & $\begin{array}{l}\text { Topical repellents may increase the number of clinical } \\
\text { cases caused by P. vivax. Our confidence in the effect } \\
\text { estimate is limited. The true effect may be substantial- } \\
\text { ly different from the estimation of the effect. }\end{array}$ \\
\hline $\begin{array}{l}\text { Parasitaemia: } P \text {. } \\
\text { vivax }\end{array}$ & 18 per 1000 & $\begin{array}{l}19 \text { per } 1000 \\
(14 \text { to } 25)\end{array}$ & $\begin{array}{l}\text { RR } 1.07 \\
\text { (0.80 to } 1.41)\end{array}$ & $\begin{array}{l}9434 \\
\text { (3 studies) }\end{array}$ & $\begin{array}{l}\oplus \oplus \odot \odot \\
\text { LOW } 7,8 \\
\text { Due to risk of bias } \\
\text { and imprecision }\end{array}$ & $\begin{array}{l}\text { Topical repellents may or may not have a protective } \\
\text { effect against } P \text {. vivax parasitaemia Our confidence in } \\
\text { the effect estimation is limited. The true effect may be } \\
\text { substantially different from the estimation of the ef- } \\
\text { fect. }\end{array}$ \\
\hline
\end{tabular}

*The risk in the intervention group (and its $95 \% \mathrm{Cl}$ ) is based on the assumed risk in the comparison group and the relative effect of the intervention (and its $95 \% \mathrm{Cl}$ ). 


\section{GRADE Working Group grades of evidence}

High certainty: we are very confident that the true effect lies close to that of the estimate of the effect.

Moderate certainty: we are moderately confident in the effect estimate: the true effect is likely to be close to the estimate of the effect, but there is a possibility that it is substantially different.

Low certainty: our confidence in the effect estimate is limited: the true effect may be substantially different from the estimate of the effect.

Very low certainty: we have very little confidence in the effect estimate: the true effect is likely to be substantially different from the estimate of effect.

1Downgraded by 1 for risk of bias: Sangoro 2014a used alternate allocation and reported a baseline imbalance; random sequence generation and allocation concealment were not described by Rowland 2004; and Sluydts 2016 did not have a placebo so the intervention was not blinded.

2Downgraded by 1 because of the large heterogeneity between the 3 trials. The $I^{2}$ statistic, which quantifies the proportion of the variation in the point estimates due to among study differences, was considered substantial at $50 \%$. The subgroup analysis to some extent explained the heterogeneity but we do not believe that there is enough evidence to suggest there is a true subgroup effect given that there is no heterogeneity in the outcome parasitaemia caused by P. falciparum where studies with and without LLINs were also analysed.

3Downgraded by 1 for imprecision because the sample size is too small, the Cls are wide, the pooled effect (0.40 to 1.07$)$ overlaps a risk ratio (RR) of 1.0 (no effect) and presents an estimate of effect ranging between beneficial and harmful.

4Downgraded by 1 for risk of bias: Hill 2007 used alternate allocation and reported a baseline imbalance; random sequence generation and allocation concealment were not described by McGready 2001.

${ }^{5}$ Downgraded by 1 for imprecision because the sample size is too small, the Cls are very wide, the pooled effect (0.62 to 1.12 ) overlaps a risk ratio (RR) of 1.0 (no effect) and presents an estimate of effect ranging between beneficial and harmful.

6Downgraded by 1 for risk of bias: random sequence generation and allocation concealment were not described by Rowland 2004; Sluydts 2016 was not placebo-controlled and intervention was not blinded.

${ }^{7}$ Downgraded by 1 for imprecision because the $\mathrm{Cls}$ are very wide, the pooled effect ( 0.80 to 1.41 ) overlaps a risk ratio (RR) of 1.0 (no effect) and presents an estimate of effect ranging between beneficial and harmful.

8Downgraded by 1 for risk of bias: random sequence generation and allocation concealment were not described by McGready 2001.

\section{Summary of findings 2 . ITC compared to placebo or no treatment for malaria prevention}

\section{ITC compared to placebo or no treatment for malaria prevention}

Patient or population: malaria prevention

Setting: malaria-endemic regions

Intervention: ITC

Comparison: placebo or no treatment

\begin{tabular}{lllll}
\hline Outcomes & $\begin{array}{l}\text { Anticipated absolute effects } \\
(95 \% \mathrm{Cl})\end{array}$ & $\begin{array}{l}\text { Relative effect } \\
(95 \% \mathrm{Cl})\end{array}$ & $\begin{array}{l}\text { Number of par- } \\
\text { ticipants } \\
\text { (studies) }\end{array}$ & $\begin{array}{l}\text { Certainty of the } \\
\text { evidence } \\
\text { (GRADE) }\end{array}$ \\
\cline { 1 - 2 } $\begin{array}{l}\text { Risk with } \\
\text { placebo or no } \\
\text { treatment }\end{array}$ & Risk with ITC & & \\
\end{tabular}




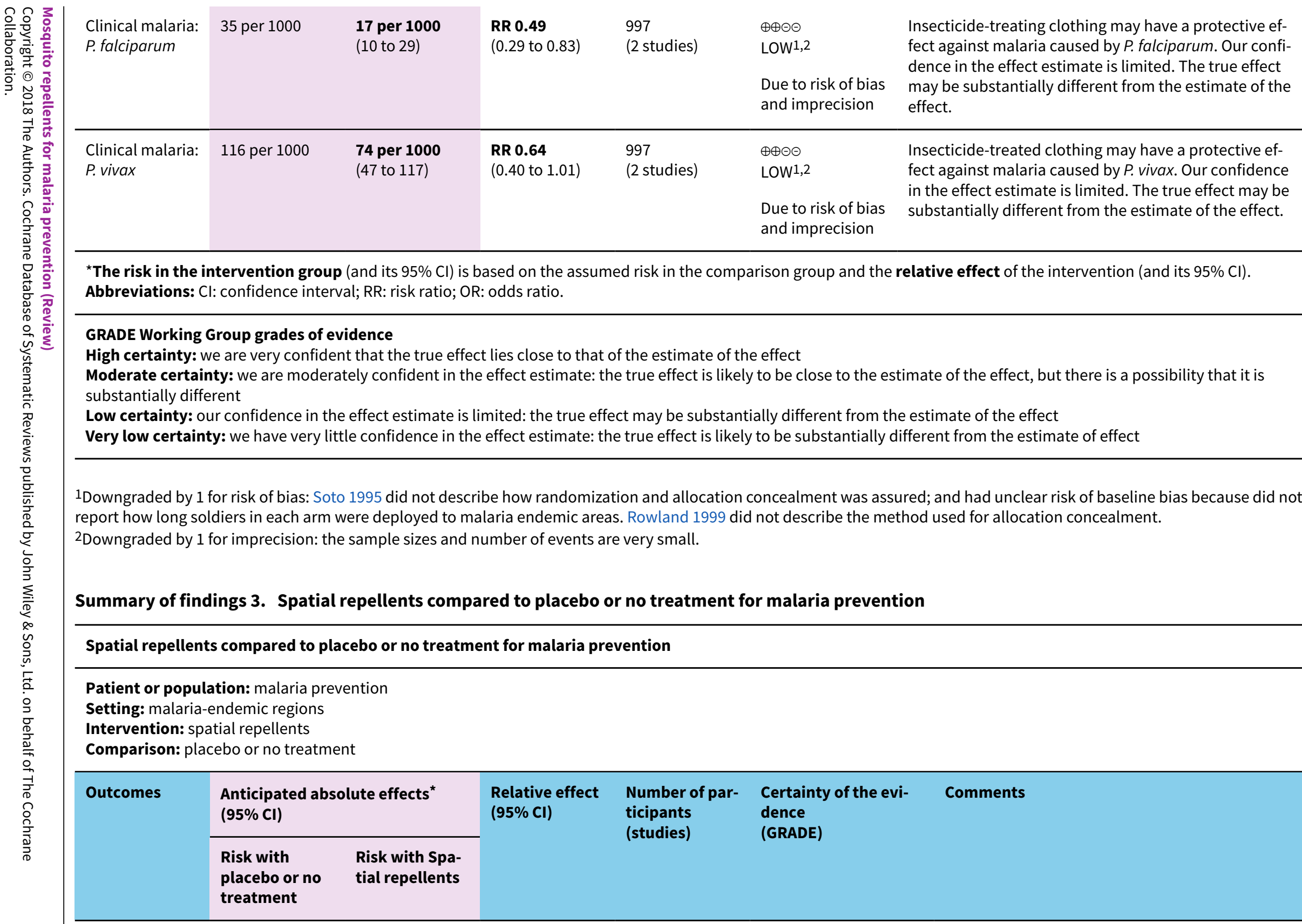




\section{B A C K G R O U N D}

\section{Description of the condition}

Malaria is caused by protozoan parasites of the genus Plasmodium. The most severe form of the disease is caused by Plasmodium falciparum. Other Plasmodium species known to cause milder cases of malaria include Plasmodium vivax, Plasmodium ovale, and Plasmodium malariae. The parasites are transmitted to people through the bite of an infected Anopheles mosquito. Malaria is widespread in tropical and subtropical regions and is considered endemic in 91 countries worldwide (WHO 2017). Symptoms of malaria include fever, chills, headache, and vomiting, and usually appear between 10 to 15 days after the bite of an infected mosquito. If left untreated, the person may develop severe complications and malaria can quickly become life-threatening by disrupting the blood supply to vital organs. Diagnosis is done through identification of the Plasmodium parasite in the patient's bloodstream, usually by microscopic examination of a blood slide or malaria rapid diagnostic tests (mRDTs).

In the past decade, great advances have been made in the fight against malaria. From 2000 to 2016 global incidence of malaria fell by $40 \%$ and related mortality by $62 \%$ (WHO 2017). This is due to massive scale-up of vector control interventions using longlasting insecticide-treated bed nets (LLINs) and indoor residual spraying (IRS), as well as the introduction of mRDTs for better malaria diagnosis and use of highly effective artemisinin-based combination therapies (ACTs). Despite these developments, an estimated three billion people living in 91 countries are still at risk of contracting malaria and 1200 children under five years old die every day in malaria-endemic regions (WHO 2017). The World Health Organization's (WHO) Global Technical Strategy (GTS) aims to reduce global malaria incidence and mortality rates by $90 \%$ by 2030 , with a milestone of at least $40 \%$ reduction by 2020 . The GTS also set targets to eliminate the disease in at least 10 countries by 2020 and 35 countries by 2030 . While the vector control component of most national malaria control programmes concentrates on distribution of LLINs and IRS, there is substantial malaria transmission within and outside Africa at times when people are outdoors (Durnez 2013). Recent estimates are that 10\% of global malaria burden occurs outside Africa, with approximately $58 \%$ of $P$. vivax cases occurring in the WHO South-East Asia Region (WHO 2017), where vectors are primarily early evening feeders (Sinka 2010; Sinka 2011). In order to achieve sustained malaria control and move towards malaria elimination, new tools will be required to interrupt transmission in environments where existing tools are not completely effective (malERA 2011). Residual malaria transmission is maintained by the presence of asymptomatic carriers, the significant number of non-compliant LLIN users, early evening outdoor-feeding Anopheles mosquitoes, and the spread of drug and insecticide resistance (White 2014). As well as preventing early evening bites, mosquito repellents may be suitable for people who have a high occupational risk of contracting malaria, such as: those working at night particularly in mining; soldiers; people in close contact with forest ecosystems; and migrants (Sangoro 2014b). It is well known that these high-risk individuals 're-seed' malaria in areas where vector control activities are carried out (Tatem 2010). With the impetus for malaria eradication of the past decade and the realization that the existing control tools alone cannot achieve this, mosquito repellents are increasingly

Mosquito repellents for malaria prevention (Review)

Copyright ( 2018 The Authors. Cochrane Database of Systematic Reviews published by John Wiley \& Sons, Ltd. on behalf of The Cochrane

Collaboration. being considered as supplementary tools in some malaria-endemic settings (Sturrock 2013).

\section{Description of the intervention}

Personal protection has been used for centuries to prevent mosquito bites (Herodotus 1996). Historically, people burned repellent plants and applied essential oils directly to their skin or clothing. In recent times, manufacturers have developed more effective products that have largely replaced traditional methods. These products include mosquito coils, long-lasting formulated repellent lotions, and insecticide treatments for clothing. Mosquito repellents are currently recommended by the WHO as the first-line malaria-prevention tool for travellers (WHO 2012), and they are commonly used by expatriates in tropical developing countries.

There are three main interventions that help prevent mosquito bites:

- applying topical repellents directly to the skin;

- wearing insecticide-treated clothing (ITC);

- using spatial repellents.

The mode of action of these three interventions on the mosquito is not the same; however they all result in preventing mosquito bites outside sleeping hours and so potentially reduce transmission of Plasmodium parasites from infected mosquitoes to humans.

\section{Topical repellents}

Topical repellents may contain a wide range of active ingredients and are available in various formulations in lotions, gels, roll-ons, and on wipes. Repellents interfere with mosquitoes' olfactory reception, affecting their ability to locate and feed on a human host. Approved active ingredients for mosquito-borne disease prevention are DEET (chemical name: N,N-diethyl-mtoluamide or N,N-diethyl-3-methyl-benzamide); icaridin (KBR 3023 [Bayrepel] and picaridin inside the USA; chemical name: 2-2hydroxyethyl-1-piperidinecarboxylic acid 1-methylpropyl ester); PMD (para-methane-3,8-diol); and IR3535 (chemical name: 3-[Nbutyl-N-acetyl]-aminopropionic acid, ethyl ester) (CDC 2014; WHO 2012). The Environmental Protection Agency (EPA) estimates that approximately 200 million people use DEET worldwide every year (WHOPES 1998).

\section{ITC}

ITC is widely used by military personnel to protect against vectorborne diseases and biting nuisance (Kitchen 2009). The synthetic pyrethroid permethrin $\left(2 \mathrm{~g} / \mathrm{m}^{2}\right)$ is used most commonly for treatment of clothing. Permethrin is approved by the WHO for this purpose because of its low dermal absorption, low mammalian toxicity, lack of odour and minimal irritation (WHOPES 2006). The mode of action of ITC is through contact irritancy, whereby mosquitoes make oriented movement away from the person after physical contact with the treated clothing surface; it also affects mosquitoes' feeding response. Both of these modes of action result in a reduction in mosquito bites to the person using the treated material.

\section{Spatial repellents}

Spatial repellents disperse active ingredients into the surrounding air that interfere with the mosquito's ability to find a host, thus preventing mosquitoes from taking a blood meal. They may 
interfere with host detection; or cause insects to fly in an undirected manner until they eventually move away from the source of repellent vapour (excito-repellency). Spatial repellents create a protective area within a given radius and can be used to protect more than one person at the same time. Dispersal of the active ingredient can be done in two ways:

- through heat, for example mosquito coils and electric emanators; or

- through evaporation, for example passive emanators made of paper or agarose gel.

The most popular format is the mosquito coil and an estimated 45 to 50 billion mosquito coils are used annually by approximately two billion people worldwide, mainly in Southeast Asia (Zhang 2010). Mosquito coils are made from a mixture of inert ingredients, such as sawdust or coconut husks, and pigment. The coils burn at a low temperature dispersing the active ingredient, usually a volatile pyrethroid with a quick knock-down action (for example, pyrethrin, D-allethrin, transfluthrin, or metofluthrin). The smoke produced by the burning of mosquito coils can cause indoor air pollution.

Electric emanators consist of an electrical heating agent that vaporizes insecticide that has been impregnated into a pad or wick. These produce no smoke but require a source of electricity, which is not available in a large proportion of homes in malaria-endemic countries.

Passive emanators do not require a source of heat or combustion. They have a large surface area which allows the passive dispersal of the volatile active ingredient into the air by evaporation. The chosen active ingredients are predominantly less polar compounds that are easily volatilized: examples include volatile pyrethroids such as metofluthrin and transfluthrin.

\section{How the intervention might work}

During the first Global Malaria Eradication Campaign the concept of vectorial capacity was developed and validated to mathematically evaluate the impact of mosquito-control interventions on malaria transmission using several measurable field parameters (GarrettJones 1964). Vectorial capacity is defined as: "the daily rate at which future inoculations of a parasite arise from a currently infective case, provided that all female vectors biting that case become infected" (Garrett-Jones 1964). The original validation demonstrated that by reducing man-vector contact (mosquito bites) by $50 \%$ there was a consequent $75 \%$ reduction in vectorial capacity. Man-vector contact can be reduced by using repellents. Mosquitoes will be repelled or disabled from feeding on a person while being exposed to the repellent. These personal protective measures can be used at any time or location, and so are suitable for controlling mosquitoes biting outdoors and during early evening hours before people go to bed. Repellents might also protect individuals from other mosquito-borne diseases such as dengue, Zika, and chikungunya.

\section{Why it is important to do this review}

The wide distribution of LLINs in malaria-endemic countries has resulted in a considerable reduction of malaria incidence and prevalence throughout affected areas (WHO 2017). However residual malaria transmission, defined as the malaria transmission occurring despite universal coverage with effective IRS or LLINs, requires other vector control interventions, particularly outdoors and outside sleeping hours. It is estimated that in South America and Southeast Asia $80 \%$ of malaria transmission occurs before sleeping hours. Even in Africa, where Anopheles mosquitoes are traditionally late feeders, up to $20 \%$ of malaria transmission takes place during early evening and early morning hours (Sangoro 2014b). During this time the only available means of protection are repellents or ITC, thus these interventions might have the potential to reduce residual transmission. This Cochrane Review aimed to measure the effectiveness of these interventions - either alone or when combined with LLINs - in reducing the incidence of malaria, to facilitate decision makers considering the inclusion of repellents in national malaria control programmes. In addition, we believe that this review may be helpful in the pursuit of Goal 3 of the United Nations Sustainable Development Goals (SDGs), to ensure healthy lives and promote well-being for all at all ages. The specific SDG 3 targets that this review addresses include:

- by 2030 , reduce the global maternal mortality ratio to less than 70 per 100,000 live births: pregnant women are more attractive to mosquitoes and therefore at a higher risk of infection than when the same women are not pregnant. In addition, pregnant women are particularly susceptible to complications of malaria. Modern repellents are safe to use among pregnant women and therefore have the potential to confer protection to a high-risk group;

- by 2030 , end preventable deaths of newborns and children under five years of age, with all countries aiming to reduce neonatal mortality to at least as low as 12 per 1000 live births and under-five mortality to at least as low as 25 per 1000 live births. Reducing the number of mosquito bites a child receives has been shown to lower the morbidity from malaria (Snow 1998). Repellents may also reduce other vector-borne diseases as the most widely used repellents are broad spectrum and prevent bites from a range of disease vectors;

- by 2030 , end the epidemics of AIDS, tuberculosis, malaria, and neglected tropical diseases, and combat hepatitis, waterborne diseases, and other communicable diseases: by directly reducing the human-vector biting rate and reducing malaria transmission.

\section{O B JECT IVES}

To assess the impact of topical repellents, insecticide-treated clothing (ITC), and spatial repellents on malaria transmission.

\section{METHOD S}

\section{Criteria for considering studies for this review}

\section{Types of studies}

We included only randomized controlled trials (RCTs) or cluster randomized controlled trials (CRCTs) with more than two units of randomization.

\section{Types of participants}

We included all adults and children living in malaria-endemic areas.

\section{Types of interventions}

We included trials with or without LLINs in both trial arms. 


\section{Intervention}

- ITC impregnated with permethrin; or

- topical repellents including DEET, icaridin, picardin, IR3535, and PMD; or

- spatial repellents including transfluthrin coils, metofluthrin coils, D-allethrin coils, pyrethrin coils, metofluthrin emanators, and transfluthrin emanators.

\section{Control}

Individuals given a placebo or no treatment.

\section{Types of outcome measures}

\section{Primary outcomes}

- Clinical malaria: confirmed through blood smears or rapid diagnostic tests (P. falciparum or P. vivax);

- malaria parasitaemia (malaria infection incidence): confirmed through thick or thin blood smears, mRDTs, or polymerase chain reaction (PCR) (P. falciparum or $P$. vivax).

\section{Secondary outcomes}

- Anaemia (haemoglobin $<10 \mathrm{~g} / \mathrm{dL}$ );

- time to first infection (days);

- all-cause fever;

- adherence to regular usage of the intervention measured through spot-checking per period of time;

- reduction in mosquitoes attempting to feed on humans;

- recorded adverse events such as skin irritation, irritation of upper airways, nausea, and headache.

\section{Search methods for identification of studies}

We identified all relevant trials regardless of language or publication status (published, unpublished, in press, and in progress) (Lefebvre 2011).

\section{Electronic searches}

We searched the following databases using the search terms and strategy described in Appendix 1: the Cochrane Infectious Diseases Group Specialized Register (up to 23 June 2017); MEDLINE (PubMed, 1966 to 26 June 2017); Embase (OVID, 1974 to 26 June 2017); CAB Abstracts (Web of Science, 1910 to 26 June 2017), and LILACS (1982 to 26 June 2017). We also searched the United States Armed Forces Pesticide Management Board website (US AFPMB; www.acq.osd.mil/eie/afpmb) on 12 August 2016; the WHO International Clinical Trials Registry Platform (ICTRP; www.who.int/trialsearch); and ClinicalTrials.gov on 26 June 2017, using 'randomised controlled Trial', 'controlled clinical trial', 'mosquito*', 'Anopheles', 'malaria', 'DEET', 'PMD', 'IR3535', 'Icaridin', 'Metofluthrin', 'Transfluthrin', 'vaporizer mat*', 'electric emanator', insecticide treated clothing', 'ITC', 'personal protection', and 'repellen*' as search terms.

\section{Searching other resources}

\section{Conference proceedings}

We searched the following conference proceedings of the relevant abstracts:

\section{- MIM conference abstract booklets (2008 to present);}

- Annual ASTMH conference (2008 to present);

- Entomological Society of America (2008 to present);

- Society of Vector Ecology of America (2008 to present).

\section{Organizations and pharmaceutical companies}

We contacted organizations (including the WHO, Centers for Disease Control and Prevention (CDC), United States Department of Agriculture (USDA), United States Agency for International Development (USAID), US AFPMB, and Deployed War Fighter Protection Program (DWFP)) and chemical companies (including Bayer, Sumitomo, Vestergaard-Frandsen, BASF, SC Johnson, Insect Shield, Mosiguard, Sara Lee, and Syngenta) for ongoing and unpublished trials.

\section{Reference lists}

We also checked the reference lists of all included trials for further relevant studies.

\section{Data collection and analysis}

\section{Selection of studies}

Two review authors (MM and MK) independently assessed the titles and abstracts of trials identified by the searches. The same two review authors assessed full-text copies of potentially relevant trials for inclusion using an eligibility form based on inclusion criteria. They compared included trials, and resolved any disagreements by discussion and consensus, with arbitration when necessary by one or two more review authors (SJM and $\mathrm{CL}$ ). We ensured that multiple publications of the same trial were only included once. We listed excluded studies, together with their reasons for exclusion, in table format.

\section{Data extraction and management}

Two review authors (MM and MV) independently extracted information from the trials using pre-piloted, electronic data extraction forms. Differences in extracted data were discussed between both authors until a consensus was reached. In cases where a consensus could not be reached, further discussions were held involving one or two more authors (SJM and $\mathrm{CL}$ ). In cases where missing data were identified, we contacted the original trial author(s) for clarification.

We extracted data on the following:

- trial design: type of trial; method of participant selection; unit of randomization (for RCTs); adjustment for clustering for CRCTs; sample size; method of blinding of participants and personnel; diagnostic method; primary vector; vector biting time; malaria endemicity; Plasmodium species;

- participants: trial settings and population characteristics; recruitment rates; withdrawal and loss to follow-up;

- intervention: description of intervention; co-interventions; description of controls; time of follow-up; passive or active case detection; compliance;

- outcomes: definition of outcome; number of events; number of participants; power; unit of analysis; incomplete outcomes/ missing data.

For dichotomous outcomes, we extracted the number of patients experiencing each outcome and the number of patients in each treatment group. For continuous outcomes, we extracted the mean 
and a measure of variance (standard error) for each treatment group.

For CRCTs we recorded the number of clusters randomized; number of clusters analysed; measure of effect (such as risk ratio, odds ratio, or mean difference) with confidence intervals (Cls) or standard deviations; number of participants; and the intra-cluster correlation coefficient (ICC) value.

\section{Assessment of risk of bias in included studies}

Two review authors (MM and MK) independently assessed risk of bias for each included trial using the Cochrane's 'Risk of bias' tool (Higgins 2011). Any discrepancies were resolved through discussion or by consulting one or two more review authors (SJM and $\mathrm{CL}$ ). We classified judgements of risk of bias as either 'low', 'high' or 'unclear', using summary graphs ('Risk of bias' summary and 'Risk of bias' graph) to display results.

We assessed each of the following components for each included $\mathrm{RCT}$ randomized by the individual and by cluster.

\section{Sequence generation}

We described the methods used to generate the allocation sequence in sufficient detail to allow an assessment of whether it produced comparable groups. We regarded a trial as having a low risk of selection bias if the sequence generation was truly random (for example computer-generated table of random numbers, tossing a coin); a high risk of bias if sequence generation was nonrandom (for example alternate randomization, randomization by birth date); or an unclear risk of bias if the randomization process was not clearly described.

\section{Balance}

We assessed if both arms of the trial were equally balanced at baseline using criteria including age, gender, malaria indicators, socioeconomic status, housing, use of other interventions, knowledge about malaria transmission, and occupation.

\section{Allocation concealment}

We described the method used to conceal allocation to treatment groups before assignment. We regarded trials as having a low risk of selection bias if allocation was truly concealed (for example central allocation of participants; use of sequentially numbered, opaque, sealed envelopes; lottery system); a high risk of bias if the allocation process was not concealed (for example open randomization, unsealed or non-opaque envelopes); or an unclear risk of bias if the process of concealing allocation was not described sufficiently to make a judgement.

\section{Blinding of participants and personnel}

We described whether blinding was present, who was blinded, and the methods used to blind trial participants and personnel. We regarded a trial as having a low risk of performance bias if blinding was present, or if the absence of blinding was unlikely to affect the outcomes; a high risk of bias if blinding was absent and likely to affect the results; or an unclear risk of bias if blinding was not clearly described.

\section{Blinding of outcome assessors}

Regarding blinding of outcome assessors: we described whether blinding of outcome assessors was present, and how they were blinded. We regarded a trial as having a low risk of detection bias if they were blinded to knowledge about which intervention the participants received; a high risk of bias if blinding was absent; or an unclear risk if blinding was not clearly described.

\section{Incomplete outcome data}

We described the percentage and proportion of patients who were lost to follow-up; reasons for attrition; and whether attrition was balanced across groups or related to outcomes. We regarded trials as having a low risk of attrition bias if there were no missing data or if missing data were balanced across groups or clusters; high risk of bias if there were missing data or if missing data were more prevalent in one of the groups; or unclear risk of bias if it is unclear whether outcome data are missing.

\section{Selective outcome reporting}

We recorded any discrepancies between the pre-specified outcomes in the Methods section and the outcomes reported, and identified outcomes that were measured but not reported on. We regarded a trial as having low risk of reporting bias if it was evident that all pre-specified outcomes were reported on; high risk of bias if it was evident that not all pre-specified outcomes were reported on; and unclear risk of bias if it was unclear whether all outcomes were reported on.

\section{Incorrect analysis}

We described whether the analysis was appropriate; whether an analysis plan was followed; and if it was adjusted for clustering.

\section{Other bias}

We described any important feature of included trials that could have affected the result.

In addition to the above, we assessed the following for each included CRCT.

\section{Recruitment bias}

Regarding recruitment bias, we described whether participants were recruited before or after randomization of clusters. We regarded trials as having low risk of recruitment bias if participants were recruited before randomization of clusters; high risk of bias if they were recruited after randomization; and unclear risk of bias if information about the timing of recruitment was unclear.

\section{Loss of clusters}

We described the number of clusters lost, as well as the reasons for attrition.

\section{Compatibility with RCTs randomized by individuals}

We noted whether the intervention effects may be systematically different from individually RCTs - that is, whether it was likely that the effect size was over- or underestimated.

\section{Measures of treatment effect}

We compared intervention and control data using risk ratios. All results were presented with their associated $95 \%$ confidence 
intervals $(95 \% \mathrm{Cls})$. Data regarding reduction in mosquito bites was compared using mean difference and standard deviation.

\section{Unit of analysis issues}

We combined results from CRCTs with individually RCTs if they had adjusted for clustering in their analysis and presented results using forest plots. If there was no adjustment for clustering in RCTs, we adjusted data before combining it with data from individually RCTs. We adjusted the data by multiplying standard errors by the square root of the design effect (Higgins 2011). If the trial did not report the ICC value, we estimated the ICC from a similar trial, or by searching external sources for example ICCs. Regarding studies which measured malaria transmission through active case detection and reported results from multiple crosssectional studies, only data from the last cross-sectional study was included in the meta-analysis.

\section{Dealing with missing data}

In case of missing data, we applied available-case analysis, only including data on the known results. The denominator used was the total number of participants who had data recorded for the specific outcome. For outcomes with no missing data, we carried out analyses on an intention-to-treat (ITT) basis. We included all participants randomized to each group in the analyses and analysed participants in the group to which they were randomized.

\section{Assessment of heterogeneity}

We inspected forest plots for overlapping $\mathrm{Cls}$ and assessed statistical heterogeneity in each meta-analysis using the $\mathrm{I}^{2}$ and $\mathrm{Chi}^{2}$ statistics. We regarded heterogeneity as moderate if $\mathrm{I}^{2}$ values are between $30 \%$ to $60 \%$; substantial if they are between $59 \%$ to $90 \%$; and considerable if they are between $75 \%$ to $100 \%$. We regarded a $\mathrm{Chi}^{2}$ test statistic with a $\mathrm{P}$ value less than or equal to 0.10 as indicative of statistically significant heterogeneity. We explored clinical and methodological heterogeneity through consideration of the trial populations, methods and interventions, and by visualization of trial results.

\section{Assessment of reporting biases}

In cases where 10 or more trials were included in each metaanalysis, we investigated reporting biases (such as publication bias) using funnel plots. We assessed funnel plot asymmetry visually, and used formal tests for funnel plot asymmetry (Harbord 2006). We explored reasons for asymmetry.

\section{Data synthesis}

We grouped trials and analysed by these interventions:

- topical repellents;

- ITC;

- spatial repellents.

Within each group, we stratified by whether LLINs were included in both intervention and control groups.

We analysed data using Review Manager 5 (RevMan 5) software (Review Manager 2014). We used fixed-effect meta-analysis to combine data when heterogeneity was absent. If considerable heterogeneity was present, we combined data using randomeffects meta-analysis and reported an average treatment effect.
We decided whether to use fixed-effect or random-effects metaanalysis based on the consideration of clinical and methodological heterogeneity between trials, as described previously.

\section{Certainty of the evidence}

We rated the certainty of the evidence using the GRADE approach (Guyatt 2011). Each important outcome was rated as follows, as described by Balshem 2011:

- high: we are very confident that the true effect lies close to that of the estimate of the effect;

- moderate: we are moderately confident in the effect estimate. The true effect is likely to be close to the estimate of the effect;

- low: our confidence in the effect estimate is limited. The true effect may be substantially different from the estimate of the effect;

- very low: we have very little confidence in the effect estimate. The true effect is likely to be substantially different from the estimate of effect.

RCTs start as high certainty evidence but can be downgraded if there are valid reasons within the following five categories: risk of bias, imprecision, inconsistency, indirectness, and publication bias. Studies can also be upgraded if there is a large effect; a doseresponse effect; and if all plausible residual confounding would reduce a demonstrated effect or would suggest a spurious effect if no effect was observed (Balshem 2011). We summarized our findings in a 'Summary of findings' table.

\section{Subgroup analysis and investigation of heterogeneity}

We explored reasons for substantial heterogeneity using subgroup analysis. We subgrouped trial data on clinical malaria and malaria parasitaemia based on whether the study had investigated the repellent intervention in combination with insecticide-treated bed nets. We assessed differences between subgroups using the $\mathrm{Chi}^{2}$ test, with a $\mathrm{P}$ value less than or equal to 0.05 indicating statistically significant differences between subgroups.

\section{Sensitivity analysis}

We performed sensitivity analysis on the primary outcome to see the effect of exclusion of trials at high risk of bias (for improper randomization methods and allocation concealment) on overall results. The same analysis was done to investigate whether the exclusion of being placebo-controlled had an effect. If the ICC value was estimated, we carried out sensitivity analyses to investigate the impact of varying the ICC on results from the meta-analysis.

We conducted three sensitivity analyses to test the robustness of our results:

- sensitivity analysis 1 : excluded trials at high risk of bias for improper randomization and allocation concealment;

- sensitivity analysis 2: excluded non-placebo controlled trials;

- sensitivity analysis 3: varied the estimated ICC for trials that did not report ICC. 


\section{RESULTS}

\section{Description of studies}

\section{Results of the search}

We searched the available literature up to 26 June 2017 and identified 440 citations from the electronic database searches and three from other sources. We identified two duplicates. We screened 441 articles by title and abstract. We selected abstracts that potentially matched our inclusion criteria, and also articles where it was unclear whether or not they fulfilled the inclusion criteria, for full-text assessment. We excluded 425 articles and identified 16 full-text articles for further assessment. After full-text assessment of these articles, we excluded and listed six articles; and we gave reasons for exclusion in the Characteristics of excluded studies table. Ten articles met the inclusion criteria and were included in the qualitative and quantitative synthesis. We have illustrated the study selection process in Figure 1.

Figure 1. Study flow diagram.

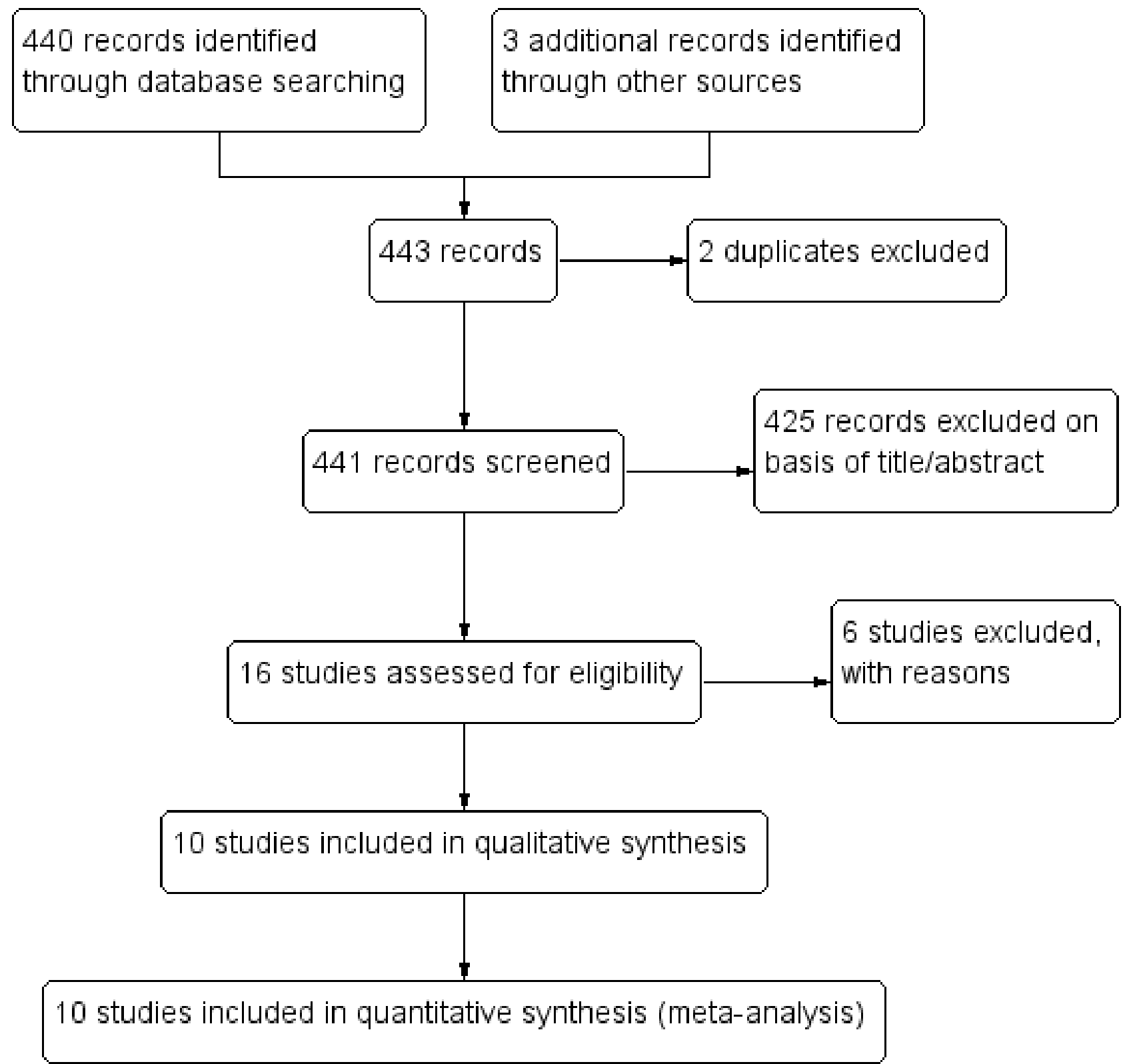

\section{Included studies}

Two RCTs, McGready 2001 and Soto 1995, and eight cRCTs - ChenHussey 2013, Hill 2007, Hill 2014, Rowland 1999, Rowland 2004, Sangoro 2014a, Sluydts 2016, and Syafruddin 2014 - met the inclusion criteria of this Cochrane Review. Data from McGready 2001 was obtained after we contacted the study author: the author provided the number of events (malaria cases) per treatment arm including the number of individuals who had more than one episode of $P$. falciparum or $P$. vivax. Only the first episode of $P$. vivax per participant was included in the analysis as individuals with multiple episodes of vivax malaria might suffer recurrent episodes of the same infection. We also contacted the authors of all the 
CRCTs that did not report ICC (Chen-Hussey 2013; Hill 2007; Sangoro 2014a; Sluydts 2016): only one author provided the ICC used on their study (Sluydts 2016). The remaining studies, for which ICC was not available, were adjusted for clustering using an estimated ICC of 0.04 - obtained from Rowland 2004, a cRCT on topical repellents - as per protocol. Sensitivity analysis was done to evaluate if variation of the estimated ICC resulted in significant change to the main results and conclusions.

Six studies investigated the impact of topical repellent compared to placebo or no treatment (Chen-Hussey 2013; Hill 2007; McGready 2001; Rowland 2004; Sangoro 2014a; Sluydts 2016). In total, 34,281 participants were included in the treatment arms and 33,016 in the control arms. The studies were conducted in a variety of countries: Laos (Chen-Hussey 2013), Bolivia (Hill 2007), Thailand (McGready 2001), Pakistan (Rowland 2004), Tanzania (Sangoro 2014a), and Cambodia (Sluydts 2016). A variety of repellents and concentrations were used: 15\% DEET (Chen-Hussey 2013; Sangoro 2014a); 20\% DEET (McGready 2001); 30\% PMD (Hill 2007); 20\% DEET and $0.5 \%$ permethrin (Rowland 2004); and picaridin (20\% picaridin for adults and $10 \%$ picaridin for children) (Sluydts 2016). Three studies used LLINs as co-interventions (Chen-Hussey 2013; Hill 2007; Sangoro 2014a). Most studies included both children and adults in the population; however one study only included pregnant women (McGready 2001).

Two studies investigated the impact of ITC compared to placebo or no treatment (Rowland 2004; Soto 1995). In total, 524 individuals were in the treatment arms, and 473 individuals were in the control arms. One study was conducted with Afghan refugees in Pakistan (Rowland 1999); and the other with soldiers based in Colombia (Soto 1995). We extracted data from Rowland 1999 using inverse variance from adjusted odds ratio and confidence intervals reported in the article. The study follow-up ranged from three to 16 weeks. Data from Soto 1995 on recorded adverse events included data from soldiers who were enrolled in the study and deployed in leishmania-endemic regions (143 per arm). These individuals were not part of the component of the study investigating the effect of
ITC on malaria incidence but because they also received the same treatments the results were included in the review regarding the outcome "recorded adverse events". No co-interventions were used in either study.

Two studies investigated the impact of spatial repellents compared to placebo or no treatment (Hill 2014; Syafruddin 2014). One study was conducted in China with 1026 households in both the intervention and control arms. We extracted data from Syafruddin 2014 and Hill 2014 by using inverse variance from adjusted odds ratio and confidence intervals reported in the articles. The study conducted in China had a trial duration of six months and investigated $0.03 \%$ transfluthrin coils in combination with or without LLINs (Hill 2014). The other study, in Indonesia, was conducted for a period of 6 months and investigated $0.00975 \%$ metofluthrin coils. Both studies screened at start all participants enrolled for follow-up and cleared pre-existent malaria infections. Syafruddin 2014 was conducted in two villages with a total population of 2120 but only an active cohort of 170 participants was enrolled for follow-up (87 in the control arm and 83 in the intervention arm). These individuals were screened and cleared at start but other villagers were not. The mosquito coils were rolled out to all village households according to treatment allocation (metofluthrin-treated or placebo coils).

\section{Excluded studies}

Six studies were excluded: three studies only had two units of randomization (Abdulsalam 2014; Hamza 2016; Kimani 2006); one study did not specify in the published article the repellent compound that was used - we contacted the corresponding author but did not receive a response (Deressa 2014); and two were not RCTs or cRCTs (Dadzie 2013; Eamsila 1994).

\section{Risk of bias in included studies}

Overall the risk of bias in the included studies was high (see Figure 2). 
Figure 2. 'Risk of bias' summary: review authors' judgements about each 'Risk of bias' item for each included study.

\begin{tabular}{|c|c|c|c|c|c|c|c|c|c|c|c|c|c|c|c|c|c|c|c|c|c|}
\hline & 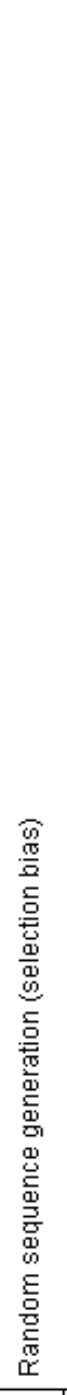 & 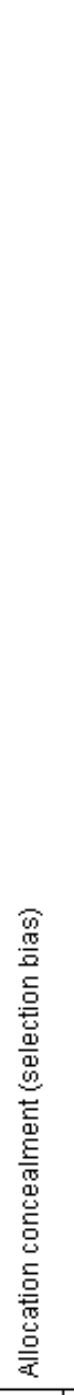 & 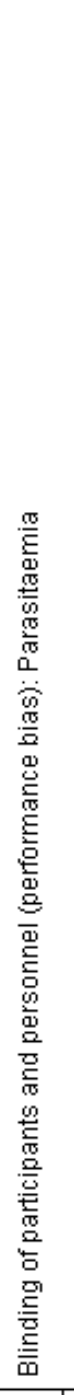 & 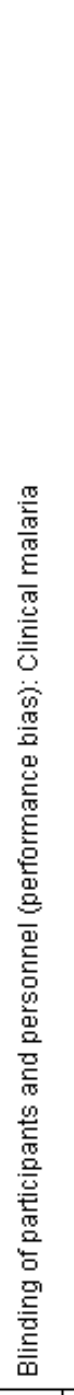 & 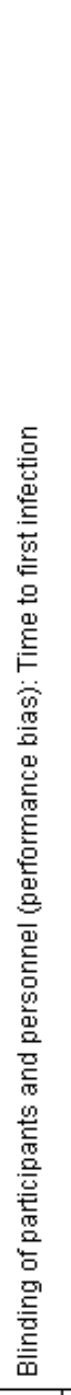 & 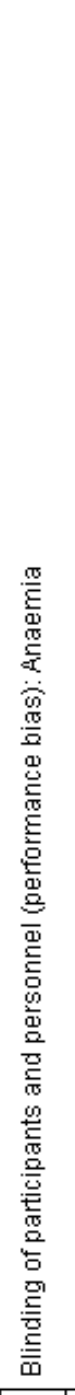 & 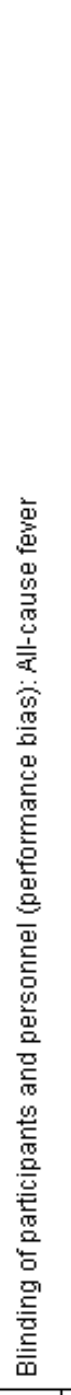 & 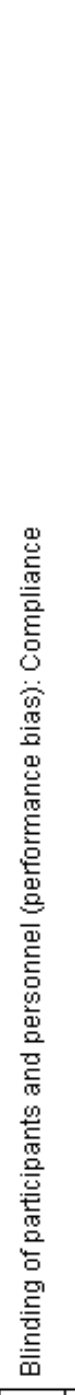 & 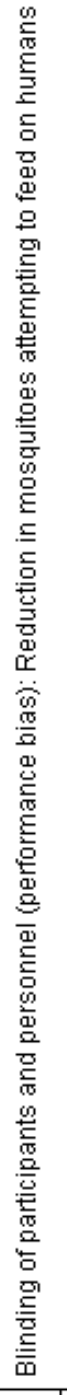 & 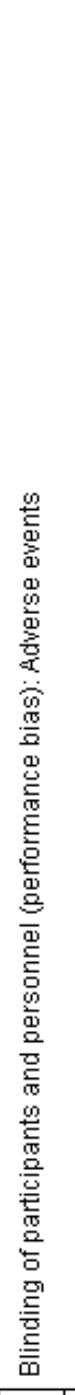 & 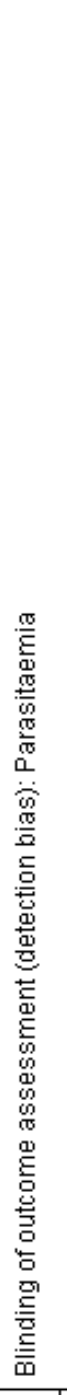 & 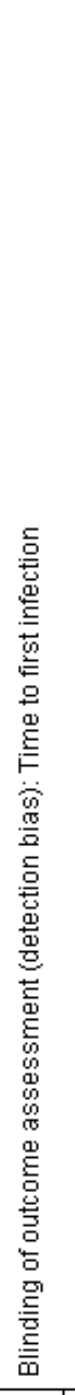 & 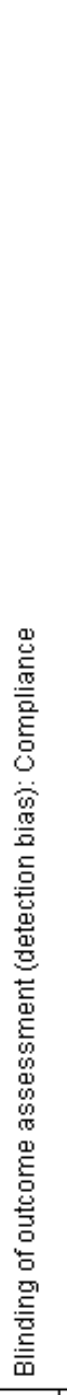 & 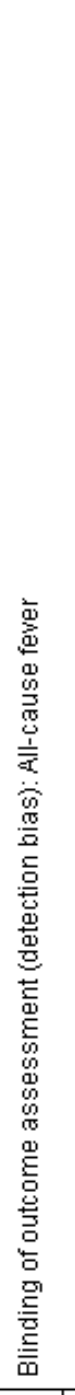 & 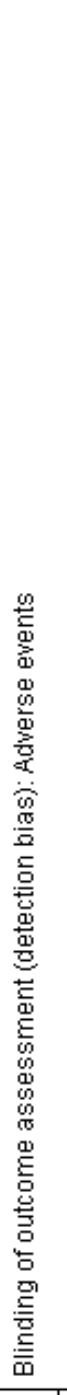 & 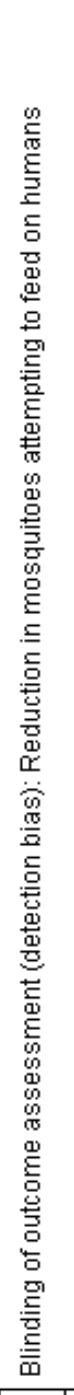 & 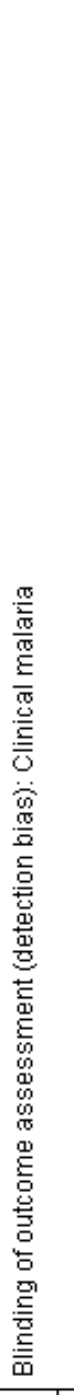 & 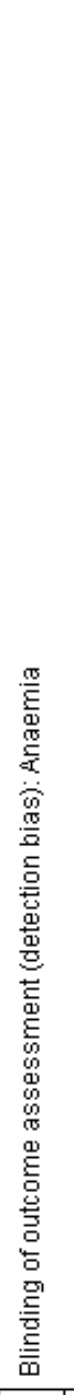 & 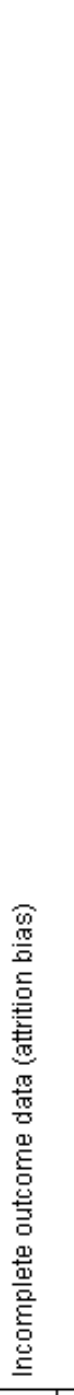 & 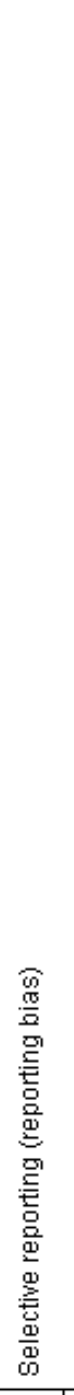 & 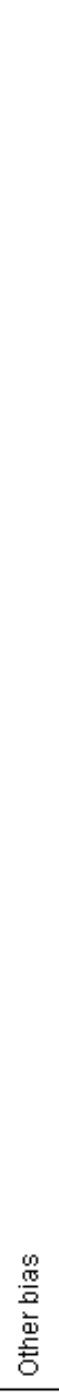 \\
\hline Chen-Hussey 2013 & $\odot$ & $\odot$ & 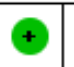 & & $\odot$ & & & 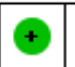 & & & $\odot$ & 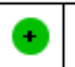 & + & & & & & & $\odot$ & $\odot$ & $\odot$ \\
\hline Hill 2007 & $\theta$ & $\theta$ & $\odot$ & & & & $\odot$ & $\odot$ & & $\odot$ & $\odot$ & & $?$ & $?$ & $?$ & & & & $\odot$ & $\odot$ & $\theta$ \\
\hline Hill 2014 & + & + & ○ & & & & & 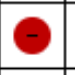 & -1 & & + & & - & & & + & & & + & $\odot$ & + \\
\hline McGready 2001 & $?$ & $?$ & + & & & + & & + & & ๑ & $\odot$ & & $\odot$ & & $\odot$ & & & 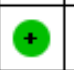 & $\odot$ & $\odot$ & $\odot$ \\
\hline Rowland 1999 & + & $?$ & & + & & & & & & + & & & & & + & & + & & $?$ & $?$ & + \\
\hline Rowland 2004 & $?$ & $?$ & & + & & & & & & + & & & & & $\odot$ & & + & & + & $?$ & $\odot$ \\
\hline Sangoro 2014a & $\theta$ & $\Theta$ & & + & & & & + & & & & & $\odot$ & & & & $\odot$ & & + & + & 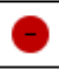 \\
\hline Sluydts 2016 & + & + & $\odot$ & $\odot$ & & & & 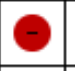 & & $\theta$ & + & & $?$ & & 1 & & $?$ & & + & + & $\odot$ \\
\hline Soto 1995 & $?$ & $?$ & & + & & & & & & $\odot$ & & & & & 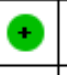 & & $\odot$ & & $\odot$ & $?$ & $?$ \\
\hline Syafruddin 2014 & $?$ & + & + & & & & & & +1 & + & + & & & & + & + & & & $\odot$ & $\odot$ & $\odot$ \\
\hline
\end{tabular}




\section{Allocation}

Only three studies, Chen-Hussey 2013, Hill 2014, and Sluydts 2016, described proper randomization and allocation concealment methods, and we therefore graded them as having low risk of selection bias. Rowland 1999 also used an adequate randomization method but did not clearly describe how allocation was performed. We considered two studies, Hill 2007 and Sangoro 2014a, to have high risk of selection bias because they used alternate allocation methods. All other studies - McGready 2001, Rowland 2004, Soto 1995, and Syafruddin 2014 - did not provide sufficient information to make a judgement about risk of bias and we judged them as having unclear risk of bias.

\section{Blinding}

Most trials were at low risk of bias and adequately blinded participants and personnel. We judged two trials, Hill 2014 and Sluydts 2016, to have high risk of performance bias as they were not placebo-controlled. Sluydts 2016 did not provide sufficient information on how the clinical data regarding malaria cases were collected and was thus graded as having an unclear risk of bias.

\section{Incomplete outcome data}

All studies but one were graded as having low risk of attrition bias with comparable rates of loss to follow-up between treatment arms. Rowland 1999 did not report on how many participants were lost to follow-up from both intervention and control arm and was thus graded as having unclear risk of bias.

\section{Selective reporting}

Selective reporting bias was low for most studies. Three studies, Rowland 1999, Rowland 2004 and Soto 1995, did not have an available protocol and were therefore graded as having unclear risk of bias.

\section{Other potential sources of bias}

Two studies, Hill 2007 and Sangoro 2014a, described baseline imbalances which is considered as a potential source of bias. These two studies were assessed as having high risk of bias. One study, Soto 1995 , described that soldiers were deployed to endemic areas for 3-8 weeks but did not report deployment time per arm and so it was judged as having an unclear risk of baseline bias.

\section{Effects of interventions}

See: Summary of findings for the main comparison Topical repellents compared to placebo or no treatment for malaria prevention; Summary of findings 2 ITC compared to placebo or no treatment for malaria prevention; Summary of findings 3 Spatial repellents compared to placebo or no treatment for malaria prevention

The findings are presented by intervention type (topical repellents, ITC, and spatial repellents).

\section{Comparison 1: topical repellents compared to placebo or no treatment for malaria prevention (see 'Summary of findings' table 1)}

\section{Clinical malaria caused by P. falciparum}

Three studies investigated the impact on clinical malaria caused by P. falciparum (Rowland 2004; Sangoro 2014a; Sluydts 2016). Overall, topical repellents had no impact on clinical malaria (risk ratio (RR) 0.65 , 95\% confidence interval (Cl) 0.40 to $1.07,3$ studies, 4447 participants, very low certainty evidence; Analysis 1.1) Figure 3. When sub-grouped by inclusion of LLINs we found one study that, in the absence of LLINs, reported a significant reduction in clinical malaria (RR $0.40,95 \% \mathrm{Cl} 0.23$ to $0.71,1$ study, 869 participants). There was no significant impact on prevention of clinical malaria when LLINs were in place (RR $0.84,95 \% \mathrm{Cl} 0.55$ to 1.27, 2 studies, 3578 participants). Sensitivity analysis was done by excluding Sluydts 2016 which was not placebo controlled and Sangoro 2014a which had high risk of bias because of using an alternate allocation method. We also performed sensitivity analysis in regard to the estimated ICC of 0.04 (Sangoro 2014a), by varying this value between 0.03 and 0.05 . The main results did not change and point estimates remained within the same values.

Figure 3. Forest plot of comparison: 1 Topical repellent compared to placebo or no treatment, outcome: 1.1 Clinical malaria caused by $P$. falciparum.

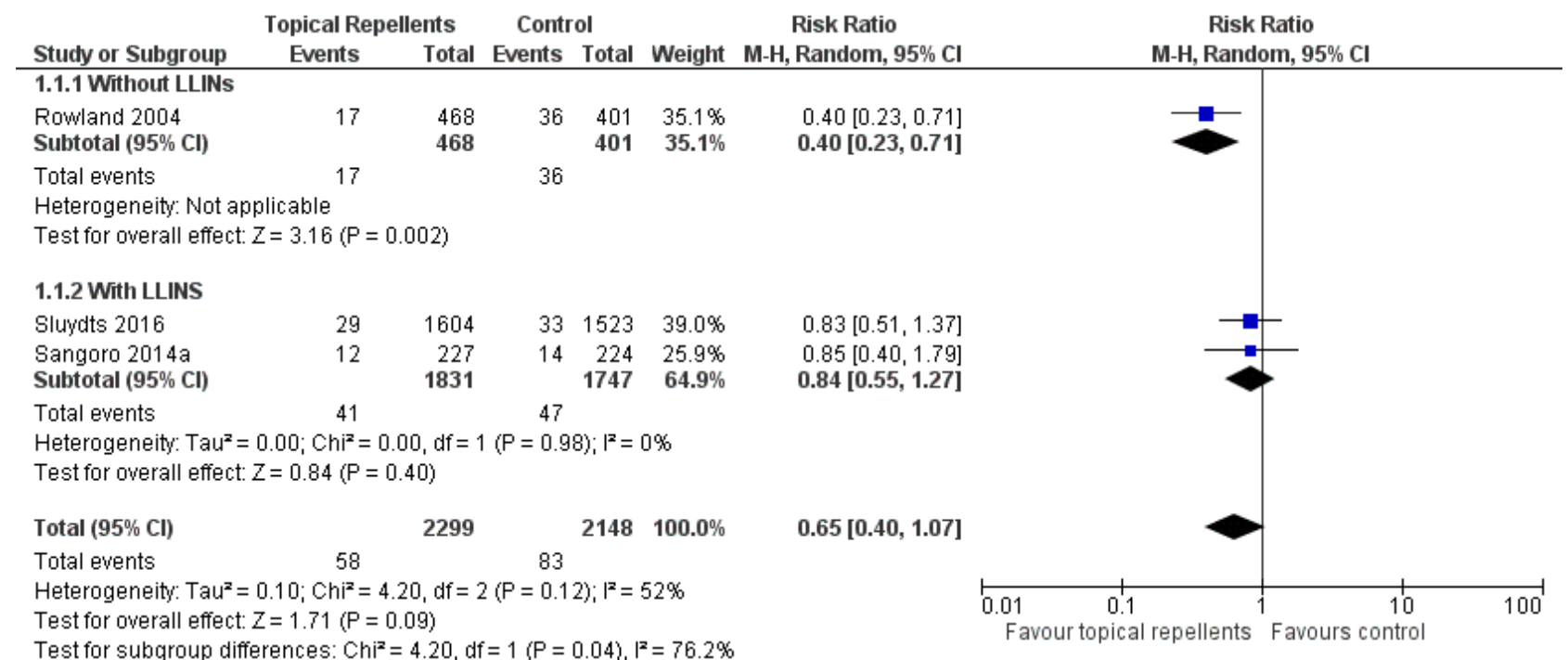




\section{P. falciparum parasitaemia}

Four studies investigated the impact on $P$. falciparum parasitaemia (Chen-Hussey 2013; Hill 2007; McGready 2001; Sluydts 2016). Overall, topical repellents had no impact onP. falciparum parasitaemia $(\mathrm{RR}=0.84,95 \% \mathrm{Cl} 0.64$ to $1.12,4$ studies, 13,310 participants, low-certainty evidence; Analysis 1.2) Figure 4. There continued to be no impact on P. falciparum parasitaemia when used in conjunction with LLINs (RR $0.91,95 \% \mathrm{Cl} 0.60$ to $1.38,3$ studies, 12,413 participants) or without LLINs (RR $0.78,95 \% \mathrm{Cl}$ 0.53 to $1.16,1$ study, 897 participants). We conducted a sensitivity analysis by excluding Sluydts 2016 as it was not placebo-controlled: the point estimate remained the same. Point estimates were also narrowly affected by removing Hill 2007 from the analysis due to risk of bias for using alternate allocation. We also performed a sensitivity analysis by varying the ICC that was estimated for ChenHussey 2013 and Hill 2007 of 0.04 between 0.03 and 0.05 and point estimates remained within the same values.

\section{Figure 4. Forest plot of comparison: 1 Topical repellent compared to placebo or no treatment, outcome: 1.2 .} falciparum parasitaemia.

\begin{tabular}{|c|c|c|c|c|c|c|c|c|c|}
\hline \multirow{2}{*}{$\frac{\text { Study or Subgroup }}{1.2 .1 \text { Without LLINs }}$} & \multicolumn{2}{|c|}{ Topical Repellents } & \multicolumn{2}{|c|}{ Control } & \multirow{2}{*}{ Weight } & \multirow{2}{*}{$\begin{array}{c}\text { Risk Ratio } \\
\text { M-H, Fixed, 95\% Cl }\end{array}$} & \multicolumn{3}{|c|}{$\begin{array}{c}\text { Risk Ratio } \\
\text { M-H, Fixed, } 95 \% \mathrm{Cl}\end{array}$} \\
\hline & & & & & & & & & \\
\hline $\begin{array}{l}\text { McGready } 2001 \\
\text { Subtotal }(95 \% \mathrm{Cl})\end{array}$ & 40 & $\begin{array}{l}449 \\
449\end{array}$ & 51 & $\begin{array}{l}448 \\
\mathbf{4 4 8}\end{array}$ & $\begin{array}{l}52.0 \% \\
52.0 \%\end{array}$ & $\begin{array}{c}0.78[0.53,1.16] \\
\mathbf{0 . 7 8}[\mathbf{0 . 5 3}, \mathbf{1 . 1 6}]\end{array}$ & & & \\
\hline $\begin{array}{l}\text { Total events } \\
\text { Heterogeneity: Not a } \\
\text { Test for overall effect }\end{array}$ & $\begin{array}{l}\text { licable } \\
=1.22(\mathrm{P}=\end{array}$ & & 51 & & & & & & \\
\hline 1.2.2 With LLINs & & & & & & & & & \\
\hline Chen-Hussey 2013 & 30 & 3408 & 28 & 3420 & $28.5 \%$ & $1.08[0.64,1.80]$ & & & \\
\hline Hill 2007 & 1 & 1780 & 5 & 1716 & $5.2 \%$ & $0.19[0.02,1.65]$ & & - & \\
\hline $\begin{array}{l}\text { Sluydts } 2016 \\
\text { Subtotal }(95 \% \mathrm{Cl})\end{array}$ & 12 & $\begin{array}{l}1050 \\
6238\end{array}$ & 14 & $\begin{array}{l}1039 \\
6175\end{array}$ & $\begin{array}{l}14.3 \% \\
\mathbf{4 8 . 0} \%\end{array}$ & $\begin{array}{r}0.85[0.39,1.82] \\
\mathbf{0 . 9 1}[\mathbf{0 . 6 0}, \mathbf{1 . 3 8}]\end{array}$ & & & \\
\hline $\begin{array}{l}\text { Total events } \\
\text { Heterogeneity: } \mathrm{Chi}^{2}= \\
\text { Test for overall effect }\end{array}$ & $\begin{array}{c}43 \\
44, \mathrm{df}=2(\mathrm{P} \\
=0.44(\mathrm{P}=\end{array}$ & 6) & $\begin{array}{r}47 \\
=18 \%\end{array}$ & & & & & & \\
\hline Total $(95 \% \mathrm{Cl})$ & & 6687 & & 6623 & $100.0 \%$ & $0.84[0.64,1.12]$ & & & \\
\hline Total events & 83 & & 98 & & & & & & \\
\hline $\begin{array}{l}\text { Heterogeneity: } \mathrm{Chi}^{2}= \\
\text { Test for overall effect } \\
\text { Test for subqroup di }\end{array}$ & $\begin{array}{l}82, \mathrm{df}=3( \\
=1.16(\mathrm{P}= \\
\text { rences: } \text { Chi }^{2}\end{array}$ & $\begin{array}{l}0.42) ; l^{2} \\
\text { 4) } \\
28, \mathrm{df}\end{array}$ & $\begin{array}{l}=0 \% \\
=1(\mathrm{P}=\end{array}$ & $0.60), 1^{2}$ & $=0 \%$ & & $\begin{array}{l}+1 \\
0.01\end{array}$ & $\begin{array}{cc}1 & 10 \\
\text { epellents } & \text { Favours control }\end{array}$ & $\frac{1}{100}$ \\
\hline
\end{tabular}

\section{Clinical malaria caused by $P$. vivax}

Two studies investigated the impact on clinical malaria for $P$. vivax (Rowland 2004; Sluydts 2016). Overall topical repellents had no impact on clinical malaria caused by P. vivax (RR $1.32,95 \% \mathrm{Cl} 0.99$ to

1.76, 2 studies, 3996 participants, low-certainty evidence; Analysis 1.3) Figure 5 . We conducted a sensitivity analysis by excluding Sluydts 2016, which was not placebo controlled. The point estimate remained close to 1 but shifted from favouring the control to favouring the intervention. 
Figure 5. Forest plot of comparison: 1 Topical repellent compared to placebo or no treatment, outcome: 1.3 Clinical malaria caused by $P$. vivax.

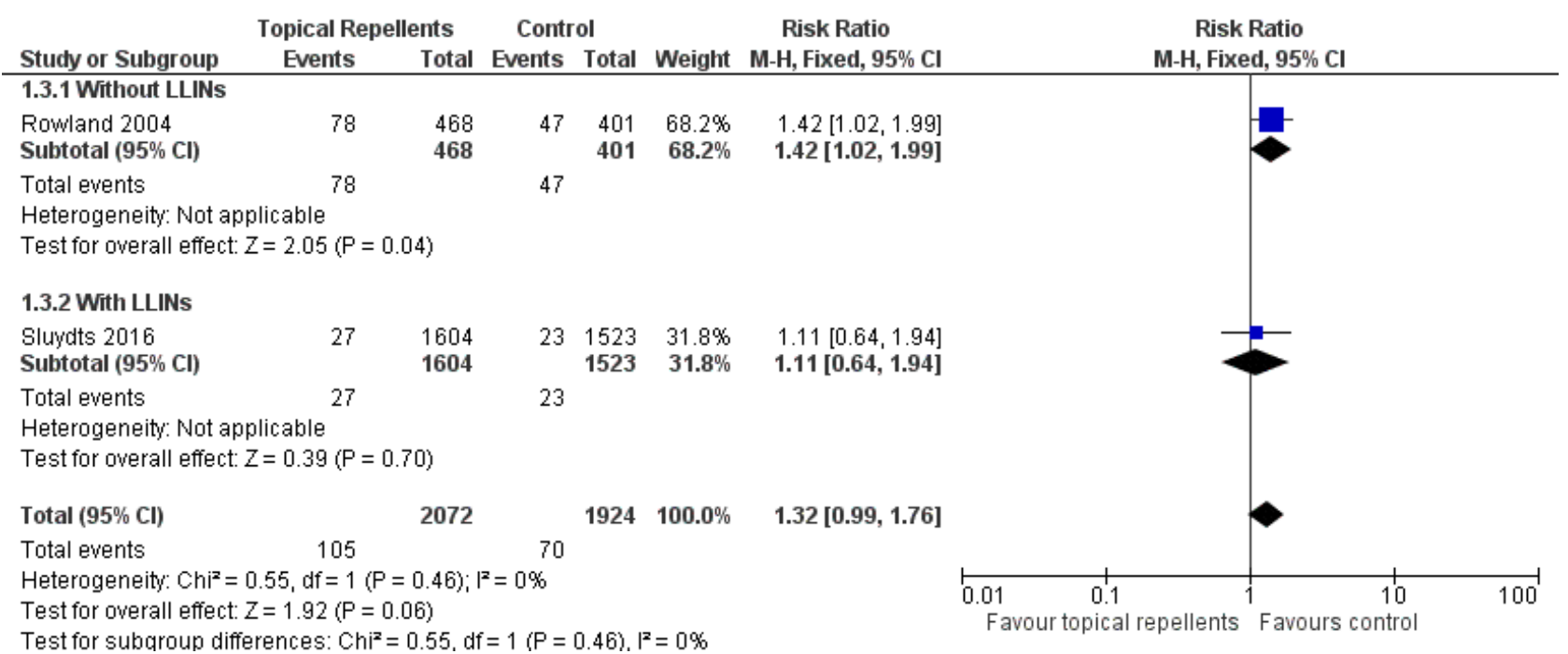

\section{P. vivax parasitaemia}

Three studies investigated the impact on $P$. vivax parasitaemia (Chen-Hussey 2013; McGready 2001; Sluydts 2016). Overall, topical repellents had no impact on $P$. vivax parasitaemia (RR 1.08, 95\% $\mathrm{Cl} 0.81$ to 1.43 , 3 studies, 9589 participants, low-certainty evidence; Analysis 1.4) Figure 6. There continued to be no impact onP. vivax parasitaemia when used in conjunction with LLINs (RR 1.24, 95\%

$\mathrm{Cl} 0.78$ to $1.97,2$ studies, 8692 participants) or without LLINs (RR $0.98,95 \%$ Cl 0.68 to $1.40,1$ study, 897 participants). We conducted a sensitivity analysis by excluding Sluydts 2016, which was not placebo controlled. The main results did not change although point estimates shifted slightly in favour of the control. We also performed a sensitivity analysis by varying the ICC, estimated for Chen-Hussey 2013 at 0.04 , between 0.03 and 0.05 : point estimates remained within the same values.

Figure 6. Forest plot of comparison: 1 Topical repellent compared to placebo or no treatment, outcome: 1.4 P. vivax parasitaemia.

\begin{tabular}{|c|c|c|c|c|c|c|c|c|c|}
\hline \multirow{2}{*}{$\frac{\text { Study or Subgroup }}{1.4 .1 \text { Without LLINs }}$} & \multicolumn{2}{|c|}{ Topical Repellents } & \multicolumn{2}{|c|}{ Control } & \multirow[t]{2}{*}{ Weight } & \multirow[t]{2}{*}{$\begin{array}{c}\text { Risk Ratio } \\
\text { M-H, Fixed, 95\% Cl }\end{array}$} & \multicolumn{3}{|c|}{$\begin{array}{c}\text { Risk Ratio } \\
\text { M-H, Fixed, } 95 \% \mathrm{Cl} \\
\end{array}$} \\
\hline & & & & & & & & & \\
\hline $\begin{array}{l}\text { McGready } 2001 \\
\text { Subtotal }(\mathbf{9 5} \% \mathrm{Cl})\end{array}$ & 52 & $\begin{array}{l}449 \\
449\end{array}$ & 53 & $\begin{array}{l}448 \\
448\end{array}$ & $\begin{array}{l}62.3 \% \\
62.3 \%\end{array}$ & $\begin{array}{r}0.98[0.68,1.40] \\
\mathbf{0 . 9 8}[\mathbf{0 . 6 8}, \mathbf{1 . 4 0}]\end{array}$ & & & \\
\hline \multicolumn{10}{|c|}{$\begin{array}{l}\text { Heterogeneity: Not applicable } \\
\text { Test for overall effect: } Z=0.12(P=0.91)\end{array}$} \\
\hline \multicolumn{10}{|l|}{ 1.4.2 With LLINs } \\
\hline Chen-Hussey 2013 & 12 & 3296 & 13 & 3307 & $15.2 \%$ & $0.93[0.42,2.03]$ & & & \\
\hline $\begin{array}{l}\text { Sluydts } 2016 \\
\text { Subtotal (95\% Cl) }\end{array}$ & 28 & $\begin{array}{l}1050 \\
4346\end{array}$ & 19 & $\begin{array}{l}1039 \\
4346\end{array}$ & $\begin{array}{l}22.4 \% \\
37.7 \%\end{array}$ & $\begin{array}{r}1.46[0.82,2.59] \\
\mathbf{1 . 2 4}[\mathbf{0 . 7 8 , 1 . 9 7 ]}\end{array}$ & & & \\
\hline \multicolumn{10}{|c|}{$\begin{array}{l}\text { Heterogeneity: } \text { Chi }^{2}=0.84, d f=1(P=0.36) ; I^{2}=0 \% \\
\text { Test for overall effect: } Z=0.92(P=0.36)\end{array}$} \\
\hline Total $(95 \% \mathrm{Cl})$ & & 4795 & & 4794 & $100.0 \%$ & $1.08[0.81,1.43]$ & & & \\
\hline Total events & 92 & & 85 & & & & & & \\
\hline $\begin{array}{l}\text { Heterogeneity: Chi }= \\
\text { Test for overall effect } \\
\text { Test for subqroup dif }\end{array}$ & $\begin{array}{l}.48, d f=2 \\
z=0.52(P= \\
\text { rences: } C h\end{array}$ & $\begin{array}{l}0.48) ; I^{7} \\
0) \\
0.64, d f\end{array}$ & $\begin{array}{l}=0 \% \\
=1 \%\end{array}$ & 2) & $0 \%$ & & $\begin{array}{lc}0.01 & 0.1 \\
\text { Favour topical }\end{array}$ & $\begin{array}{cc}1 & 10 \\
\text { repellents } & \text { Favours control }\end{array}$ & 100 \\
\hline
\end{tabular}

\section{Anaemia}

One study investigated the impact on anaemia (McGready 2001). Topical repellents had no impact on anaemia (RR 1.06, 95\% Cl 0.91 to $1.23,1$ study, 587 participants; Analysis 1.5).

\section{All-cause fever}

One study investigated the impact on all-cause fever (Hill 2007). Participants that used topical repellents were half as likely to develop a fever when compared to participant in the control arm (RR $0.44,95 \% \mathrm{Cl} 0.35$ to $0.55,1$ study, 3496 participants; Analysis 1.6). 


\section{Adherence to the intervention}

Five studies reported adherence to the intervention (Chen-Hussey 2013; Hill 2007; McGready 2001; Sangoro 2014a; Sluydts 2016). All five report self-reported adherence, measured monthly or weekly or non-periodically. Four studies report a variety of methods of objective monitoring of adherence: estimating weight of repellent bottles (Chen-Hussey 2013; Hill 2007); random sniff checks or spot checks (Hill 2007; McGready 2001); number of bottles issued to households (Sangoro 2014a). Two studies reported the proportion of participants that have been adherent to the intervention. ChenHussey 2013 reported $61.3 \%$ adherence in the intervention arm and $62.2 \%$ in the control arm. Hill 2007 reported $98.5 \%$ compliance in both arms (Analysis 1.7)

\section{Adverse events}

Four studies reported adverse events (Hill 2007; McGready 2001; Rowland 2004; Sluydts 2016). Three studies used interviews to assess the occurrence of adverse events (Hill 2007; McGready 2001; Rowland 2004), of which one study also provided a questionnaire to a small sample of the study population (Rowland 2004). Sluydts 2016 did not describe the methods of measuring and recording adverse events. Very few adverse events were reported, and all related to skin irritation or warming sensation (Analysis 1.8). McGready 2001 reported the occurrence of adverse events to $6 \%$ of the participants but did not specify the nature of the adverse events or in which treatment arm they had occurred. We contacted the authors, and they informed us that all adverse events had been described as skin warming sensation and had been restricted to the study arm that had been allocated thanaka with 20\% DEET. No serious adverse events were reported requiring intervention discontinuation.

\section{Other outcomes}

No data were available for the comparisons of reduction in mosquito bites and time to first infection.

\section{Comparison 2: ITC compared to placebo or no treatment for} malaria prevention (see 'Summary of findings' table 2)

\section{Clinical malaria caused by P. falciparum}

Two studies investigated the impact on clinical malaria caused byP. falciparum (Rowland 1999; Soto 1995). Overall, ITC halved the incidence of clinical malaria (RR $0.49,95 \% \mathrm{Cl} 0.29$ to $0.83,2$ studies, 997 participants, low-certainty evidence; Analysis 2.1; Figure 7). Results remained the same after we conducted a sensitivity analysis by excluding Rowland 1999 (CRCT).

Figure 7. Forest plot of comparison: 2 ITC compared to placebo or no treatment, outcome: 2.1 Clinical malaria caused by $P$. falciparum.

\begin{tabular}{|c|c|c|c|c|c|c|c|c|}
\hline Study or Subgroup & log[Risk Ratio] & SE & Weight & $\begin{array}{c}\text { Risk Ratio } \\
\text { IV, Fixed, } 95 \% \mathrm{Cl}\end{array}$ & & $\begin{array}{r}\text { Risk } \\
\mathrm{N}, \text { Fixed } \\
\end{array}$ & $\begin{array}{l}\text { Ratio } \\
\text {, } 95 \% \mathrm{Cl}\end{array}$ & \\
\hline Soto 1995 & -1.9812 & 1.5196 & $3.1 \%$ & $0.14[0.01,2.71]$ & & & $\square$ & \\
\hline Rowland 1999 & -0.6733 & 0.2707 & $96.9 \%$ & $0.51[0.30,0.87]$ & & & & \\
\hline Total (95\% Cl) & & & $100.0 \%$ & $0.49[0.29,0.83]$ & & & & \\
\hline \multicolumn{4}{|c|}{$\begin{array}{l}\text { Heterogeneity: } \mathrm{Chi}^{2}=0.72, \mathrm{df}=1(\mathrm{P}=0.40) ; \mathrm{I}^{2}=0 \% \\
\text { Test for overall effect: } Z=2.68(P=0.007)\end{array}$} & & 0.002 & $\begin{array}{l}0.1 \\
\text { ours ITC }\end{array}$ & $\begin{array}{c}10 \\
\text { Favours control }\end{array}$ & 500 \\
\hline
\end{tabular}

\section{Clinical malaria caused byP. vivax}

Two studies investigated the impact on clinical malaria for $P$. vivax (Rowland 1999; Soto 1995). Overall, ITC reduced by $64 \%$ the risk of clinical malaria caused by $P$. vivax (RR $0.64,95 \% \mathrm{Cl} 0.40$ to 1.01 ,
2 studies, 997 participants, low-certainty evidence; Analysis 2.2) Figure 8. After we carried out a sensitivity analysis by excluding Rowland 1999 (CRCT) results shifted in favour of the intervention but had wider confidence intervals, crossing the point estimate of no effect.

Figure 8. Forest plot of comparison: 2 ITC compared to placebo or no treatment, outcome: 2.2 Clinical malaria caused by $P$. vivax.

\begin{tabular}{|c|c|c|c|c|c|c|c|c|}
\hline Study or Subgroup & log[Risk Ratio] & SE & Weight & $\begin{array}{c}\text { Risk Ratio } \\
\text { IN, Fixed, } 95 \% \mathrm{Cl} \\
\end{array}$ & & $\begin{array}{r}\text { Risk F } \\
\text { IV, Fixed, }\end{array}$ & $\begin{array}{l}\text { Ratio } \\
\text {, } 95 \% \mathrm{Cl}\end{array}$ & \\
\hline Soto 1995 & -1.1736 & 0.6852 & $11.6 \%$ & $0.31[0.08,1.18]$ & & & & \\
\hline Rowland 1999 & -0.3567 & 0.2486 & $88.4 \%$ & $0.70[0.43,1.14]$ & & & & \\
\hline Total $(95 \% \mathrm{Cl})$ & & & $100.0 \%$ & $0.64[0.40,1.01]$ & & & & \\
\hline \multicolumn{4}{|c|}{$\begin{array}{l}\text { Heterogeneity: } \mathrm{Chi}^{2}=1.26, \mathrm{df}=1(\mathrm{P}=0.26) ; \mathrm{I}^{2}=20 \% \\
\text { Test for overall effect: } Z=1.93(\mathrm{P}=0.05)\end{array}$} & & 0.01 & $\begin{array}{l}0.1 \\
\text { Favours ITC }\end{array}$ & $\begin{array}{c}10 \\
\text { Favours control }\end{array}$ & 100 \\
\hline
\end{tabular}

\section{Adverse events}

Two studies reported adverse events from interviews with participants (Rowland 1999; Soto 1995). Only two events of skin irritation were reported in the 997 participants across the two studies (Analysis 2.3). No serious adverse events requiring trial discontinuation were reported. 


\section{Other outcomes}

No data were available for the comparison of the following outcomes: P. falciparum parasitaemia, P. vivax parasitaemia, time to first infection, anaemia, all-cause fever, adherence to the intervention, and reduction in mosquito bites.

Comparison 3: spatial repellents compared to placebo or no treatment for malaria prevention (see 'Summary of findings' table 3)

\section{Plasmodium species' parasitaemia}

Hill 2014 investigated the impact of spatial repellents on bothP. falciparum and P. vivax infections. Syafruddin 2014 did not differentiate between Plasmodium species and presented incidence numbers of malaria irrespective of causing agent. Both studies cleared $P$. vivax infections at start. In order to allow a meta-analysis and compare data from both studies, we combined the data from Hill 2014 into total number of infections caused by Plasmodium species (13 cases in total: repellent arm reported 1 case of $P$. falciparum and the control arm reported 2 cases of $P$. falciparum and 10 of $P$. vivax). The papers reported results adjusted for clustering and we extracted these data and entered them in the analysis. Results from the meta-analysis show that spatial repellents had no impact onPlasmodium species' parasitaemia (RR $0.24,95 \% \mathrm{Cl} 0.03$ to 1.72 , 2 studies, 6683 participants, very low certainty evidence; Analysis 3.1) Figure 9.

Figure 9. Forest plot of comparison: 3 Spatial repellents compared to placebo or no treatment, outcome: 3.1 Plasmodium spp. parasitaemia.

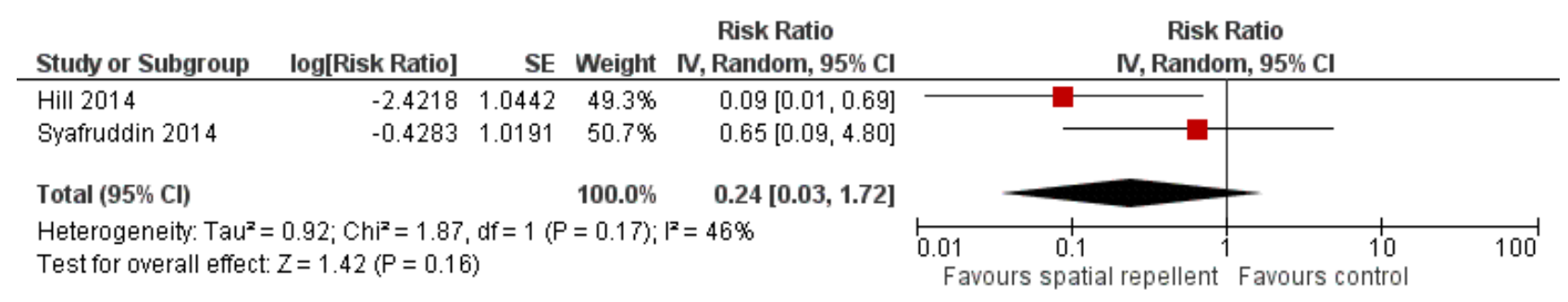

\section{Adherence to the intervention}

One study - Hill 2014 - reported adherence to the intervention through self-reporting and counting of empty coil boxes using a monthly survey. Hill 2014 reported compliance between $89.3 \%$ and $97.8 \%$ in the control arm and between $98.5 \%$ and $98.6 \%$ in the treatment arm (Analysis 3.2).

\section{Reduction in mosquito bites}

One study reported reduction in mosquito bites (Hill 2014). The mean number of bites was 2.1 in the spatial repellent arm (standard deviation (SD) 1.9) and 12.9 (SD 7.6) in the control arm (Analysis 3.3). Syafruddin 2014 also measured the reduction in mosquito bites caused by use of metofluthrin coils. Syafruddin 2014 reported a $32.9 \%$ reduction in mosquito landings in households using the metofluthrin coils, however the data presented in the article could not be extracted and added to the meta-analysis.

\section{Adverse events}

One study investigated adverse events related to the use of mosquito coils (Syafruddin 2014). Participants were interviewed during random spot-checks and asked if any adverse event had occurred. No adverse events were reported.

\section{Other outcomes}

No data were available for the comparison of the following outcomes: clinical malaria caused by $P$. falciparum or $P$. vivax; time to first infection; anaemia; and all-cause fever.

\section{DISCUSSION}

We have discussed the findings of the main outcomes by intervention type (topical repellents, ITC, and spatial repellents).

\section{Summary of main results}

\section{Topical repellents}

Results from the overall meta-analysis indicate that the included trials did not demonstrate that topical repellents have a protective effect against clinical malaria caused by either $P$. falciparum or $P$. vivax (very low certainty evidence and low-certainty evidence respectively). The same was observed in trials that used active case detection and measured the effect of topical repellents on malaria parasitaemia caused by $P$. falciparum or $P$. vivax (lowcertainty evidence). Regarding $P$. vivax infections, topical repellents may in fact increase the risk of infection. However, it is unclear if this result has a plausible biological explanation or if the finding was due to confounding factors. The most likely possible confounding factor is the recrudescent infections that may have been unbalanced between study arms because none of the studies investigating topical repellents cleared parasites at start. Subgroup analysis was undertaken to assess trials conducted with and without LLINs as co-interventions. Only two studies, which were both conducted with displaced populations, did not include LLINs. Rowland 2004 reported fewer $P$. falciparum malaria cases in the intervention group given repellent soap (RR $0.40,95 \% \mathrm{Cl} 0.23$ to 0.71); however McGready 2001 measured no reduction in malaria infection incidence by either $P$. falciparum or $P$. vivax. Trials where LLINs were distributed to the participants and repellents were used as an additional protective generally reported no additional protection against malaria.

Compliance was an issue in the included studies (see Table 1). Most studies reported poor compliance or difficulty in reliably measuring compliance. Most studies used self-reporting methods such as interviews and questionnaires or indirect methods such as weighing bottles or counting bottles of repellents. These methods are not reliable as participants may lie to please the investigating team (response bias), dispose of the repellent or share the repellent 
bottles with others. Sluydts 2016 conducted an observational study where compliance was evaluated in a pool of households from different clusters and observed compliance between $6 \%$ and $15 \%$, as opposed to self-reported compliance of $70 \%$. Other studies Chen-Hussey 2013 and Sangoro 2014a - also reported difficulties measuring compliance. Self-reported compliance was generally found to be high (> 80\%); however the unreliable nature of the data might overestimate compliance. The issue of compliance may relate to product acceptability. Social studies showed that participants liked using topical repellents (Rowland 2004), but often forgot to use them or did not use them appropriately (Chen-Hussey 2013). It is questionable if topical repellents can be used for malaria prevention in the general population as daily compliance and poor standardization (amount of repellent used, surface area applied, time of application, and period between repeated applications) are major limitations of this intervention. In addition, poor compliance leads to a decrease in study power and requires studies with very large numbers of participants which are also increasingly unfeasible as malaria prevalence drops across regions.

The included studies were performed in diverse ecological and epidemiological settings (see Table 2), across hypo-endemic regions (malaria prevalence < 5\%) (Chen-Hussey 2013; Hill 2007; Sluydts 2016), and meso-endemic regions (malaria prevalence $5 \%$ to 15\%) (McGready 2001; Rowland 2004; Sangoro 2014a), using both active and passive case detection and different diagnostic methods (see Table 3). We used malaria prevalence data from each study's control to calculate the necessary sample size and noted that except for Rowland 2004, which was only slightly underpowered, all other studies were severely underpowered. Even the very large trial that was conducted in Cambodia with over 48,000 participants was severely underpowered, effectively needing over half a million participants to reach its objectives (Sluydts 2016). Reasons included the very low prevalence of malaria in the study area $(<2 \%)$ as well as the large size of the clusters which reduced the effective sample size after adjusting for clustering. The sample size estimation that we calculated assumed $100 \%$ compliance, which is unrealistic, meaning that the sample sizes would need to be even larger. The sample size for a CRCT aiming to investigate the effect of topical repellents on malaria needs to be so large that its feasibility is questionable, making it arguable if RCTs and CRCTs are the best methodology. There is undeniable evidence from entomological studies that topical repellents can provide bite protection from mosquitoes and reduce vector-human contact, making them a very efficient personal protection tool, but our review results conclude that, despite their high efficiency, topical repellents as an intervention might have very poor effectiveness with regard to malaria prevention.

\section{ITC}

Results from the meta-analysis trials indicate that ITC may protect against clinical malaria caused by either $P$. falciparum or $P$. vivax (low-certainty evidence). The studies were conducted with soldiers and refugees who did not have access to LLINs or other personal protection tools. Compliance with the intervention was not measured in either trial but it is highly likely to have been high, given the limited options of soldiers and refugees with regard to clothing. Also, studies reported that participants perceived additional protection from other insects, such as fleas and bedbugs, suggesting a high product acceptability.

\section{Spatial repellents}

A meta-analysis of the outcome Plasmodium species' parasitaemia was performed. Both studies cleared P.vivax infections at start (Hill 2014; Syafruddin 2014). Results from the meta-analysis did not demonstrate a protective effect of spatial repellents against acquiring Plasmodium species' parasitaemia (very low certainty evidence). There was a considerable heterogeneity between the studies and very large confidence intervals around the point estimates. The studies used two different volatile pyrethroids: Hill 2014 used transfluthrin $0.03 \%$ and Syafruddin 2014 used metofluthrin $0.00925 \%$. However this difference between the studies is an unlikely explanation for the observed heterogeneity because both compounds were tested before trial start and reported to reduce vector biting rates (Barbara 2011; Hill 2014). Hill 2014 was severely underpowered and reported very few events the study took place in an area with very low malaria transmission (see Table 2). Syafruddin 2014 was done in an area with higher malaria prevalence (see Table 2); however it only followed up 170 individuals ( 83 in the intervention arm and 87 in the control arm) and was also underpowered.

\section{Overall completeness and applicability of evidence}

Studies on topical repellents were undertaken in various malariaendemic countries (Bolivia, Cambodia, Laos, Pakistan, Tanzania, and Thailand) with malaria prevalence ranging between $0.31 \%$ and $11.4 \%$ forP. falciparum and $0.4 \%$ and $11.8 \%$ for $P$. vivax (see Table 2). Most studies were conducted with entire resident communities, involving adults and children of all ages. One study focused strictly on displaced pregnant women of Karen ethnicity in Thailand; and one study was conducted amongst Afghan refugees in a refugee camp in Pakistan. Some of the studies investigated topical repellents as complementary tool to LLINs. Given that LLINs are highly effective against malaria and are the backbone of all national malaria control programs, studies that did not include them may not be providing useful information to policy makers. However the included studies that did not use LLINs were conducted with vulnerable displaced populations and therefore the results may still be applicable to disaster situations or other situations where LLIN use may be compromised. Compliance may have affected the results of some of the included studies; however low compliance reflects what is likely to happen in the 'real world' and suggests that topical repellents may not be an option for malaria control programmes.

With regard to ITC, no study has been done in the general population. Both studies involved vulnerable populations: soldiers deployed in malaria-endemic regions (Soto 1995); and refugees (Rowland 1999). These populations are exposed to a higher risk of malaria, potentially have lower immunity than resident populations of that endemic area, live in harsher conditions and potentially wash their clothing less frequently and differently compared to the general population. This might have implications on the efficacy and effectiveness of the intervention. It is arguable if the results from our meta-analysis are applicable to the general population; further studies on civilian and undisplaced populations would be of interest to policy makers as ITC may to some extent reduce the risk of malaria. It is also important to evaluate the benefit of using ITC in combination with LLINs, as studies available so far did not include LLINs in their design and may not provide adequate information on the additional protection it may provide to populations who already use LLINs. 
Two studies investigating spatial repellents met the inclusion criteria for this review. The studies were both conducted in Asia (China and Indonesia) amongst the general population. It is unclear if the studies could be representative of other regions.

This review focused on malaria; however, mosquito repellents may have a broader applicability in regard to protection from other vector-borne diseases particularly transmitted by Aedes mosquitoes, such as dengue, chikungunya, and Zika viruses. An additional systematic review addressing this limitation would summarize the available evidence of the effect of this intervention on Aedes-borne diseases.

\section{Quality of the evidence}

The results of the main outcomes were graded as either very low or low-certainty evidence. We downgraded mainly due to risk of bias generated by improper methodologies for random sequence generation and allocation concealment; and by imprecision, as most studies were severely underpowered, estimates had wide confidence intervals, there were very few events, and the point estimate included the point of no effect $(R R=1)$. In the case of spatial repellents we also downgraded for inconsistency, as trials reported very different results, leading to a high degree of unexplainable heterogeneity.

\section{Potential biases in the review process}

We attempted to minimize bias in the review process by conducting a comprehensive search of published and unpublished literature, without language restrictions. Two review authors, who had no involvement in the included study, independently screened abstracts, extracted data and assessed risk of bias. We resolved any discrepancies by involving a third review author. We were unable to create funnel plots to assess reporting biases, since fewer than $10 \mathrm{RCTs} / \mathrm{CRCT}$ per intervention (topical repellents, ITC and spatial repellents) met the inclusion criteria.

\section{Agreements and disagreements with other studies or reviews}

A systematic review done by Wilson 2014 which included randomized and non-RCTs on topical repellents concluded that these are unlikely to provide effective protection against malaria and called for further well-designed trials. Our findings are in accordance with Wilson 2014, as we also conclude that there is insufficient evidence to make recommendations regarding topical repellents for malaria prevention. We did not find any other systematic review which aimed to investigate the effect of spatial repellents or ITC on malaria prevention.

\section{AUTHORS' CONCLUSIONS}

\section{Implications for practice}

We are unable to make well-informed recommendations with regard to including or not including topical repellents, ITC, or spatial repellents in malaria control programmes as the available evidence is low to very low certainty. The use of ITC in refugee camps or disaster situations may be useful as ITC provided some malaria prevention; however further research needs to be done in order to generate stronger evidence to support this.

\section{Implications for research}

We conclude that there are insufficient well-designed trials on topical repellents to draw evidence-based conclusions and make well-informed recommendations to policy makers regarding tropical repellents as a malaria prevention tool. However, there is lean evidence that the use of ITC may be useful in refugee camps or other disaster settings as they provided some malaria prevention in the absence of LLINs; further research needs to be done in order to generate stronger evidence to support this. There is a need to consider methodologies other than RCTs and CRCTs for the evaluation of malaria prevention methods such as topical repellents, ITC and spatial repellents at community level. Low compliance alongside decreasing malaria prevalence levels in potential study sites are major limitations for the design of future RCT or CRCTs because an unfeasible number of participants would need to be followed up to reach sufficient statistical power. All of the trials considered in this review were considered to be underpowered, including Sluydts 2016 which recruited over 20,000 participants per arm. Further studies on ITC involving general populations are needed to broaden the applicability of the results and to increase the certainty of the evidence. We also conclude that there are insufficient studies on spatial repellents to generate evidence-based conclusions regarding spatial repellents for malaria prevention.

\section{ACKNOWLEDGEMENTS}

We are indebted to the mentorship of Prof. Paul Garner of the Liverpool School of Tropical Medicine.

This work was partly supported through a grant from the Global Malaria Programme, World Health Organization.

MM was supported by a fellowship offered by the Effective Health Care Research Consortium, supported by Cochrane South Africa and the South African Medical Research Council, to attend a five-day workshop in Cape Town to work on this review. This Consortium and the editorial base for the Cochrane Infectious Diseases Group is funded by UKaid from the UK government for the benefit of low- and middle-income countries (Grant: 5242). The views expressed in this publication do not necessarily reflect UK government policy. 


\section{R E F E R E N C E S}

\section{References to studies included in this review}

Chen-Hussey 2013 \{published data only\}

Chen-Hussey V, Carneiro I, Keomanila H, Gray R, Bannavong S, Phanalasy $\mathrm{S}$, et al. Can topical insect repellents reduce malaria? A cluster-randomised controlled trial of the insect repellent $\mathrm{N}, \mathrm{N}$-diethyl-m-toluamide (DEET) in Lao PDR. PLoS ONE 2013;8(8):e70664.

\section{Hill 2007 \{published data only\}}

Hill N, Lenglet A, Arnéz AM, Carneiro I. Plant based insect repellent and insecticide treated bed nets to protect against malaria in areas of early evening biting vectors: double blind randomised placebo controlled clinical trial in the Bolivian Amazon. BMJ 2007;335(7628):1023.

\section{Hill 2014 \{published data only\}}

Hill N, Zhou HN, Wang P, Guo X, Carneiro I, Moore SJ. A household randomized, controlled trial of the efficacy of $0.03 \%$ transfluthrin coils alone and in combination with long-lasting insecticidal nets on the incidence of Plasmodium falciparum and Plasmodium vivax malaria in Western Yunnan Province, China. Malaria Journal 2014;13:208.

\section{McGready 2001 \{published data only\}}

McGready R, Hamilton KA, Simpson J A, Cho T, Luxemburger C, Edwards R, et al. Safety of the insect repellent N,N-diethyl-Mtoluamide (DEET) in pregnancy. American Journal of Tropical Medicine and Hygiene 2001;65(4):285-9.

\section{Rowland 1999 \{published data only\}}

Rowland M, Durrani N, Hewitt S, Mohammed N, Bouma M, Carneiro I, et al. Permethrin-treated chaddars and topsheets: appropriate technology for protection against malaria in Afghanistan and other complex emergencies. Transactions of the Royal Society of Tropical Medicine and Hygiene 1999;93(5):465-72.

\section{Rowland 2004 \{published data only\}}

Rowland M, Downey G, Rab A, Freeman T, Mohammad N, Rehman $\mathrm{H}$, et al. DEET mosquito repellent provides personal protection against malaria: a household randomized trial in an Afghan refugee camp in Pakistan. Tropical Medicine \& International Health 2004;9(3):335-42.

\section{Sangoro 2014a \{published data only\}}

Miller JE. Low cost repellents for malaria prevention in rural Africa: the jury is still out. ASTMH 60th Annual Meeting, 2011 Dec 4-8; Philadelphia. American Journal of Tropical Medicine and Hygiene 2011;6(Suppl. 1):369-70.

* Sangoro O, Turner E, Simfukwe E, Miller JE, Moore SJ. A cluster-randomized controlled trial to assess the effectiveness of using $15 \%$ DEET topical repellent with long-lasting insecticidal nets (LLINs) compared to a placebo lotion on malaria transmission. Malaria Journal 2014;13:324.

Sangoro P, Simfukwe E, Moore SJ. Cluster randomized controlled trial to determine the additional benefits of topical repellents to long lasting insecticide nets (LLINs) on malaria incidence. ASTMH 60th Annual Meeting, 2011 Dec 4-8; Philadelphia. American Journal of Tropical Medicine and Hygiene 2011;6(Suppl. 1):229.

\section{Sluydts 2016 \{published data only\}}

Sluydts V, Durnez L, Heng S, Gryseels C, Canier L, Kim S, et al. Efficacy of topical mosquito repellent (picaridin) plus longlasting insecticidal nets versus long-lasting insecticidal nets alone for control of malaria: a cluster randomised controlled trial. Lancet Infectious Diseases 2016;16(10):1169-77.

\section{Soto 1995 \{published data only\}}

Soto J, Medina F, Dember N, Berman J. Efficacy of permethrinimpregnated uniforms in the prevention of malaria and leishmaniasis in Colombian soldiers. Clinical Infectious Diseases 1995;21(3):599-602.

\section{Syafruddin 2014 \{published data only\}}

Syafruddin D, Bangs MJ, Sidik D, Elyazar I, Asih PB, Chan K, et al. Impact of a spatial repellent on malaria incidence in two villages in Sumba, Indonesia. American Journal of Tropical Medicine and Hygiene 2014;91(6):1079-87.

\section{References to studies excluded from this review}

Abdulsalam 2014 \{published data only\}

Abdulsalam YM, Muhammad H, Abduljalal A, Iliyasu Z, Muhammad B, Bello MM, et al. Effectiveness of transfluthrincoated inflammable-fumes insecticide-paper (Rambo) in the prevention of malaria in Kano, Nigeria. International Journal of Infectious Diseases 2014;21(1):154.

\section{Dadzie 2013 \{published data only\}}

Dadzie S, Boakye D, Asoala V, Koram K, Kiszewski A, Appawu M. A community-wide study of malaria reduction: evaluating efficacy and user-acceptance of a low-cost repellent in northern Ghana. American Journal of Tropical Medicine and Hygiene 2013;88(2):309-14

\section{Deressa 2014 \{published data only\}}

Deressa W, Yihdego Y, Kebede Z, Batisso E, Tekalegne A, Dagne $G$. Effect of combining mosquito repellent and insecticide treated net on malaria prevalence in Southern Ethiopia: cluster randomised trial. Parasite \& Vectors 2014;7:132.

\section{Eamsila 1994 \{published data only\}}

Eamsila C, Frances S P, Strickman D. Evaluation of permethrintreated military uniforms for personal protection against malaria in northeastern Thailand. Journal of the American Mosquito Control Association 1994;10(4):515-21.

\section{Hamza 2016 \{published data only\}}

Hamza M, Bello M, Ma'aruf M, Manu A, Ado A, Dalhatu Y, et al. Effectiveness of transfluthrin-coated inflammable-fumes insecticide-paper (Rambo) in the prevention of malaria in Kano, Nigeria. Sub-Saharan African Journal of Medicine 2016;3(2):111. 
Kimani 2006 \{published data only\}

Kimani EW, Vulule JM, Kuria IW, Mugisha F. Use of insecticidetreated clothes for personal protection against malaria: a community trial. Malaria Journal 2006;5:63.

\section{References to ongoing studies}

\section{ACTRN12616001434482 \{published data only\}}

ACTRN12616001434482. Effectiveness of mosquito repellent delivered through village health volunteers on malaria incidence in artemisinin resistance containment programs in South-East Myanmar. www.anzctr.org.au/Trial/Registration/ TrialReview.aspx?ACTRN=12616001434482 14-10-2016.

\section{NCT02294188 \{published data only\}}

NCT02294188. Spatial Repellent Products for Control of Vector Borne Diseases - Malaria - Indonesia (SR-M-IDR). clinicaltrials.gov/ct2/show/NCT02294188 17-11-2014.

\section{NCT02653898 \{published data only\}}

NCT02653839. Malaria elimination pilot study in military forces in Cambodia. clinicaltrials.gov/ct2/show/NCT02653839 08-01-2016.

\section{NCT02938975 \{published data only\}}

NCT02938975. Field efficacy of insecticide treated uniforms and skin repellents for malaria prevention. clinicaltrials.gov/ct2/ show/NCT02938975.

\section{Additional references}

\section{Balshem 2011}

Balshem H, Helfand M, Schünemann HJ, Oxman AD, Kunz R, Brozek J, et al. GRADE guidelines: 3. Rating the quality of evidence. Journal of Clinical Epidemiology 2011;64(4):401-6.

\section{Barbara 2011}

Barbara KA, Sukowati S, Rusmiarto S, Susapto D, Bangs MJ, Kinzer MH. Survey of Anopheles mosquitoes (Diptera:Culicidae) in West Sumba District, Indonesia. Southeast Asian Journal of Tropical Medicine and Public Health 2011;42(1):71-82.

\section{CDC 2014}

Centers for Disease Control and Prevention. In: Brunette GW editor(s). CDC Health Information for International Travel. New York: Oxford University Press, 2014.

\section{Durnez 2013}

Durnez L, Coosemans M. Chapter 21: Residual transmission of malaria: an old issue for new approaches. In: Manguin S editor(s). Anopheles mosquitoes - new insights into malaria vectors. Rijeka, Croatia: Intech, 2013.

\section{Garrett-Jones 1964}

Garrett-Jones C. Prognosis for interruption of malaria transmission through assessment of the mosquito's vectorial capacity. Nature 1964;204:1173-5.

\section{Guyatt 2011}

Guyatt GH, Oxman AD, Schünemann HJ, Tugwell P, Knottnerus A. GRADE guidelines: a new series of articles in the Journal of Clinical Epidemiology. Journal of Clinical Epidemiology 2011;64(4):380-2.

\section{Harbord 2006}

Harbord RM, Egger M, Sterne JA. A modified test for smallstudy effects in meta-analyses of controlled trials with binary endpoints. Statistics in Medicine 2006;25(20):3443-57.

\section{Herodotus 1996}

Herodotus. Herodotus: The Histories. London: Penguin, 1996.

\section{Higgins 2011}

Higgins JP, Altman DG, Gøtzsche PC, Jüni P, Moher D, Oxman AD, et al. The Cochrane Collaboration's tool for assessing risk of bias in randomised trials. BMJ (Clinical Research Ed.) 2011;343:d5928.

\section{Kitchen 2009}

Kitchen LW, Lawrence KL, Coleman RE. The role of the United States military in the development of vector control products, including insect repellents, insecticides, and bed nets. Journal of Vector Ecology: Journal of the Society for Vector Ecology 2009;34(1):50-61.

\section{Lefebvre 2011}

Lefebvre C, Manheimer E, Glanville J. Chapter 6: Searching for studies. In: Higgins JP, Green S, editor(s). Cochrane Handbook for Systematic Reviews of Interventions Version 5.1.0 (updated March 2011). The Cochrane Collaboration, 2011. Available from handbook.cochrane.org.

\section{MalERA 2011}

malERA Consultative Group on Vector Control. A research agenda for malaria eradication: vector control. PLoS Medicine 2011;8(1):e1000401.

\section{Moore 2002}

Moore SJ, Lenglet A, Hill N. Field evaluation of three plant-based insect repellents against malaria vectors in Vaca Diez Province, the Bolivian Amazon. Journal of the American Mosquito Control Association 2002;18(2):107-10.

\section{Review Manager 2014 [Computer program]}

Nordic Cochrane Centre, The Cochrane Collaboration. Review Manager 5 (RevMan 5). Version 5.3. Copenhagen: Nordic Cochrane Centre, The Cochrane Collaboration, 2014.

\section{Sangoro 2014b}

Sangoro PO, Moore SJ. Evaluation of Repellent Efficacy in Reducing Disease Incidencee. In: Debboun M, Frances SP, Strickman D editor(s). Repellents: principles, methods and uses. 2nd Edition. Boca Raton, Florida: CRC Press, 2014.

\section{Sangoro 2014c}

Sangoro O, Lweitojera D, Simfukwe E, Ngonyani H, Mbeyela E, Lugiko D, et al. Use of a semi-field system to evaluate the efficacy of topical repellents under user conditions provides a 
disease exposure free technique comparable with field data. Malaria Journal 2014;13:159.

\section{Sinka 2010}

Sinka ME, Rubio-Palis Y, Manguin S, Patil AP, Temperley WH, Gething PW, et al. The dominant Anopheles vectors of human malaria in the Americas: occurrence data, distribution maps and bionomic précis. Parasites \& Vectors 2010;3:72.

\section{Sinka 2011}

Sinka ME, Bangs MJ, Manguin S, Chareonviriyaphap T, Patil AP, Temperley WH, et al. The dominant Anopheles vectors of human malaria in the Asia-Pacific region: occurrence data, distribution maps and bionomic précis. Parasites \& Vectors 2011;4:89.

\section{Snow 1998}

Snow RW, Peshu N, Forster D, Bomu G, Mitsanze E, Ngumbao E, et al. Environmental and entomological risk factors for the development of clinical malaria among children on the Kenyan coast. Transactions of the Royal Society of Tropical Medicine and Hygiene 1998;92(4):381-5.

\section{Sturrock 2013}

Sturrock HJ, Hsiang MS, Cohen JM, Smith DL, Greenhouse B, Bousema T, et al. Targeting asymptomatic malaria infections: active surveillance in control and elimination. PLoS Medicine 2013;10(6):e1001467.

\section{Tatem 2010}

Tatem AJ, Smith DL. International population movements and regional Plasmodium falciparum malaria elimination strategies. Proceedings of the National Academy of Sciences of the United States of America 2010;107(27):12222-7. [DOI: 10.1073/pnas.1002971107]

\section{Van Roey 2014}

Van Roey K, Sokny M, Denis L, Van den Broeck N, Heng S, Siv S, et al. Field evaluation of picaridin repellents reveals differences in repellent sensitivity between Southeast Asian vectors of

\section{CHARACTERISTICS OF STUDIES}

Characteristics of included studies [ordered by study ID] malaria and arboviruses. PLoS Neglected Tropical Diseases 2014;8(12):e3326.

\section{White 2014}

White NJ, Pukrittayakamee S, Hien TT, Faiz MA, Mokuolu OA, Dondorp AM. Malaria. Lancet 2014;383(9918):723-35.

\section{WHO 2012}

World Health Organization. International Travel and Health. Geneva: World Health Organization, 2012.

\section{WHO 2017}

World Health Organization. World Malaria Report 2017. http:// apps.who.int/iris/bitstream/10665/259492/1/9789241565523eng.pdf?ua=1 (accessed 4 February 2018).

\section{WHOPES 1998}

WHOPES. Report of First Meeting of the Global Collaboration for the Development of Pesticides for Public Health (GCDPP). 1998 14-15 October; WHO/HQ Geneva. www.who.int/whopes/gcdpp/ en/oct98_gcdpp_report.pdf (accessed 25 March 2014).

\section{WHOPES 2006}

WHOPES. Pesticides and their application: For the control of vectors and pests of public health importance. 6th edition. whqlibdoc.who.int/hq/2006/WHO_CDS_NTD_WHOPES_ GCDPP_2006.1_eng.pdf (accessed 25 March 2014).

\section{Wilson 2014}

Wilson AL, Chen-Hussey V, Logan JG, Lindsay SW. Are topical insect repellents effective against malaria in endemic populations? A systematic review and meta-analysis. Malaria Journal 2014;13:446.

\section{Zhang 2010}

Zhang L, Jiang Z, Tong J, Wang Z, Han Z, Zhang J. Using charcoal as base material reduces mosquito coil emissions of toxins. Indoor Air 2010;20(2):176-84.

* Indicates the major publication for the study

\section{Chen-Hussey 2013}

$\begin{array}{ll}\text { Methods } & \text { Cluster randomized controlled trial (RCT) } \\ & \text { Unit of randomization was household. } \\ & \text { Intra-cluster correlation coefficient (ICC) was not reported. } \\ & \text { Trial duration: up to } 8 \text { months' follow-up in } 2009 \text { and } 2010\end{array}$

Participants

Adults or children living in endemic regions of Laos in Attapeu Sekong Provinces.

Participants were not screened at start for $P$. vivax. 
Chen-Hussey 2013 (Continued)

Co-interventions: LLINs

Treatment arms:

- Repellent arm: 795 households; 3972 participants; and

- Placebo arm: 802 households; 4008 participants.

\begin{tabular}{ll}
\hline Outcomes & - Participants with malaria parasitaemia confirmed through mRDTs (P. falciparum or P. vivax); \\
- Time to first infection (mean time in person/months to first malaria infection); and \\
- Self-reported adherence to regular usage of the intervention. \\
\hline Notes & Conducted in Laos. \\
& Trial registration number: NCT00938379 \\
& Funded by Population Services International.
\end{tabular}

\section{Risk of bias}

\begin{tabular}{lll}
\hline Bias & Authors' judgement & Support for judgement \\
\hline $\begin{array}{l}\text { Random sequence genera- } \\
\text { tion (selection bias) }\end{array}$ & Low risk & $\begin{array}{l}\text { Equal group allocation, stratified by village. Heads of households picked treat- } \\
\text { ment codes through lottery system. }\end{array}$ \\
\hline $\begin{array}{l}\text { Allocation concealment } \\
\text { (selection bias) }\end{array}$ & Low risk & Heads of households picked treatment codes out of a bowl. \\
\hline $\begin{array}{l}\text { Blinding of participants } \\
\text { and personnel (perfor- } \\
\text { mance bias) }\end{array}$ & Low risk & The treatment allocation was blinded to both participants and field staff. \\
Parasitaemia & & \\
\hline
\end{tabular}

\begin{tabular}{lll}
$\begin{array}{l}\text { Blinding of participants } \\
\text { and personnel (perfor- } \\
\text { mance bias) }\end{array}$ & Low risk & \\
Time to first infection & \\
\hline $\begin{array}{l}\text { Blinding of participants } \\
\text { and personnel (perfor- } \\
\text { mance bias) }\end{array}$ & Low risk & The treatment allocation was blinded to both participants and field staff. \\
Compliance & &
\end{tabular}

\begin{tabular}{|c|c|c|}
\hline $\begin{array}{l}\text { Blinding of outcome as- } \\
\text { sessment (detection bias) } \\
\text { Parasitaemia }\end{array}$ & Low risk & $\begin{array}{l}\text { Assessment of parasitaemia or time to first infection are objective outcomes. } \\
\text { "Field staff carrying out randomisation and follow-up surveys and trial staff } \\
\text { performing data entry and analysis were blinded for the length of the trial." }\end{array}$ \\
\hline $\begin{array}{l}\text { Blinding of outcome as- } \\
\text { sessment (detection bias) } \\
\text { Time to first infection }\end{array}$ & Low risk & $\begin{array}{l}\text { Assessment of parasitaemia or time to first infection are not biased because } \\
\text { these are objective outcomes. }\end{array}$ \\
\hline $\begin{array}{l}\text { Blinding of outcome as- } \\
\text { sessment (detection bias) } \\
\text { Compliance }\end{array}$ & Low risk & The treatment allocation was blinded to both participants and field staff. \\
\hline $\begin{array}{l}\text { Incomplete outcome data } \\
\text { (attrition bias) }\end{array}$ & Low risk & $\begin{array}{l}\text { Similar attrition between } 2 \text { groups: } 11.7 \% \text { in intervention and } 13.2 \% \text { in control } \\
\text { groups were lost to follow-up/excluded/withdrew. }\end{array}$ \\
\hline
\end{tabular}


Chen-Hussey 2013 (Continued)

All outcomes

Selective reporting (re- Low risk porting bias)
Primary outcome was reported as per protocol. Secondary outcomes included all-cause fever, but this was not reported; however it is non-essential information for this study.

The data presented on compliance was self-reported, there was no reporting of compliance measured through "sniff-checks" although it was described in the Methods section.

Baseline imbalance

Study arms had similar baseline characteristics.

\section{Hill 2007}

$\begin{array}{ll}\text { Methods } & \text { Cluster-RCT } \\ \text { Unit of randomization: household }\end{array}$

ICC was not reported.

Trial duration: 6 months from March to September 2003.

\begin{tabular}{ll}
\hline Participants & Adults or children living in malaria-endemic area \\
\hline Interventions & Topical repellent lotion containing 30\% PMD versus placebo lotion. \\
Co-interventions: LLINs \\
Treatment arms: \\
- Repellent arm (30\% PMD) + LLINs: 424 households (1967 individuals) \\
- Placebo arm + LLINs: 436 households (2041 individuals)
\end{tabular}

\begin{tabular}{ll}
\hline Outcomes & - Participants with malaria parasitaemia confirmed through mRDTs (specific to P. falciparum); \\
- All-cause fever; \\
- Self-reported adherence to regular usage of the intervention; and \\
- Recorded adverse events. \\
\hline Conducted in the Bolivian Amazon, Vaca Diez and Pando Provinces \\
Trial registration number: NCT00144716 \\
Funded by Gates Malaria Partnership grant from London School of Hygiene and Tropical Medicine
\end{tabular}

\section{Risk of bias}

\begin{tabular}{lll}
\hline Bias & Authors' judgement & Support for judgement \\
\hline $\begin{array}{ll}\text { Random sequence genera- } \\
\text { tion (selection bias) }\end{array}$ & High risk & $\begin{array}{l}\text { Sequence generation was not random. } \\
\text { "Field staff followed the strict inclusion criteria to randomise participants at } \\
\text { the household level following a basic sequential alternate A/B/A/B regimen. } \\
\end{array}$ \\
& Field staff and study participants were blind to the group allocation."
\end{tabular}


Hill 2007 (Continued)

Allocation concealment High risk (selection bias)
Sequence generation was alternated. Personnel knew which treatment was given next.

"Field staff followed the strict inclusion criteria to randomise participants at the household level following a basic sequential alternate A/B/A/B regimen.

Field staff and study participants were blind to the group allocation."

Blinding of participants Low risk Field staff and participants were blinded to the treatment allocation.

and personnel (perfor-

mance bias)

Parasitaemia

\begin{tabular}{|c|c|c|}
\hline $\begin{array}{l}\text { Blinding of participants } \\
\text { and personnel (perfor- } \\
\text { mance bias) } \\
\text { All-cause fever }\end{array}$ & Low risk & Field staff and participants were blinded to the treatment allocation. \\
\hline $\begin{array}{l}\text { Blinding of participants } \\
\text { and personnel (perfor- } \\
\text { mance bias) } \\
\text { Compliance }\end{array}$ & Low risk & Field staff and participants were blinded to the treatment allocation. \\
\hline
\end{tabular}

Blinding of participants Low risk Field staff and participants were blinded to the treatment allocation.
and personnel (perfor-
mance bias)
Adverse events

\begin{tabular}{|c|c|c|}
\hline $\begin{array}{l}\text { Blinding of outcome as- } \\
\text { sessment (detection bias) } \\
\text { Parasitaemia }\end{array}$ & Low risk & $\begin{array}{l}\text { Primary outcome is objective (mRDT result), so although it is not described if } \\
\text { the outcome assessor is blinded, lack of blinding was unlikely to bias the re- } \\
\text { sults. }\end{array}$ \\
\hline
\end{tabular}

\begin{tabular}{|c|c|c|}
\hline $\begin{array}{l}\text { Blinding of outcome as- } \\
\text { sessment (detection bias) } \\
\text { Compliance }\end{array}$ & Unclear risk & Blinding of outcome assessment for adherence to intervention is unclear. \\
\hline
\end{tabular}

\begin{tabular}{ll}
\hline Blinding of outcome as- & Unclear risk
\end{tabular}

All-cause fever

\begin{tabular}{|c|c|c|}
\hline $\begin{array}{l}\text { Blinding of outcome as- } \\
\text { sessment (detection bias) } \\
\text { Adverse events }\end{array}$ & Unclear risk & Blinding of outcome assessment for adverse events is unclear. \\
\hline $\begin{array}{l}\text { Incomplete outcome data } \\
\text { (attrition bias) } \\
\text { All outcomes }\end{array}$ & Low risk & $\begin{array}{l}\text { The number of participants lost to follow-up was similar between treatment } \\
\text { arms. }\end{array}$ \\
\hline $\begin{array}{l}\text { Selective reporting (re- } \\
\text { porting bias) }\end{array}$ & Low risk & All the outcomes set to be measured were reported. \\
\hline Other bias & High risk & $\begin{array}{l}\text { Baseline imbalance } \\
\text { "There were no significant differences in most household characteristics (num- } \\
\text { ber of household members, roof material, water source, heating source, or } \\
\text { possession of electricity, fridge, and radio) between the two groups (data not } \\
\text { shown), but households allocated to the repellent group were slightly more } \\
\text { likely to own a television than those allocated to the placebo group ( } P=0.056 \text { ) } \\
\text { (table 1). There were also no significant differences in age or sex between the }\end{array}$ \\
\hline
\end{tabular}


Unit of randomization: household

ICC is not reported.

Trial duration: 1 month baseline and 6 months' intervention from April to October 2007.

$\begin{array}{ll}\text { Participants } & \text { Adults or children living in an endemic region } \\ & \text { Participants were screened for } P \text {. vivax and parasites were cleared at start. }\end{array}$

Interventions
Cosquito coils ( $0.03 \%$ transfluthrin) and no treatment.
Treatment arms:
- Control (no treatments) arm - 513 households
$-0.03 \%$ transfluthrin coils arm -512 households
- LLINs arm -513 households
- LLINs $+0.03 \%$ transfluthrin coils arm -514 households

\begin{tabular}{ll}
\hline Outcomes & - Participants with malaria parasitaemia confirmed through mRDTs (P. falciparum or P. vivax) and veri- \\
fied by external microscopist through thick film; \\
- Adherence to regular usage of the intervention measured through village leaders' reports and self-re- \\
porting; and \\
- Reduction in indoor density of mosquitoes measured through collections using CDC light traps indoor \\
households from the four treatment arms (monthly arithmetic mean of mosquito densities). \\
\hline Conducted in rural areas of China in the Ruili County, Yunnan Province, close to the Myanmar border. \\
Trial registration number: NCT00442442 \\
Funded by SC Johnson
\end{tabular}

\section{Risk of bias}

\begin{tabular}{lll}
\hline Bias & Authors' judgement & Support for judgement \\
\hline $\begin{array}{ll}\text { Random sequence genera- } \\
\text { tion (selection bias) }\end{array}$ & Low risk & Allocation was done using lottery system: \\
& $\begin{array}{l}\text { "Households enrolled at baseline were randomly allocated by the lottery } \\
\text { method to one of the four intervention arms (i) nothing, (ii) coils alone, (iii) } \\
\text { LLINs alone or (iv) coils and LLINs." }\end{array}$ \\
\hline
\end{tabular}

$\begin{aligned} & \text { Allocation concealment } \\ & \text { (selection bias) }\end{aligned} \quad$ Low risk Allocation was done using lottery system so allocation was concealed:


Hill 2014 (Continued)

"Households enrolled at baseline were randomly allocated by the lottery method to one of the four intervention arms (i) nothing, (ii) coils alone, (iii) LLINs alone or (iv) coils and LLINs."

$\begin{array}{ll}\begin{array}{l}\text { Blinding of participants } \\ \text { and personnel (perfor- }\end{array} & \text { High risk } \\ \begin{array}{l}\text { mance bias) } \\ \text { Parasitaemia }\end{array} & \begin{array}{l}\text { Participants and field staff were not blinded. Participants may have changed } \\ \text { their behaviour if they knew to which treatment they had been allocated. }\end{array} \\ & \text { "Field workers and participants were not blinded to treatment allocation, as } \\ & \text { this was impossible in practice. However, the field staff collecting monthly RDT } \\ \text { data were not aware of the intervention which individuals had been using thus } & \text { achieving single blinding (investigator) of the study." }\end{array}$

Blinding of participants High risk Participants and field staff were not blinded. Participants may have changed and personnel (perfortheir behaviour by knowing the treatment they had been allocated to.

mance bias)

Compliance

"Field workers and participants were not blinded to treatment allocation, as this was impossible in practice. However, the field staff collecting monthly RDT data were not aware of the intervention which individuals had been using thus achieving single blinding (investigator) of the study."

"...the untreated control group continued to use their own personal protection methods. It would be unethical to ask anyone not to do this but a record was kept of such ad-hoc coil use in the negative control group and those reporting the use of one box or more ( 10 coils $/ 5$ nights) were excluded from the analysis for that round.(...) Conversely, those in the control arm were less likely to follow the request of the study directors to not use any intervention, with $13-19 \%$ using local coils for 3 or more days in the month prior to the survey."

\begin{tabular}{|c|c|c|}
\hline $\begin{array}{l}\text { Blinding of participants } \\
\text { and personnel (perfor- }\end{array}$ & High risk & $\begin{array}{l}\text { The team collecting the mosquitoes could have been biased if they knew } \\
\text { which houses belonged to each treatment. }\end{array}$ \\
\hline
\end{tabular}

mance bias)

Reduction in mosquitoes attempting to feed on humans

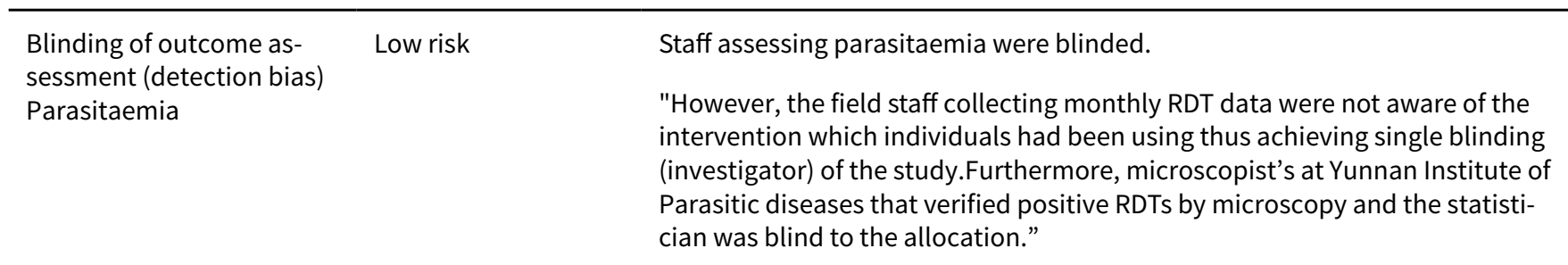

\begin{tabular}{|c|c|c|}
\hline $\begin{array}{l}\text { Blinding of outcome as- } \\
\text { sessment (detection bias) } \\
\text { Compliance }\end{array}$ & High risk & $\begin{array}{l}\text { Compliance was measured indirectly through counting of empty boxes of } \\
\text { coils. }\end{array}$ \\
\hline
\end{tabular}

\begin{abstract}
Blinding of outcome assessment (detection bias) Reduction in mosquitoes attempting to feed on humans
\end{abstract}

Low risk

Data is objective therefore the risk of detection bias is low.

Incomplete outcome data Low risk Loss to follow-up was less than $2 \%$ in all treatment arms.
(attrition bias)
All outcomes

Selective reporting (re- $\quad$ Low risk $\quad$ All outcomes were reported.
porting bias)


Hill 2014 (Continued)
Other bias
Low risk
Baseline imbalance
Study arms had similar baseline characteristics.

McGready 2001

$\begin{array}{ll}\text { Methods } & \text { RCT } \\ & \text { Trial duration: } 17 \text { months between April } 1995 \text { and September } 1996 .\end{array}$

\begin{tabular}{ll}
\hline Participants & Participants were women who were 3 to 7 months' pregnant. \\
& Participants were not screened at start for $P$. vivax. \\
\hline Interventions & Co-intervention: none \\
& Treatment arms: \\
- Thanaka containing 20\% DEET arm - 449; and & - Thanaka arm - 448. \\
\hline - Participants with malaria parasitaemia confirmed through blood smears (P. falciparum and P. vivax); \\
- Adherence to regular usage of the intervention measured through self-reporting; \\
- Anaemia; and \\
- Recorded adverse events. \\
The study was carried out in camps for displaced people of the Karen ethnic minority in endemic re- \\
gions of Thailand. \\
The project was funded by the Danish Bilharziasis Laboratory and was part of the Wellcome-Mahidol \\
University of Oxford Tropical Medicine Research Programme funded by the Wellcome Trust.
\end{tabular}

\section{Risk of bias}

\begin{tabular}{|c|c|c|}
\hline Bias & Authors' judgement & Support for judgement \\
\hline $\begin{array}{l}\text { Random sequence genera- } \\
\text { tion (selection bias) }\end{array}$ & Unclear risk & Not described \\
\hline $\begin{array}{l}\text { Allocation concealment } \\
\text { (selection bias) }\end{array}$ & Unclear risk & Not described \\
\hline $\begin{array}{l}\text { Blinding of participants } \\
\text { and personnel (perfor- } \\
\text { mance bias) } \\
\text { Parasitaemia }\end{array}$ & Low risk & $\begin{array}{l}\text { Double-blinded RCT, both personnel and participants were blinded to the in- } \\
\text { tervention. }\end{array}$ \\
\hline $\begin{array}{l}\text { Blinding of participants } \\
\text { and personnel (perfor- } \\
\text { mance bias) } \\
\text { Anaemia }\end{array}$ & Low risk & $\begin{array}{l}\text { Double-blinded RCT, both personnel and participants were blinded to the in- } \\
\text { tervention. }\end{array}$ \\
\hline
\end{tabular}


McGready 2001 (Continued)

Blinding of participants Low risk Double-blinded RCT, both personnel and participants were blinded to the inand personnel (performance bias)

Compliance tervention.

$\begin{aligned} & \text { Blinding of participants } \\ & \text { and personnel (perfor- }\end{aligned}$
$\begin{aligned} & \text { mance bias) } \\ & \text { Adverse events }\end{aligned}$

\begin{tabular}{|c|c|c|}
\hline $\begin{array}{l}\text { Blinding of outcome as- } \\
\text { sessment (detection bias) } \\
\text { Parasitaemia }\end{array}$ & Low risk & $\begin{array}{l}\text { Double-blinded RCT, both personnel and participants were blinded to the in- } \\
\text { tervention. }\end{array}$ \\
\hline
\end{tabular}

\begin{tabular}{|c|c|c|}
\hline $\begin{array}{l}\text { Blinding of outcome as- } \\
\text { sessment (detection bias) } \\
\text { Compliance }\end{array}$ & Low risk & $\begin{array}{l}\text { Double blinded RCT, both personnel and participants were blinded to the in- } \\
\text { tervention. }\end{array}$ \\
\hline $\begin{array}{l}\text { Blinding of outcome as- } \\
\text { sessment (detection bias) } \\
\text { Adverse events }\end{array}$ & Low risk & $\begin{array}{l}\text { Double-blinded RCT, both personnel and participants were blinded to the in- } \\
\text { tervention. }\end{array}$ \\
\hline $\begin{array}{l}\text { Blinding of outcome as- } \\
\text { sessment (detection bias) } \\
\text { Anaemia }\end{array}$ & Low risk & This is an objective outcome. \\
\hline $\begin{array}{l}\text { Incomplete outcome data } \\
\text { (attrition bias) } \\
\text { All outcomes }\end{array}$ & Low risk & $\begin{array}{l}\text { Attrition between arms was similar, data was not reported in the published but } \\
\text { retrieved through communication with the author. }\end{array}$ \\
\hline $\begin{array}{l}\text { Selective reporting (re- } \\
\text { porting bias) }\end{array}$ & Low risk & $\begin{array}{l}\text { Reporting was not clear in the published article but data of events between } \\
\text { treatment arms was sent to us after communicating with the author. }\end{array}$ \\
\hline Other bias & Low risk & $\begin{array}{l}\text { Baseline imbalance } \\
\text { "Between April } 1995 \text { and September 1996, } 897 \text { pregnant women were enrolled } \\
\text { in the study, } 449 \text { into the DET and thanaka group and } 448 \text { into the thanaka } \\
\text { alone group with no difference in baseline characteristics" }\end{array}$ \\
\hline
\end{tabular}

Rowland 1999

\begin{tabular}{ll}
\hline Methods & Cluster-RCT \\
& Unit of randomization: household \\
& ICC was not reported. \\
& Trial duration: 16 weeks from July to November 1996 \\
\hline Participants & Adults or children living in malaria-endemic regions \\
& Participants were not screened at start for $P$. vivax. \\
\hline Interventions & Treated clothing in the form of chaddars (permethrin $0.1 \mathrm{mg} / \mathrm{cm}^{2}$ ) versus placebo \\
Co-interventions: none \\
Treatment arms:
\end{tabular}


Rowland 1999 (Continued)

- Treated chaddar arm: 51 households (438 individuals)

- Placebo arm: 51 households (387 individuals)

\begin{tabular}{l}
\hline Outcomes \\
parum or P. vivax); and \\
- Recorded adverse events.
\end{tabular}

Notes Trial was conducted with Afghan refugees in Adizai settlement in north-western Pakistan.

Funded by HealthNet International's Malaria and Leishmaniasis control and research programme.

\section{Risk of bias}

\begin{tabular}{lll}
\hline Bias & Authors' judgement & Support for judgement \\
\hline $\begin{array}{ll}\text { Random sequence genera- } \\
\text { tion (selection bias) }\end{array}$ & Low risk & $\begin{array}{l}\text { Random number generator used against list of health centre family registra- } \\
\text { tion cards. }\end{array}$ \\
& "To achieve this sample size, $20 \%$ of refugee households were selected using a \\
random number generator against the & list of health centre family registration cards." \\
\end{tabular}

$\begin{array}{ll}\begin{array}{l}\text { Allocation concealment } \\ \text { (selection bias) }\end{array} & \text { Not described. } \\ & \text { "Selected households were randomly divided into intervention and placebo } \\ & \begin{array}{l}\text { groups, and if more than one family lived in a single house all families therein } \\ \text { were allocated to the same treatment group." }\end{array}\end{array}$

\begin{tabular}{ll}
\hline $\begin{array}{l}\text { Blinding of participants } \\
\text { and personnel (perfor- }\end{array}$ & Low risk \\
$\begin{array}{l}\text { mance bias) } \\
\text { Clinical malaria }\end{array}$ & "Field workers were under the assumption that both placebo and permethrin \\
& were effective. Health centre staff did not know which families were in \\
& which group."
\end{tabular}

\begin{tabular}{ll}
\hline Blinding of participants & Low risk \\
$\begin{array}{l}\text { and personnel (perfor- } \\
\text { mance bias) }\end{array}$ & Participants and staff were blinded. \\
Adverse events & "Field workers were under the assumption that both placebo and permethrin \\
& were effective. Health centre staff did not know which families were in which \\
& group."
\end{tabular}

\begin{tabular}{|c|c|c|}
\hline $\begin{array}{l}\text { Blinding of outcome as- } \\
\text { sessment (detection bias) } \\
\text { Adverse events }\end{array}$ & Low risk & "Health centre staff did not know which families were in which group" \\
\hline
\end{tabular}

\begin{tabular}{l}
\hline $\begin{array}{l}\text { Blinding of outcome as- } \\
\text { sessment (detection bias) } \\
\text { Clinical malaria }\end{array}$ \\
\hline
\end{tabular}

\begin{tabular}{|c|c|c|}
\hline $\begin{array}{l}\text { Incomplete outcome data } \\
\text { (attrition bias) } \\
\text { All outcomes }\end{array}$ & Unclear risk & $\begin{array}{l}\text { Not stated how many people were lost to follow-up, or how/if this was mea- } \\
\text { sured. }\end{array}$ \\
\hline $\begin{array}{l}\text { Selective reporting (re- } \\
\text { porting bias) }\end{array}$ & Unclear risk & $\begin{array}{l}\text { Protocol not available and author failed to communicate with the review } \\
\text { team. }\end{array}$ \\
\hline Other bias & Low risk & Baseline imbalance \\
\hline
\end{tabular}


Rowland 2004

\begin{tabular}{ll}
\hline Methods & Cluster-RCT \\
& Unit of randomizations: household \\
& Intra-cluster correlation coefficient factor of 0.04. \\
& Trial duration: 7 months between August 1999 and February 2000.
\end{tabular}

\section{Participants}

Adults and children living in malaria-endemic regions

Participants were not screened at start for P. vivax.

\begin{tabular}{|c|c|c|}
\hline Interventions & \multicolumn{2}{|c|}{$\begin{array}{l}\text { Topical repellent - Mosbar soap ( } 20 \% \text { DEET }+0.5 \% \text { permethrin) versus placebo lotion } \\
\text { Co-interventions: none } \\
\text { Treatment arms: } \\
\text { - Mosbar soap ( } 20 \% \text { DEET + 0.5\% permethrin) arm: } 67 \text { households ( } 618 \text { participants) } \\
\text { - Placebo arm: } 60 \text { households ( } 530 \text { participants) }\end{array}$} \\
\hline Outcomes & \multicolumn{2}{|c|}{$\begin{array}{l}\text { - Participants with clinical malaria confirmed through blood smears or rapid diagnostic tests ( } P \text {. falci- } \\
\text { parum or P. vivax); and } \\
\text { - Recorded adverse events. }\end{array}$} \\
\hline Notes & \multicolumn{2}{|c|}{$\begin{array}{l}\text { Trial was conducted with Afghan refugees in malaria-endemic region of Pakistan. } \\
\text { Funded by HealthNet International's Malaria and Leishmaniasis control and research programme. }\end{array}$} \\
\hline \multicolumn{3}{|l|}{ Risk of bias } \\
\hline Bias & Authors' judgement & Support for judgement \\
\hline $\begin{array}{l}\text { Random sequence genera- } \\
\text { tion (selection bias) }\end{array}$ & Unclear risk & $\begin{array}{l}\text { Not described } \\
\text { "By applying simple randomisation } 13 \% \text { ( } 67 \text { of } 510) \text { of households were allo- } \\
\text { cated to the repellent soap group and a similar proportion }(12 \%, 60 \text { of } 510) \text { to } \\
\text { the placebo control." }\end{array}$ \\
\hline $\begin{array}{l}\text { Allocation concealment } \\
\text { (selection bias) }\end{array}$ & Unclear risk & Not described \\
\hline $\begin{array}{l}\text { Blinding of participants } \\
\text { and personnel (perfor- } \\
\text { mance bias) } \\
\text { Clinical malaria }\end{array}$ & Low risk & $\begin{array}{l}\text { Participants were blinded: although they had been given two different prod- } \\
\text { ucts, a soap or a lotion, they were not aware which one had repellent proper- } \\
\text { ties. }\end{array}$ \\
\hline $\begin{array}{l}\text { Blinding of participants } \\
\text { and personnel (perfor- } \\
\text { mance bias) } \\
\text { Adverse events }\end{array}$ & Low risk & Participants and personnel were blinded. \\
\hline
\end{tabular}


Rowland 2004 (Continued)

Blinding of outcome as- Low risk Participants and personnel were blinded. sessment (detection bias)

Adverse events

Blinding of outcome as- Low risk $\quad$ Microscopists were blinded to the treatment allocation.
sessment (detection bias)

sessment (detection bias)

Clinical malaria

Incomplete outcome data Low risk No losses to follow-up were reported.

(attrition bias)

All outcomes

\begin{tabular}{lll}
\hline $\begin{array}{l}\text { Selective reporting (re- } \\
\text { porting bias) }\end{array}$ & Unclear risk & $\begin{array}{l}\text { Protocol not available and author failed to communicate with the review } \\
\text { team. }\end{array}$ \\
\hline Other bias & Low risk & $\begin{array}{l}\text { Baseline imbalance } \\
\text { Study arms had similar baseline characteristics. }\end{array}$ \\
\hline
\end{tabular}

\section{Sangoro 2014a}

$\begin{array}{ll}\text { Methods } & \text { Cluster-RCT } \\ \text { Unit of randomization: cluster of houses } \\ \text { ICC is not reported. }\end{array}$

Trial duration: 14 months from July 2009 to August 2010

\begin{tabular}{ll}
\hline Participants & Adults or children living in endemic areas. \\
\hline Interventions & 15\% DEET lotion versus placebo lotion \\
Co-interventions: LLINs \\
Treatment arms: \\
- DEET 15\% + LLINs arm - 10 clusters, 468 households and 2224 participants \\
- Placebo + LLINs arm - 10 clusters, 469 households and 2202 participants
\end{tabular}

Outcomes

- Participants with clinical malaria confirmed through blood smears or rapid diagnostic tests (P. falciparum); and

- Adherence to regular usage of the intervention.

Notes

Trial was conducted in rural communities of the Ulanga district, Kilombero Valley, Tanzania.

Trial registration number: ISRCTN92202008

Funded by Population Services International.

\section{Risk of bias}

\section{Bias}

Random sequence genera- High risk tion (selection bias) 
Sangoro 2014a (Continued)

Allocation concealment High risk Allocation was not concealed. The method described was basic sequential al(selection bias) ternate $A / B / A / B$.

Blinding of participants and personnel (perfor-

mance bias)

Clinical malaria

Blinding of participants Low risk
and personnel (perfor-
mance bias)
Compliance

The treatment allocation was blinded to both participants and field staff.

$\begin{array}{lll}\text { Blinding of outcome as- } & \text { High risk } & \begin{array}{l}\text { Compliance was indirectly reported by measuring the amount of lotion re- } \\ \text { maining in the bottle. }\end{array}\end{array}$

Compliance

Blinding of outcome as-
sessment (detection bias) $\quad$ Low risk Clinical malaria was diagnosed by mRDT which is an objective method.

Clinical malaria

\begin{tabular}{lll}
$\begin{array}{l}\text { Incomplete outcome data } \\
\text { (attrition bias) } \\
\text { All outcomes }\end{array}$ & Low risk \\
\hline $\begin{array}{l}\text { Selective reporting (re- } \\
\text { porting bias) }\end{array}$ & Low risk & All outcomes were reported. \\
\hline Other bias & High risk & $\begin{array}{l}\text { Baseline imbalance: } \\
\text { "Bias was introduced into the study by an imbalance in socio-economic status } \\
\text { between the two study groups. The control group demonstrated a higher so- } \\
\text { cio-economic status than the control arm." }\end{array}$
\end{tabular}

\section{Sluydts 2016}

$\begin{array}{ll}\text { Methods } & \text { Cluster-RCT } \\ & \text { Unit of randomization: cluster of houses } \\ \text { ICC was calculated per survey; survey } 4 \text { ICC was } 0.0294 .\end{array}$

Trial duration: approximately 20 months from April 2012 until November 2013 inclusive.

\begin{tabular}{ll} 
Participants & Adults and children living in malaria-endemic regions. \\
& Participants were not screened at start for P. vivax. \\
\hline Interventions & Picaridin KBR3023 (topical repellent) versus no treatment \\
& Picaridin $10 \%$ for children $<10$ years and Picaridin $20 \%$ in individuals $<10$ years \\
Co-interventions: LLINs & Treatment arms: \\
- Picaridin KBR3023 arm - 49 clusters from 57 villages ( 5642 households, 25,051 individuals)
\end{tabular}




\begin{tabular}{ll}
\hline Outcomes & - Participants with clinical malaria confirmed through blood smears or rapid diagnostic tests (P. falci- \\
parum or P. vivax); & - Participants with malaria parasitaemia confirmed through thick or thin blood smears, mRDTs or PCR \\
& (P. falciparum or P.vivax); \\
& - Adherence to regular usage of the intervention through self-reporting and observational studies; and \\
- Recorded adverse events. & \\
\hline Totes & Trial was conducted in Ratanakiri province, Cambodia. \\
& Trial registration number: NCT01663831 \\
Funded by the Bill and Melinda Gates Foundation.
\end{tabular}

\section{Risk of bias}

\begin{tabular}{lll}
\hline Bias & Authors' judgement & Support for judgement \\
\hline $\begin{array}{l}\text { Random sequence genera- } \\
\text { tion (selection bias) }\end{array}$ & Low risk & $\begin{array}{l}\text { Random sequence, calculation of restriction factor, and validity matrix was } \\
\text { carried out in R using “onemillion_random. RData". }\end{array}$ \\
\hline $\begin{array}{l}\text { Allocation concealment } \\
\text { (selection bias) }\end{array}$ & Low risk & $\begin{array}{l}\text { All clusters were allocated a treatment at start using a computer generated } \\
\text { random sequence. }\end{array}$ \\
\hline $\begin{array}{l}\text { Blinding of participants } \\
\begin{array}{l}\text { and personnel (perfor- } \\
\text { mance bias) }\end{array}\end{array}$ & High risk \\
\begin{tabular}{l} 
Parasitaemia \\
\hline
\end{tabular}
\end{tabular}

\begin{tabular}{|c|c|c|}
\hline $\begin{array}{l}\text { Blinding of participants } \\
\text { and personnel (perfor- } \\
\text { mance bias) } \\
\text { Clinical malaria }\end{array}$ & High risk & There was no placebo given to control group. \\
\hline
\end{tabular}

\begin{tabular}{|c|c|c|}
\hline $\begin{array}{l}\text { Blinding of participants } \\
\text { and personnel (perfor- } \\
\text { mance bias) } \\
\text { Compliance }\end{array}$ & High risk & $\begin{array}{l}\text { There was no placebo given to control group so it is unclear how compli- } \\
\text { ance might have been affected. Control group was given LLIN and interven- } \\
\text { tion group was given a topical repellent in addition to the LLIN. It is possible } \\
\text { that participants felt they would be protected by the repellent and so would } \\
\text { choose not to use their bed net. }\end{array}$ \\
\hline
\end{tabular}

\begin{tabular}{|c|c|c|}
\hline $\begin{array}{l}\text { Blinding of participants } \\
\text { and personnel (perfor- }\end{array}$ & High risk & $\begin{array}{l}\text { There was no placebo given to control so those given repellent lotions might } \\
\text { have felt more likely to suffer adverse effects. }\end{array}$ \\
\hline
\end{tabular}

Adverse events

\begin{tabular}{lll}
\hline $\begin{array}{l}\text { Blinding of outcome as- } \\
\text { sessment (detection bias) } \\
\text { Parasitaemia }\end{array}$ & Low risk & Parasitaemia was measured by PCR which is an objective test. \\
\hline $\begin{array}{l}\text { Blinding of outcome as- } \\
\text { sessment (detection bias) } \\
\text { Compliance }\end{array}$ & Unclear risk & $\begin{array}{l}\text { Compliance was only measured in the treatment arm because there was no } \\
\text { placebo. }\end{array}$ \\
\hline
\end{tabular}


Sluydts 2016 (Continued)

$\begin{array}{lll}\text { Blinding of outcome as- } & \text { High risk } & \begin{array}{l}\text { Adverse effects were self-reported and could have been influenced by the par- } \\ \text { sessment (detection bias) }\end{array} \\ \text { Adverse events } & \text { ticipant knowing that he/she had been given a fully effective mosquito repel- } \\ \text { lent. }\end{array}$

Adverse events

Unclear risk

The trial was not placebo-controlled: individuals that received the repellent

Blinding of outcome as-

could have mentioned this to medical staff and influenced their diagnosis of sessment (detection bias)

clinical malaria.

\begin{tabular}{lll}
\hline $\begin{array}{l}\text { Incomplete outcome data } \\
\text { (attrition bias) } \\
\text { All outcomes }\end{array}$ & Low risk & Attrition was similar between groups. \\
\hline $\begin{array}{l}\text { Selective reporting (re- } \\
\text { porting bias) }\end{array}$ & Low risk & Reporting was done according to protocol. \\
\hline Other bias & Low risk & Baseline imbalance. \\
& Restrained randomization controlled for baseline imbalances \\
\hline
\end{tabular}

\section{Soto 1995}

$\begin{array}{ll}\text { Methods } & \text { RCT } \\ \text { Duration of the trial: } 3 \text { to } 5 \text { weeks followed by } 4 \text { weeks' follow-up }\end{array}$

\begin{tabular}{ll}
\hline Participants & Colombian Army members stationed in endemic areas \\
\hline Interventions & Insecticide treated clothing versus placebo \\
& Treatment arms: \\
& - ITC - 86 individuals; \\
& - Placebo - 86 individuals. \\
\hline Outcomes & - Participants with clinical malaria confirmed through blood smears or rapid diagnostic tests (P. falci- \\
parum or $P$. vivax); and \\
- Recorded adverse events. \\
\hline Notes & Trial was conducted in the Colombian Amazon.
\end{tabular}

\section{Risk of bias}

\begin{tabular}{lll}
\hline Bias & Authors' judgement & Support for judgement \\
\hline $\begin{array}{l}\text { Random sequence genera- } \\
\text { tion (selection bias) }\end{array}$ & Unclear risk & $\begin{array}{l}\text { The randomization process is not described. } \\
\text { Quote "troops were randomly assigned to receive either permethrin-impreg- } \\
\text { nated or non-impregnated uniforms" }\end{array}$ \\
\hline $\begin{array}{l}\text { Allocation concealment } \\
\text { (selection bias) }\end{array}$ & Unclear risk & Poorly described. \\
\hline $\begin{array}{l}\text { Blinding of participants } \\
\text { and personnel (perfor- } \\
\text { mance bias) }\end{array}$ & Low risk & Medical attendants and soldiers were blinded to the intervention. \\
\hline
\end{tabular}


Soto 1995 (Continued)

Clinical malaria

Blinding of participants Low risk Medical attendants and soldiers were blinded to the intervention.
and personnel (perfor-
mance bias)
Adverse events

\begin{tabular}{|c|c|c|}
\hline $\begin{array}{l}\text { Blinding of outcome as- } \\
\text { sessment (detection bias) } \\
\text { Adverse events }\end{array}$ & Low risk & Medical attendants and soldiers were blinded to the intervention. \\
\hline $\begin{array}{l}\text { Blinding of outcome as- } \\
\text { sessment (detection bias) } \\
\text { Clinical malaria }\end{array}$ & Low risk & Medical attendants and soldiers were blinded to the intervention. \\
\hline $\begin{array}{l}\text { Incomplete outcome data } \\
\text { (attrition bias) } \\
\text { All outcomes }\end{array}$ & Low risk & $\begin{array}{l}\text { All patients completed the study and there were no losses to follow-up, no } \\
\text { treatment withdrawals, no trial group changes and no major adverse events. } \\
\text { Adherence to instructions (wearing clothes) was not monitored so not possible } \\
\text { to assess whether soldiers were compliant. }\end{array}$ \\
\hline $\begin{array}{l}\text { Selective reporting (re- } \\
\text { porting bias) }\end{array}$ & Unclear risk & Protocol not available and the corresponding author failed to communicate. \\
\hline Other bias & Unclear risk & $\begin{array}{l}\text { Baseline imbalance } \\
\text { Both study arms recruited similar number of soldiers and deployed them to } \\
\text { the same endemic area. However, the number of weeks soldiers in each study } \\
\text { arm were deployed in the field was not reported per arm. } \\
\text { "Each soldier was in the area of endemicity for 3-8 weeks." }\end{array}$ \\
\hline
\end{tabular}

\section{Syafruddin 2014}

Matched pair cluster-RCT, with the matching done according to village.
Unit of randomization: cluster
ICC not reported.
Trial duration: 6 months

Trial duration: 6 months

Male adults between 18 and 60 years old, residents of malaria-endemic regions.
Participants were screened at start and parasites were cleared.

Interventions Mosquito coils ( $0.00975 \%$ metofluthrin) versus Placebo coils

No co-interventions

Treatment arms:

- Metofluthrin treated coils: 2 clusters with total of 216 households, population of 1001 individuals and 83 participants (males 18 to 60 years old) enrolled for follow-up;

- Placebo coils: 2 clusters with total of 229 households, population of 1119 and 87 participants (males 18 to 60 years old) enrolled for follow-up.

Outcomes - Participants with Plasmodium spp. parasitaemia confirmed through blood smear.


Syafruddin 2014 (Continued)

- Reduction in mosquito landings measured through human landing catch.

- Adverse events.

Notes

Trial was conducted in Umbugendo and Wainyapu in Southwest Sumba District, East Nusa Tenggara Province, Indonesia.

Funded by Bill and Melinda Gates Foundation

\section{Risk of bias}

\begin{tabular}{lll}
\hline Bias & Authors' judgement & Support for judgement \\
\hline $\begin{array}{l}\text { Random sequence genera- } \\
\text { tion (selection bias) }\end{array}$ & Unclear risk & Randomization method was not described. \\
\hline $\begin{array}{l}\text { Allocation concealment } \\
\text { (selection bias) }\end{array}$ & Low risk & $\begin{array}{l}\text { The trial as a matched pair cRCT with matching done according to village lev- } \\
\text { el. There were only two clusters in each village: therefore after treatment was } \\
\text { allocated to one cluster, it was obvious which treatment would be allocated to } \\
\text { the next cluster. }\end{array}$ \\
\hline $\begin{array}{l}\text { Blinding of participants } \\
\text { and personnel (perfor- } \\
\text { mance bias) }\end{array}$ & Low risk & $\begin{array}{l}\text { Blinding of both participants and personnel was in place. } \\
\text { Parasitaemia }\end{array}$ \\
$\begin{array}{l}\text { "The study administrator obtained a list of lot manufacturing codes from the } \\
\text { coil manufacturer (S.C. Johnson Co., Ho Chi Minh, Vietnam) that identified } \\
\text { coils as either active or placebo. The administrator then assigned a code spe- } \\
\text { cific to each home and labelled packages of coils corresponding to cluster as- } \\
\text { signment to active or placebo coil treatment. These assignments were kept in } \\
\text { a sealed envelope in a secure location within the managing centre of the re- } \\
\text { search program (Jakarta). Thus, the investigators, research team, study sub- } \\
\text { jects, and residents were blinded as to which cluster received active versus } \\
\text { placebo coils until after completion of the study." }\end{array}$
\end{tabular}

Blinding of participants Low risk Technicians collecting the mosquitoes were blinded to the interventions.
and personnel (perfor-

mance bias)

Reduction in mosquitoes attempting to feed on humans

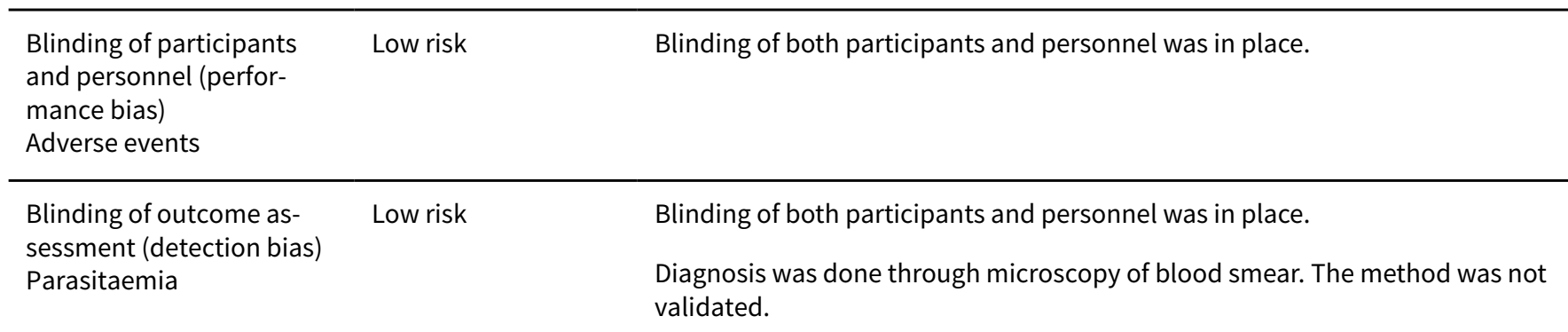

\begin{tabular}{|c|c|c|}
\hline $\begin{array}{l}\text { Blinding of outcome as- } \\
\text { sessment (detection bias) } \\
\text { Adverse events }\end{array}$ & Low risk & Blinding of both participants and personnel was in place. \\
\hline
\end{tabular}

Blinding of outcome as- $\quad$ Low risk $\quad$ Blinding of both participants and personnel was in place.
sessment (detection bias)
Reduction in mosquitoes
attempting to feed on hu-
mans


Syafruddin 2014 (Continued)
Incomplete outcome data
(attrition bias)
Low risk No withdrawals were reported.

All outcomes

\begin{tabular}{lll}
\hline $\begin{array}{l}\text { Selective reporting (re- } \\
\text { porting bias) }\end{array}$ & Low risk & $\begin{array}{l}\text { The primary outcomes set out by the author in the registered protocol match } \\
\text { those reported in the paper. }\end{array}$ \\
\hline Other bias & Low risk & Baseline imbalance \\
& Study arms had similar baseline characteristics.
\end{tabular}

Abbreviations: RCT: randomized controlled trial.

Characteristics of excluded studies [ordered by study ID]

\begin{tabular}{ll}
\hline Study & Reason for exclusion \\
\hline Abdulsalam 2014 & The study only had two units of randomization. \\
\hline Dadzie 2013 & The study was not a randomized controlled trial (RCT). \\
\hline Deressa 2014 & The study did not specify the repellent compound tested. \\
\hline Eamsila 1994 & The study was not a RCT. \\
\hline Hamza 2016 & The study only had two units of randomization. \\
\hline Kimani 2006 & The study only had two units of randomization. \\
\hline
\end{tabular}

Abbreviations: RCT: randomized controlled trial.

Characteristics of ongoing studies [ordered by study ID]

\section{ACTRN12616001434482}

Trial name or title

Methods

\begin{tabular}{ll}
\hline Participants & $\begin{array}{l}\text { Men and women of all ages residing in the study area. High-risk populations (mobile and migrant } \\
\text { people and residents who are also forest dwellers) will be targeted to receive the repellent. }\end{array}$ \\
\hline Interventions & \begin{tabular}{l}
$12 \%$ DEET cream versus no treatment \\
\hline Outcomes
\end{tabular} \\
$\begin{array}{ll}\text { The primary epidemiological outcomes will be incidence of Plasmodium spp. infection (diagnosed } \\
\text { by an mRDT) and incidence of malaria illness. }\end{array}$ \\
\hline Starting date & 01-04-2015 \\
\hline Contact information & Freya Fowkes (freya.fowkes@burnet.edu.au) \\
\hline Notes & www.anzctr.org.au/Trial/Registration/TrialReview.aspx?ACTRN=12616001434482 \\
\hline
\end{tabular}

Effectiveness of mosquito repellent delivered through village health volunteers on malaria incidence in artemisinin resistance containment programs in South-East Myanmar 
NCT02294188

\begin{tabular}{ll}
\hline Trial name or title & Spatial Repellent Products for Control of Vector Borne Diseases - Malaria - Indonesia \\
\hline Methods & Cluster-RCT \\
\hline Participants & Residents of malaria-endemic regions of Indonesia \\
\hline Interventions & Spatial repellent passive emanators versus placebo \\
\hline Outcomes & $\begin{array}{l}\text { The primary epidemiological endpoint will be the incidence density of first time malaria infections } \\
\text { among human cohorts during the follow-up period as detected by polymerase chain reaction assay } \\
\text { (PCR). }\end{array}$ \\
\hline Starting date & May 2015 \\
\hline Contact information & Neil Lobo (nlobo@nd.edu) \\
\hline Notes & clinicaltrials.gov/ct2/show/NCT02294188 \\
\hline
\end{tabular}

\section{NCT02653898}

\begin{tabular}{ll}
\hline Trial name or title & Malaria Elimination Pilot Study in Military Forces in Cambodia \\
\hline Methods & Cluster-RCT \\
\hline Participants & Residents of military encampments on the Thai-Cambodian border \\
\hline Interventions & $\begin{array}{l}\text { Focused screening and treatment, malaria prophylaxis and insecticide-treated uniforms versus un- } \\
\text { treated uniforms }\end{array}$ \\
\hline Outcomes & $\begin{array}{l}\text { The primary epidemiological outcome will be the absolute risk reduction based on the proportion } \\
\text { of subjects remaining malaria-free at the end of } 6 \text { months between the study arms as diagnosed by } \\
\text { PCR-corrected malaria microscopy }\end{array}$ \\
\hline Starting date & January 2016 \\
\hline Contact information & Chanthap Lon (chantapl@afrims.org) \\
\hline Notes & clinicaltrials.gov/ct2/show/record/NCT02653898 \\
\hline
\end{tabular}

\section{NCT02938975}

\begin{tabular}{ll}
\hline Trial name or title & Field Efficacy Of Insecticide Treated Uniforms And Skin Repellents for Malaria Prevention (URCT) \\
\hline Methods & Cluster-RCT using a 4-arm non-inferiority design with 12 months of follow-up \\
\hline Participants & Healthy recruits of the Tanzanian National Service Program JKT Mgambo Camp. \\
\hline Interventions & $\begin{array}{l}\text { Ultra } 30 \text { insect repellent lotion (30\% Lipo DEET) in combination or not with permethrin facto- } \\
\text { ry-treated army combat uniforms. }\end{array}$ \\
\hline
\end{tabular}


NCT02938975 (Continued)

Outcomes

The primary epidemiological outcome will be the incidence of $P$. falciparum malaria through monthly measurement of malaria positivity by direct polymerase chain reaction (PCR) to detect parasite DNA.

\begin{tabular}{ll}
\hline Starting date & November 2017 \\
\hline Contact information & Sarah Moore (smoore@ihi.or.tz) \\
\hline Notes & clinicaltrials.gov/ct2/show/record/NCT02938975
\end{tabular}

Abbreviations: RCT: randomized controlled trial.

\section{DATA AND ANALYSES}

\section{Comparison 1. Topical repellent compared to placebo or no treatment}

\begin{tabular}{|c|c|c|c|c|}
\hline Outcome or subgroup title & No. of studies & $\begin{array}{l}\text { No. of partici- } \\
\text { pants }\end{array}$ & Statistical method & Effect size \\
\hline $\begin{array}{l}1 \text { Clinical malaria caused by } \\
\text { Plasmodium falciparum }\end{array}$ & 3 & 4447 & Risk Ratio (M-H, Random, 95\% Cl) & $0.65[0.40,1.07]$ \\
\hline 1.1 Without LLINs & 1 & 869 & Risk Ratio (M-H, Random, 95\% Cl) & $0.40[0.23,0.71]$ \\
\hline 1.2 With LLINS & 2 & 3578 & Risk Ratio (M-H, Random, 95\% Cl) & $0.84[0.55,1.27]$ \\
\hline $\begin{array}{l}2 \text { Plasmodium falciparum } \\
\text { parasitaemia }\end{array}$ & 4 & 13310 & Risk Ratio (M-H, Fixed, 95\% Cl) & $0.84[0.64,1.12]$ \\
\hline 2.1 Without LLINs & 1 & 897 & Risk Ratio (M-H, Fixed, 95\% Cl) & $0.78[0.53,1.16]$ \\
\hline 2.2 With LLINs & 3 & 12413 & Risk Ratio (M-H, Fixed, 95\% Cl) & $0.91[0.60,1.38]$ \\
\hline $\begin{array}{l}3 \text { Clinical malaria caused by } \\
\text { Plasmodium vivax }\end{array}$ & 2 & 3996 & Risk Ratio (M-H, Fixed, 95\% Cl) & $1.32[0.99,1.76]$ \\
\hline 3.1 Without LLINS & 1 & 869 & Risk Ratio (M-H, Fixed, 95\% Cl) & $1.42[1.02,1.99]$ \\
\hline 3.2 With LLINs & 1 & 3127 & Risk Ratio (M-H, Fixed, 95\% Cl) & $1.11[0.64,1.94]$ \\
\hline $\begin{array}{l}4 \text { Plasmodium vivax para- } \\
\text { sitaemia }\end{array}$ & 3 & 9589 & Risk Ratio (M-H, Fixed, 95\% Cl) & $1.08[0.81,1.43]$ \\
\hline 4.1 Without LLINs & 1 & 897 & Risk Ratio (M-H, Fixed, 95\% Cl) & $0.98[0.68,1.40]$ \\
\hline 4.2 With LLINs & 2 & 8692 & Risk Ratio (M-H, Fixed, 95\% Cl) & $1.24[0.78,1.97]$ \\
\hline 5 Anaemia & 1 & 587 & Risk Ratio (M-H, Fixed, 95\% Cl) & $1.06[0.91,1.23]$ \\
\hline 6 All-cause fever & 1 & 3496 & Risk Ratio (M-H, Fixed, 95\% Cl) & $0.44[0.35,0.55]$ \\
\hline $\begin{array}{l}7 \text { Adherence to the inter- } \\
\text { vention }\end{array}$ & & & Other data & No numeric data \\
\hline
\end{tabular}




\section{Outcome or subgroup title No. of studies}

No. of partici- Statistical method

Effect size

pants

Analysis 1.1. Comparison 1 Topical repellent compared to placebo or no treatment, Outcome 1 Clinical malaria caused by Plasmodium falciparum.

\begin{tabular}{|c|c|c|c|c|c|}
\hline Study or subgroup & $\begin{array}{l}\text { Topical Re- } \\
\text { pellents } \\
n / N\end{array}$ & $\begin{array}{l}\text { Control } \\
n / N\end{array}$ & $\begin{array}{c}\text { Risk Ratio } \\
\text { M-H, Random, } 95 \% \mathrm{Cl}\end{array}$ & Weight & $\begin{array}{c}\text { Risk Ratio } \\
\text { M-H, Random, } 95 \% \mathrm{Cl}\end{array}$ \\
\hline \multicolumn{6}{|l|}{ 1.1.1 Without LLINs } \\
\hline Rowland 2004 & $17 / 468$ & $36 / 401$ & - & $35.05 \%$ & $0.4[0.23,0.71]$ \\
\hline Subtotal $(95 \% \mathrm{Cl})$ & 468 & 401 & $\infty$ & $35.05 \%$ & $0.4[0.23,0.71]$ \\
\hline \multicolumn{6}{|c|}{ Total events: 17 (Topical Repellents), 36 (Control) } \\
\hline \multicolumn{6}{|c|}{ Heterogeneity: Not applicable } \\
\hline \multicolumn{6}{|c|}{ Test for overall effect: $\mathrm{Z}=3.16(\mathrm{P}=0)$} \\
\hline \multicolumn{6}{|l|}{ 1.1.2 With LLINS } \\
\hline Sluydts 2016 & $29 / 1604$ & $33 / 1523$ & $\rightarrow$ & $39.01 \%$ & $0.83[0.51,1.37]$ \\
\hline Sangoro 2014a & $12 / 227$ & $14 / 224$ & $\longrightarrow$ & $25.93 \%$ & $0.85[0.4,1.79]$ \\
\hline Subtotal $(95 \% \mathrm{Cl})$ & 1831 & 1747 & & $64.95 \%$ & $0.84[0.55,1.27]$ \\
\hline \multicolumn{6}{|c|}{ Total events: 41 (Topical Repellents), 47 (Control) } \\
\hline \multicolumn{6}{|c|}{ Heterogeneity: $\operatorname{Tau}^{2}=0 ; \mathrm{Chi}^{2}=0, \mathrm{df}=1(\mathrm{P}=0.98) ; \mathrm{I}^{2}=0 \%$} \\
\hline \multicolumn{6}{|c|}{ Test for overall effect: $Z=0.84(P=0.4)$} \\
\hline Total $(95 \% \mathrm{Cl})$ & 2299 & 2148 & & $100 \%$ & $0.65[0.4,1.07]$ \\
\hline \multicolumn{6}{|c|}{ Total events: 58 (Topical Repellents), 83 (Control) } \\
\hline \multicolumn{6}{|c|}{ Heterogeneity: $\operatorname{Tau}^{2}=0.1 ; \mathrm{Chi}^{2}=4.2, \mathrm{df}=2(\mathrm{P}=0.12) ; \mathrm{I}^{2}=52.39 \%$} \\
\hline \multicolumn{6}{|c|}{ Test for overall effect: $Z=1.71(P=0.09)$} \\
\hline \multicolumn{6}{|c|}{ Test for subgroup differences: $\mathrm{Chi}^{2}=4.2, \mathrm{df}=1(\mathrm{P}=0.04), \mathrm{I}^{2}=76.18 \%$} \\
\hline
\end{tabular}

Analysis 1.2. Comparison 1 Topical repellent compared to placebo or no treatment, Outcome 2 Plasmodium falciparum parasitaemia.

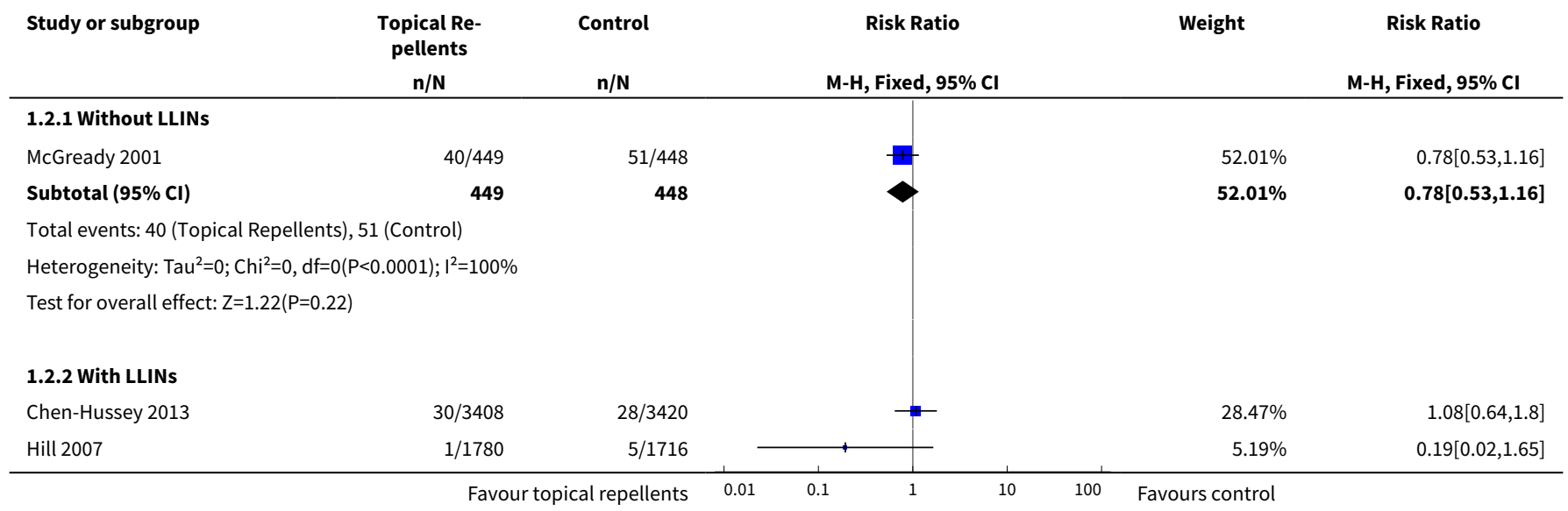




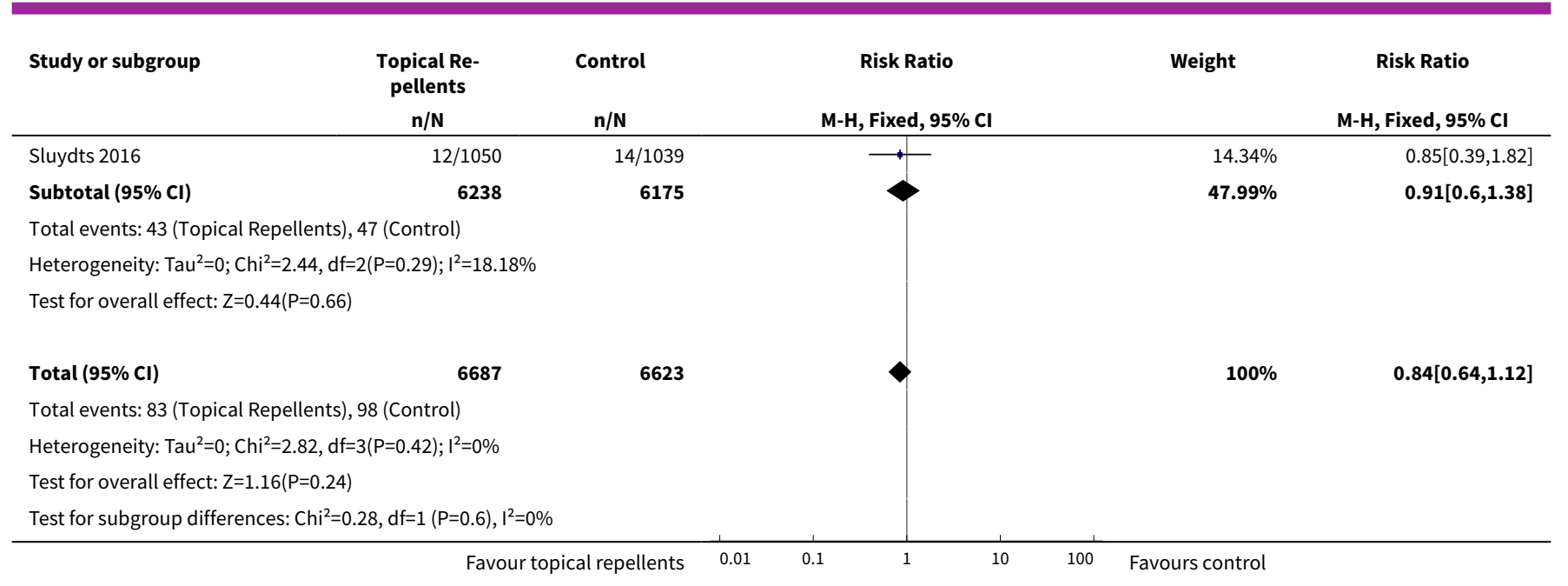

Analysis 1.3. Comparison 1 Topical repellent compared to placebo or no treatment, Outcome 3 Clinical malaria caused by Plasmodium vivax.

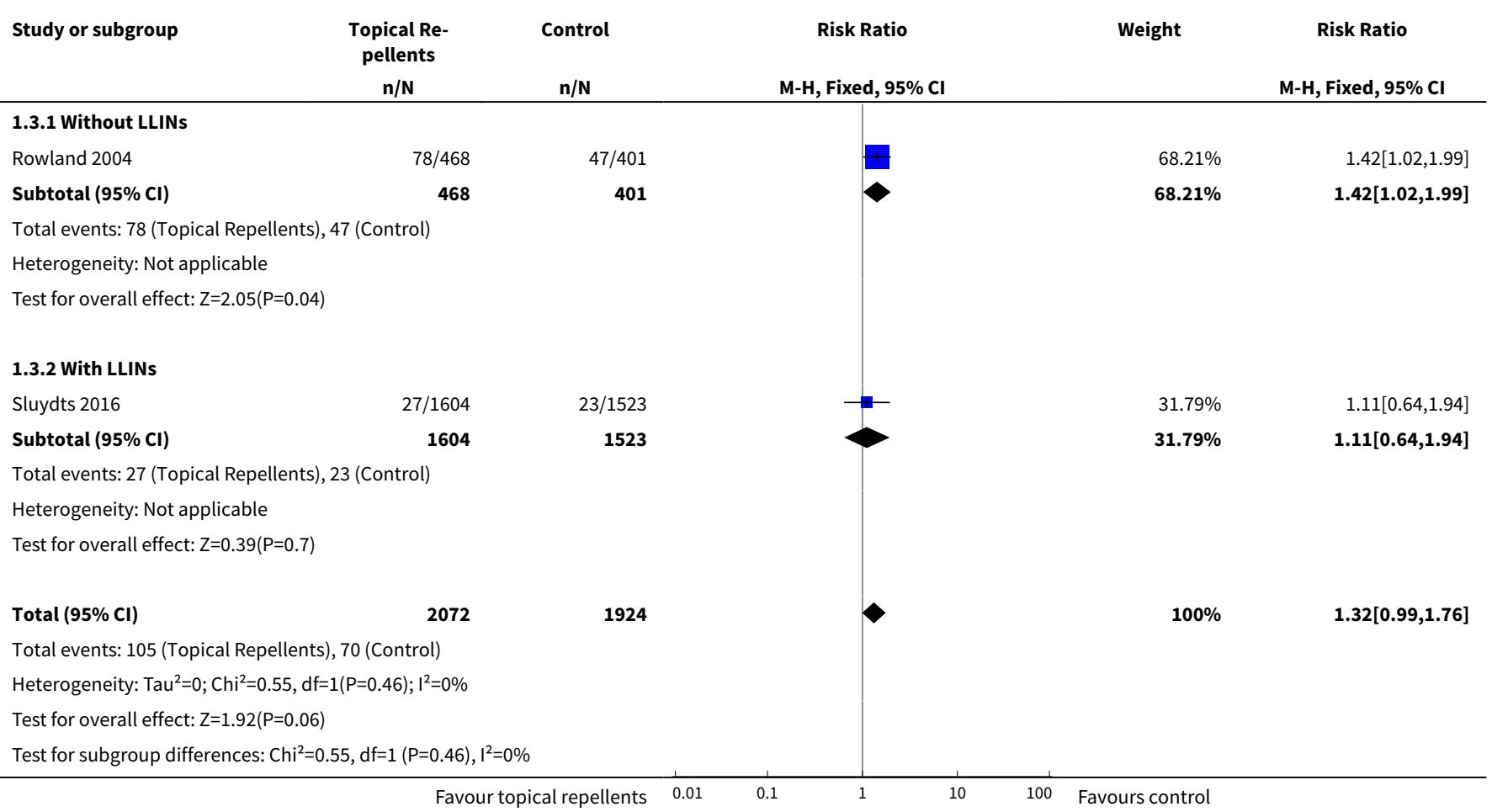


Analysis 1.4. Comparison 1 Topical repellent compared to placebo or no treatment, Outcome 4 Plasmodium vivax parasitaemia.

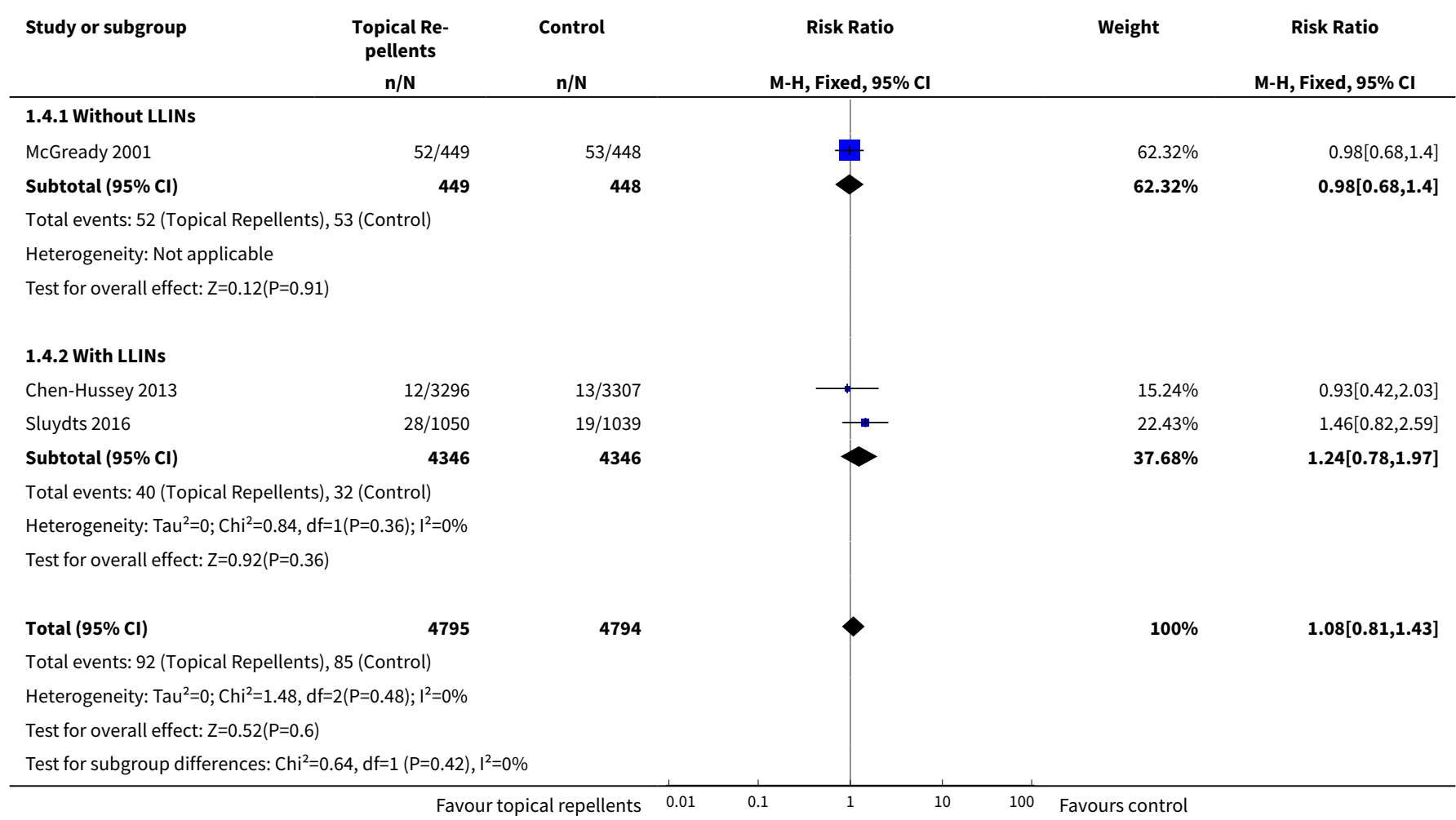

\section{Analysis 1.5. Comparison 1 Topical repellent compared to placebo or no treatment, Outcome 5 Anaemia.}

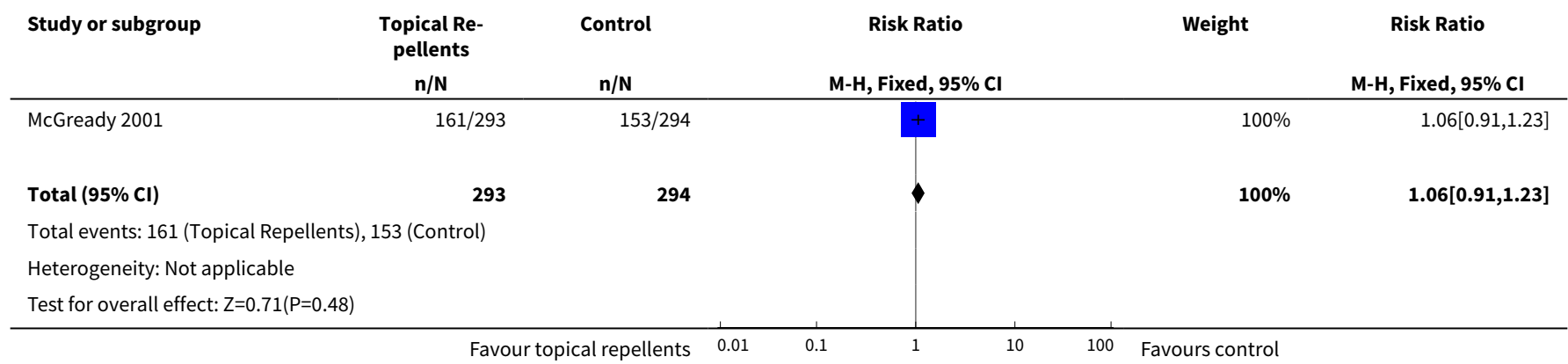

\section{Analysis 1.6. Comparison 1 Topical repellent compared to placebo or no treatment, Outcome 6 All-cause fever.}

\begin{tabular}{|c|c|c|c|c|c|}
\hline \multirow[t]{2}{*}{ Study or subgroup } & \multirow{2}{*}{$\begin{array}{c}\text { Topical Re- } \\
\text { pellents } \\
n / N\end{array}$} & \multirow{2}{*}{$\begin{array}{c}\text { Control } \\
\mathrm{n} / \mathrm{N} \\
\end{array}$} & Risk Ratio & \multirow[t]{2}{*}{ Weight } & \multirow{2}{*}{$\begin{array}{c}\text { Risk Ratio } \\
\text { M-H, Fixed, 95\% Cl }\end{array}$} \\
\hline & & & M-H, Fixed, $95 \% \mathrm{Cl}$ & & \\
\hline Hill 2007 & $99 / 1716$ & $236 / 1780$ & & $100 \%$ & $0.44[0.35,0.55]$ \\
\hline Total $(95 \% \mathrm{Cl})$ & 1716 & 1780 & $\diamond$ & $100 \%$ & $0.44[0.35,0.55]$ \\
\hline \multicolumn{6}{|c|}{ Total events: 99 (Topical Repellents), 236 (Control) } \\
\hline
\end{tabular}




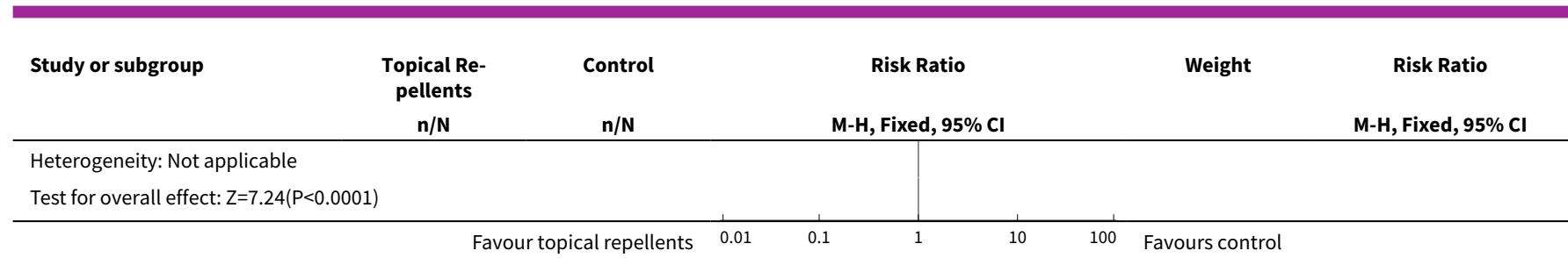

\section{Analysis 1.7. Comparison 1 Topical repellent compared to placebo} or no treatment, Outcome 7 Adherence to the intervention.

\begin{tabular}{|c|c|c|c|c|}
\hline \multicolumn{5}{|c|}{ Adherence to the intervention } \\
\hline Study & Follow up length & Method & Compliance repellent arm & Compliance treatment arm \\
\hline Chen-Hussey 2013 & Monthly & $\begin{array}{l}\text { Self reporting } \\
\text { Estimating weight of repellent } \\
\text { bottles. }\end{array}$ & $61.3 \%$ & $62.2 \%$ \\
\hline Hill 2007 & Monthly & $\begin{array}{l}\text { Self reporting } \\
\text { Random unanounced "sniff } \\
\text { check" } \\
\text { Estimating weight of repellent } \\
\text { bottles. }\end{array}$ & $98.5 \%$ & $98.5 \%$ \\
\hline McGready 2001 & Weekly & $\begin{array}{l}\text { Self reporting } \\
\text { Random spot checks }\end{array}$ & Unclear & Unclear \\
\hline Sangoro $2014 a$ & Monthly & $\begin{array}{l}\text { Self reporting } \\
\text { Mean number of bottles issued } \\
\text { to each household }\end{array}$ & Unclear & Unclear \\
\hline Sluydts 2016 & Non-periodic & $\begin{array}{l}\text { Self reporting } \\
\text { Observational studies }\end{array}$ & Unclear & Unclear \\
\hline
\end{tabular}

\section{Analysis 1.8. Comparison 1 Topical repellent compared to placebo or no treatment, Outcome 8 Adverse events.}

\begin{tabular}{|c|c|c|c|c|c|c|}
\hline \multicolumn{7}{|c|}{ Adverse events } \\
\hline Study & Follow up length & Method & Unit & $\begin{array}{l}\text { Description of } \\
\text { adverse events }\end{array}$ & Intervention arm & Control arm \\
\hline Hill 2007 & Monthly surveys & Interview & Even per household & None reported & $0 / 424$ & $0 / 436$ \\
\hline McGready 2001 & Weekly surveys & Interview & Unclear & $\begin{array}{l}6 \% \text { of the partici- } \\
\text { pants } \\
\text { reported skin warm- } \\
\text { ing sensation. }\end{array}$ & Unclear & Unclear \\
\hline Sluydts 2016 & Unclear & Unclear & Unclear & Not described & 41/unclear & \\
\hline
\end{tabular}

\section{Comparison 2. ITC compared to placebo or no treatment}

\begin{tabular}{lllll}
\hline Outcome or subgroup title & No. of studies & $\begin{array}{l}\text { No. of partici- } \\
\text { pants }\end{array}$ & Statistical method & Effect size \\
\hline $\begin{array}{l}1 \text { Clinical malaria caused by Plasmodi- } \\
\text { um falciparum }\end{array}$ & 2 & & Risk Ratio (Fixed, 95\% Cl) & $0.49[0.29,0.83]$ \\
\hline $\begin{array}{l}2 \text { Clinical malaria caused by Plasmodi- } \\
\text { um vivax }\end{array}$ & 2 & Risk Ratio (Fixed, 95\% Cl) & $0.64[0.40,1.01]$ \\
\hline
\end{tabular}


No. of participants
Effect size

Statistical method

Other data

No numeric data

Analysis 2.1. Comparison 2 ITC compared to placebo or no treatment, Outcome 1 Clinical malaria caused by Plasmodium falciparum.

\begin{tabular}{|c|c|c|c|c|c|c|c|}
\hline \multirow[t]{2}{*}{ Study or subgroup } & \multirow{2}{*}{$\begin{array}{l}\text { ITC } \\
\mathrm{N}\end{array}$} & \multirow{2}{*}{$\begin{array}{c}\text { Control } \\
\text { N }\end{array}$} & \multirow{2}{*}{$\begin{array}{c}\text { log[Risk } \\
\text { Ratio] } \\
\text { (SE) }\end{array}$} & \multicolumn{2}{|r|}{ Risk Ratio } & \multirow[t]{2}{*}{ Weight } & \multirow{2}{*}{$\begin{array}{l}\text { Risk Ratio } \\
\text { Fixed, } 95 \% \mathrm{Cl}\end{array}$} \\
\hline & & & & & IV, Fixed, 95\% CI & & \\
\hline Soto 1995 & 86 & 86 & $-2(1.52)$ & & 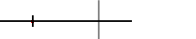 & $3.08 \%$ & $0.14[0.01,2.71]$ \\
\hline Rowland 1999 & 0 & 0 & $-0.7(0.271)$ & & 1 & $96.92 \%$ & $0.51[0.3,0.87]$ \\
\hline Total $(95 \% \mathrm{Cl})$ & & & & & $>$ & $100 \%$ & $0.49[0.29,0.83]$ \\
\hline \multicolumn{8}{|c|}{ Heterogeneity: $\mathrm{Tau}^{2}=0 ; \mathrm{Chi}^{2}=0.72, \mathrm{df}=1(\mathrm{P}=0.4) ; \mathrm{I}^{2}=0 \%$} \\
\hline \multicolumn{8}{|c|}{ Test for overall effect: $Z=2.68(P=0.01)$} \\
\hline & & & Favours ITC & 0.002 & 0.1 & Favours & \\
\hline
\end{tabular}

Analysis 2.2. Comparison 2 ITC compared to placebo or no treatment, Outcome 2 Clinical malaria caused by Plasmodium vivax.

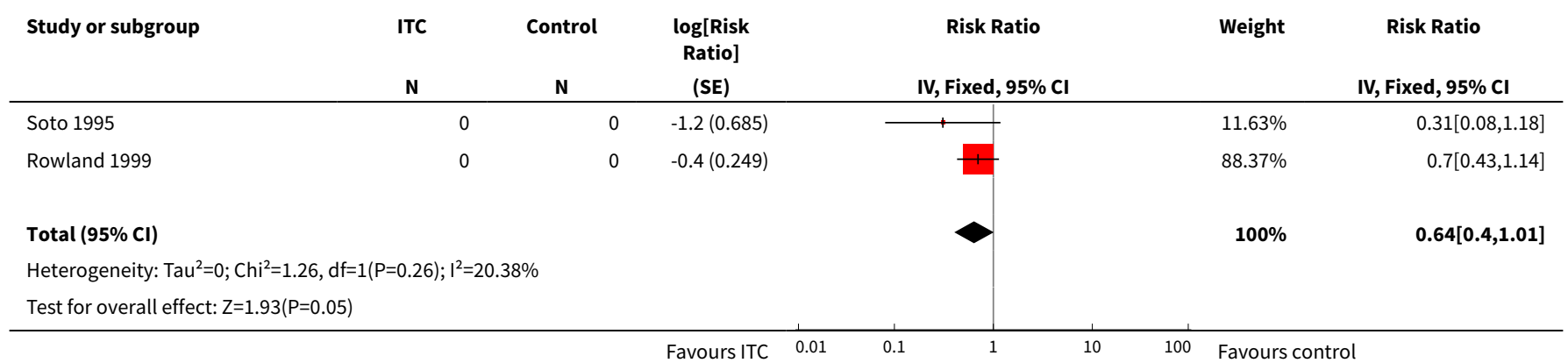

Analysis 2.3. Comparison 2 ITC compared to placebo or no treatment, Outcome 3 Adverse events.

\begin{tabular}{llllll} 
Study & Follow up length & Method & $\begin{array}{c}\text { Adverse events } \\
\text { Unit }\end{array}$ & $\begin{array}{c}\text { Description of } \\
\text { adverse events }\end{array}$ & $\begin{array}{c}\text { Intervention arm } \\
\text { Control arm }\end{array}$ \\
\hline Rowland 1999 & 16 weeks & Interview & Event per household & None reported & $0 / 438$ \\
\hline Soto 1995 & End of trial & Interview & $\begin{array}{l}\text { Event per partici- } \\
\text { pant }\end{array}$ & Skin irritation & $2 / 229$ \\
\hline
\end{tabular}


Comparison 3. Spatial repellents compared to placebo or no treatment

\begin{tabular}{lllll}
\hline Outcome or subgroup title & No. of studies & $\begin{array}{l}\text { No. of partici- } \\
\text { pants }\end{array}$ & Statistical method & Effect size \\
\hline 1 Plasmodium spp. parasitaemia & 2 & & $\begin{array}{l}\text { Risk Ratio (Random, 95\% } \\
\text { Cl) }\end{array}$ & $0.24[0.03,1.72]$ \\
\hline 2 Adherence to the intervention & 1 & Other data & No numeric data \\
\hline 3 Reduction in mosquito bites & 16 & $\begin{array}{l}\text { Mean Difference (IV, Fixed, } \\
95 \% \text { Cl) }\end{array}$ & $-10.8[-16.23,-5.37]$ \\
\hline 4 Adverse events & & Other data & No numeric data \\
\hline
\end{tabular}

Analysis 3.1. Comparison 3 Spatial repellents compared to placebo or no treatment, Outcome 1 Plasmodium spp. parasitaemia.

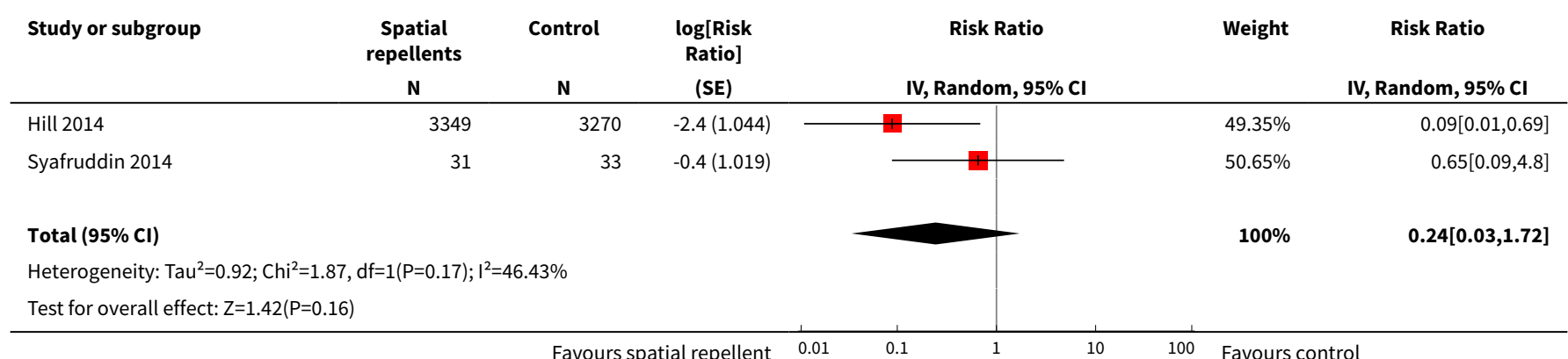

Analysis 3.2. Comparison 3 Spatial repellents compared to placebo or no treatment, Outcome 2 Adherence to the intervention.

\begin{tabular}{|c|c|c|c|c|}
\hline \multicolumn{5}{|c|}{ Adherence to the intervention } \\
\hline Study & Follow up length & Method & Compliance control arms & Compliance treatment arms \\
\hline Hill 2014 & monthly survey & $\begin{array}{l}\text { Self reporting } \\
\text { Counting of empty coil boxes }\end{array}$ & $\begin{array}{l}\text { No treatment arm: } 89.3 \% \\
\text { LLINs only arm: } 97.8 \%\end{array}$ & $\begin{array}{l}\text { Repellent coils arm: } 98.6 \% \\
\text { Repellent coils + LLINs arm: } \\
98.5 \%\end{array}$ \\
\hline
\end{tabular}

Analysis 3.3. Comparison 3 Spatial repellents compared to placebo or no treatment, Outcome 3 Reduction in mosquito bites.

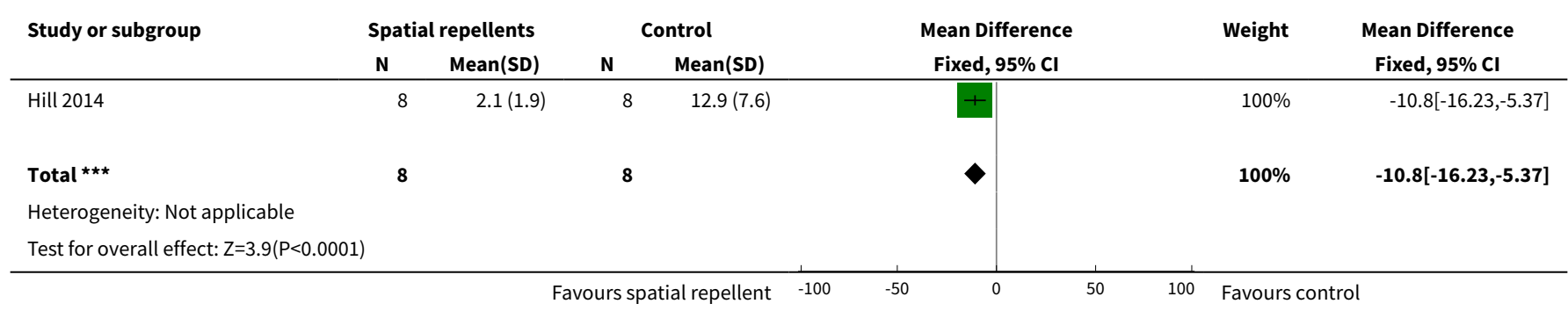


Analysis 3.4. Comparison 3 Spatial repellents compared to placebo or no treatment, Outcome 4 Adverse events.

\begin{tabular}{llllll} 
Study & Follow-up length & Method & $\begin{array}{c}\text { Adverse events } \\
\text { Unit }\end{array}$ & $\begin{array}{c}\text { Description of } \\
\text { adverse events }\end{array}$ & $\begin{array}{c}\text { Intervention arm } \\
\text { Control arm }\end{array}$ \\
\hline Syafruddin 2014 & 6 months & Interviews & Random spot-checks & None described & None reported \\
\hline
\end{tabular}




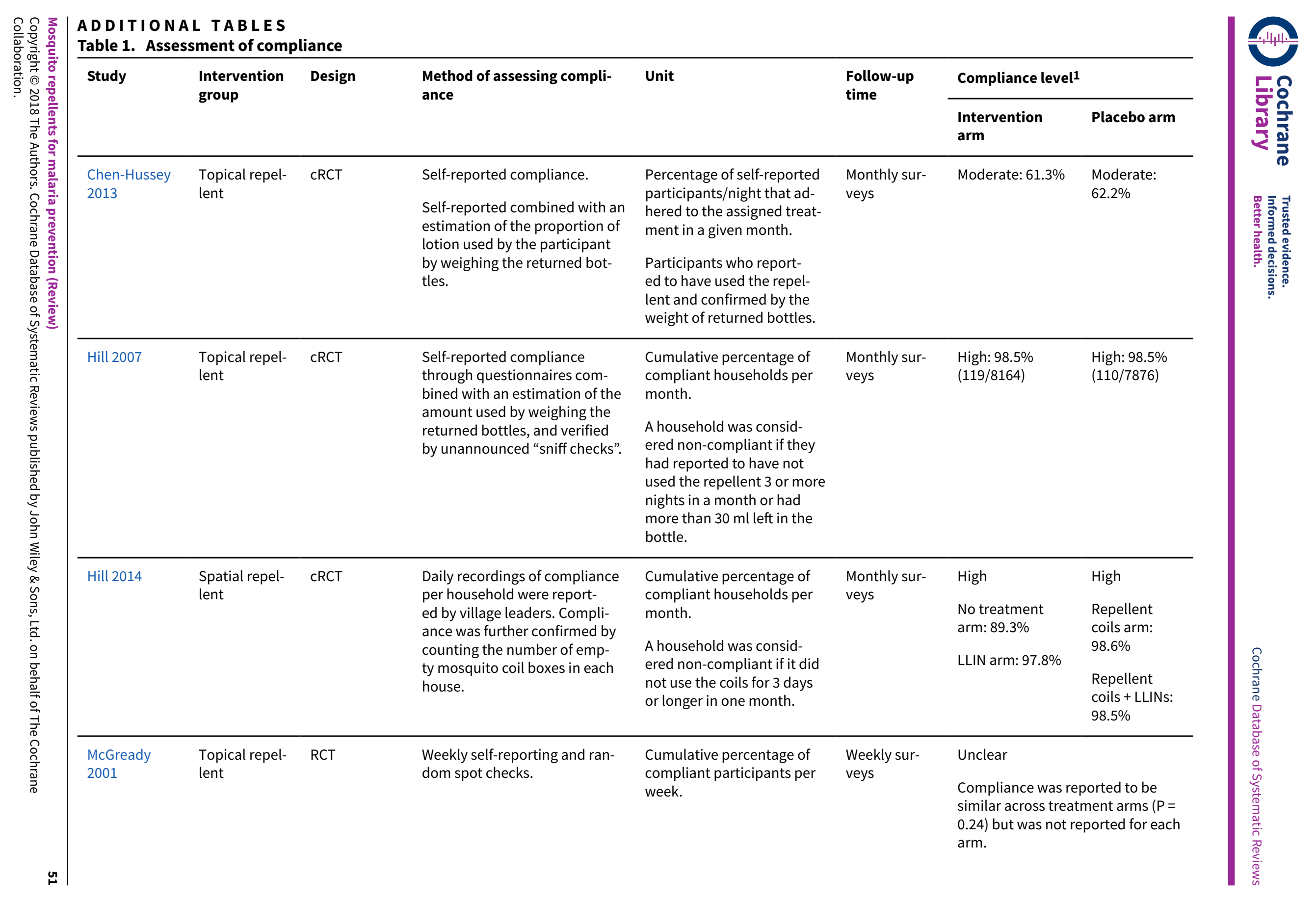




\begin{tabular}{|c|c|c|c|c|c|c|c|}
\hline \multicolumn{8}{|r|}{$\begin{array}{l}\text { Self-reported compliance: } 90.5 \% \\
(87,715 / 96,955) \\
\text { Compliance measured by spot } \\
\text { checks: } 84.6 \%(1918 / 2267)\end{array}$} \\
\hline 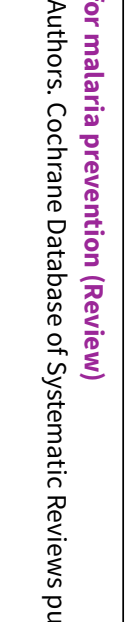 & $\begin{array}{l}\text { Sangoro } \\
2014 a\end{array}$ & $\begin{array}{l}\text { Topical repel- } \\
\text { lent }\end{array}$ & CRCT & $\begin{array}{l}\text { Self-reported compliance } \\
\text { through questionnaires com- } \\
\text { bined with an estimation of the } \\
\text { amount used by counting the } \\
\text { empty returned bottles. }\end{array}$ & $\begin{array}{l}\text { Mean number of bottles } \\
\text { of repellent issued to each } \\
\text { household per month. }\end{array}$ & $\begin{array}{l}\text { Monthly sur- } \\
\text { veys }\end{array}$ & $\begin{array}{l}\text { Unclear } \\
\text { Authors stated that self-reported } \\
\text { data was unreliable so they used } \\
\text { the data from the empty bottles to } \\
\text { estimate compliance. Compliance } \\
\text { was poorly reported. The authors } \\
\text { reported mean number of bottles } \\
\text { issued per household per month } \\
\text { rather than estimating the compli- } \\
\text { ance level for each treatment arm: } \\
\text { Repellent arm: } 6.73 \text { bottles ( } 95 \% \mathrm{Cl} \\
6.51 \text { to } 6.95) \\
\text { Placebo arm: } 6.92 \text { bottles }(95 \% \mathrm{Cl} \\
6.68 \text { to } 7.16)\end{array}$ \\
\hline 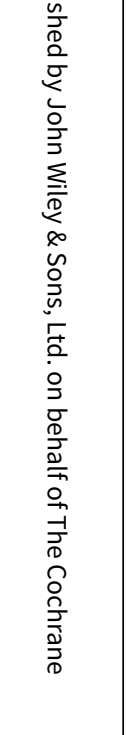 & Sluydts 2016 & $\begin{array}{l}\text { Topical repel- } \\
\text { lent }\end{array}$ & CRCT & $\begin{array}{l}\text { Self-reported compliance was } \\
\text { assessed using questionnaires } \\
\text { during } 3 \text { surveys in October } \\
\text { 2012, March } 2013 \text { and October } \\
\text { 2013. } \\
\text { The repellent consumption rate } \\
\text { was measured per family every } \\
2 \text { weeks during the repellent } \\
\text { distribution by visual inspec- } \\
\text { tion of the leftover repellent di- } \\
\text { vided into categories (for exam- } \\
\text { ple, empty, half full, full). } \\
\text { A social science study was done } \\
\text { to assess the acceptability and } \\
\text { use of repellents in } 10 \text { selected } \\
\text { clusters. }\end{array}$ & $\begin{array}{l}\text { Unit of measurement was } \\
\text { not clearly defined. } \\
\text { Self-reported compliance } \\
\text { is likely the percentage of } \\
\text { compliant households dur- } \\
\text { ing the survey period but } \\
\text { was not defined in the arti- } \\
\text { cle. } \\
\text { The repellent consumption } \\
\text { rate was not reported. } \\
\text { Social study reported per- } \\
\text { centage of participants ob- } \\
\text { served to comply with the } \\
\text { application of the repellent } \\
\text { from a small selection of } 10 \\
\text { clusters in the intervention } \\
\text { group. }\end{array}$ & $\begin{array}{l}\text { Non-period- } \\
\text { ic surveys (in } \\
\text { October 2012, } \\
\text { March } 2013 \\
\text { and October } \\
\text { 2013) along } \\
\text { the duration } \\
\text { of the trial. }\end{array}$ & $\begin{array}{l}\text { Self-reported } \\
\text { compliance was } \\
\text { reported around } \\
70 \% \text {. } \\
\text { However, obser- } \\
\text { vational studies } \\
\text { reported compli- } \\
\text { ance between } 6 \% \\
\text { and } 15 \% \text {. }\end{array}$ \\
\hline
\end{tabular}

) 1 Levels of compliance: high: > 80\%; moderate: $50 \%$ to $79 \%$; low: $<50 \%$. 
Table 2. Epidemiology of malaria and major vector of the study region

\begin{tabular}{|c|c|c|c|c|c|c|c|}
\hline Study & Intervention & Design & Transmission intensity $\mathbf{1 , 2}$ & Region & Main malaria vectors & Biting times & $\begin{array}{l}\text { Efficacy of } \\
\text { the inter- } \\
\text { vention at } \\
\text { repelling } \\
\text { Anophelines } \\
\text { tested at } \\
\text { baseline? (V) } \\
\text { N) }\end{array}$ \\
\hline $\begin{array}{l}\text { Chen-Hussey } \\
2013\end{array}$ & $\begin{array}{l}\text { Topical repel- } \\
\text { lent }\end{array}$ & CRCT & $\begin{array}{l}\text { Hypoendemic } \\
0.83 \% \text { P. falciparum } \\
0.4 \% \text { P. vivax } \\
\text { Measured through active case } \\
\text { detection }\end{array}$ & $\begin{array}{l}\text { South East } \\
\text { Asia - Laos }\end{array}$ & $\begin{array}{l}\text { Anopheles dirus } \\
\text { An. minimus } \\
\text { An. maculatus }\end{array}$ & $\begin{array}{l}\text { From 18:00 to 2:00 } \\
\text { with peak biting time } \\
\text { from 21.00 to } 02.00 .\end{array}$ & No \\
\hline Hill 2007 & $\begin{array}{l}\text { Topical repel- } \\
\text { lent }\end{array}$ & CRCT & $\begin{array}{l}\text { Hypoendemic } \\
0.31 \% \text { P. falciparum } \\
\text { Measured through active case } \\
\text { detection }\end{array}$ & $\begin{array}{l}\text { South Amer- } \\
\text { ica: Bolivian } \\
\text { Amazon Re- } \\
\text { gion }\end{array}$ & An. darlingi & $\begin{array}{l}\text { Peak biting activity be- } \\
\text { tween } 8 \text { p.m. and } 10 \\
\text { p.m. }\end{array}$ & $\begin{array}{l}\text { Yes } \\
\text { Moore } 2002\end{array}$ \\
\hline Hill 2014 & $\begin{array}{l}\text { Spatial repel- } \\
\text { lent }\end{array}$ & CRCT & $\begin{array}{l}\text { Hypoendemic } \\
0.06 \% \text { P. falciparum } \\
0.28 \% \text { P. vivax } \\
\text { Measured through active case } \\
\text { detection }\end{array}$ & $\begin{array}{l}\text { South East } \\
\text { Asia: Yunnan } \\
\text { Province of } \\
\text { China }\end{array}$ & $\begin{array}{l}\text { An. sinensis } \\
\text { An. minimus } \\
\text { An. kochi } \\
\text { An. splendidus } \\
\text { An barbirostris } \\
\text { An. vagus } \\
\text { An. jeyporiensis } \\
\text { An. annularis } \\
\text { An. philippinsis } \\
\text { An. tessallatus } \\
\text { An. maculatus }\end{array}$ & $\begin{array}{l}\text { Given the diversity of } \\
\text { vectors in the area the } \\
\text { biting activity occurs } \\
\text { from early evening ex- } \\
\text { tending to later in the } \\
\text { night. }\end{array}$ & Yes \\
\hline
\end{tabular}




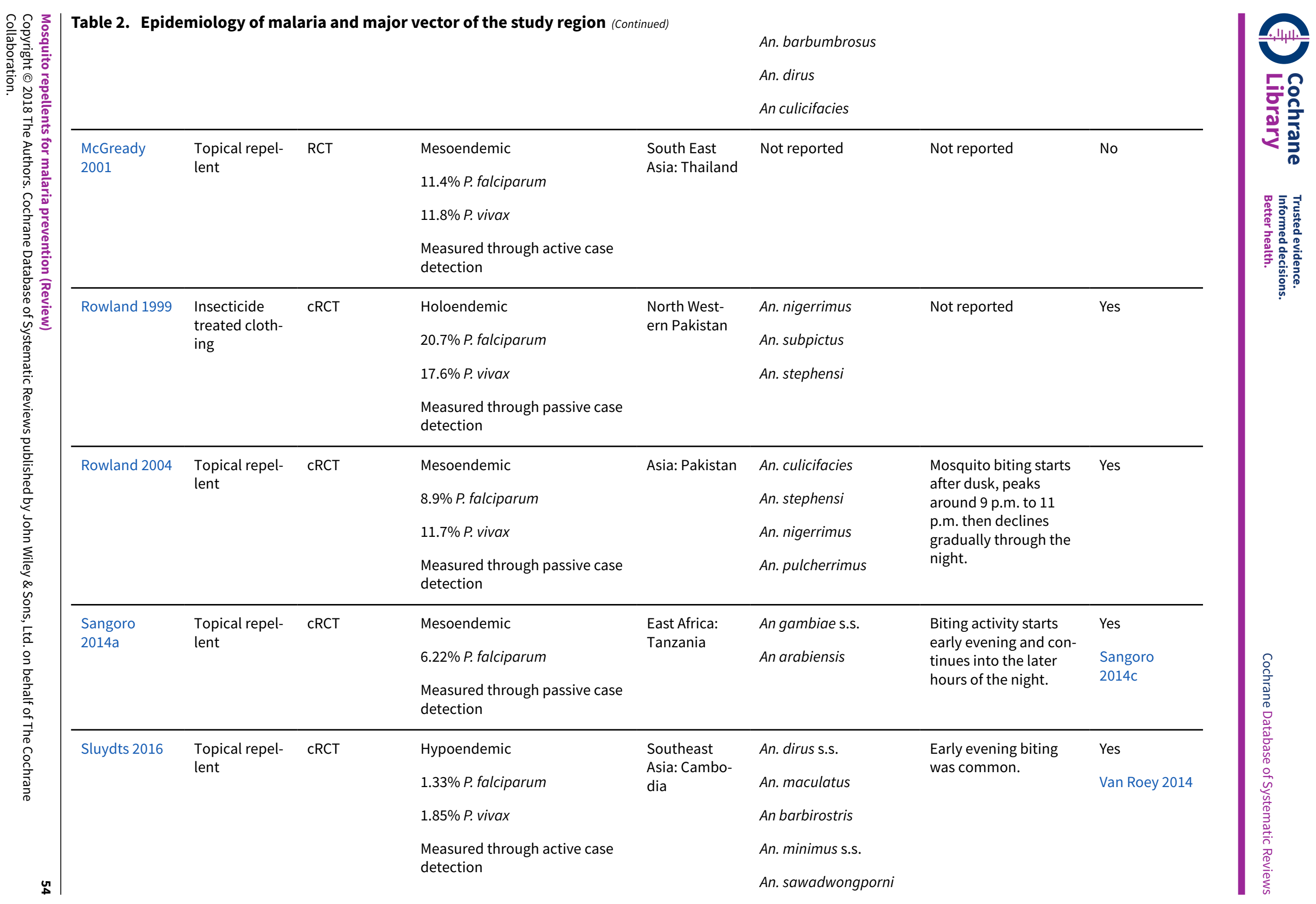




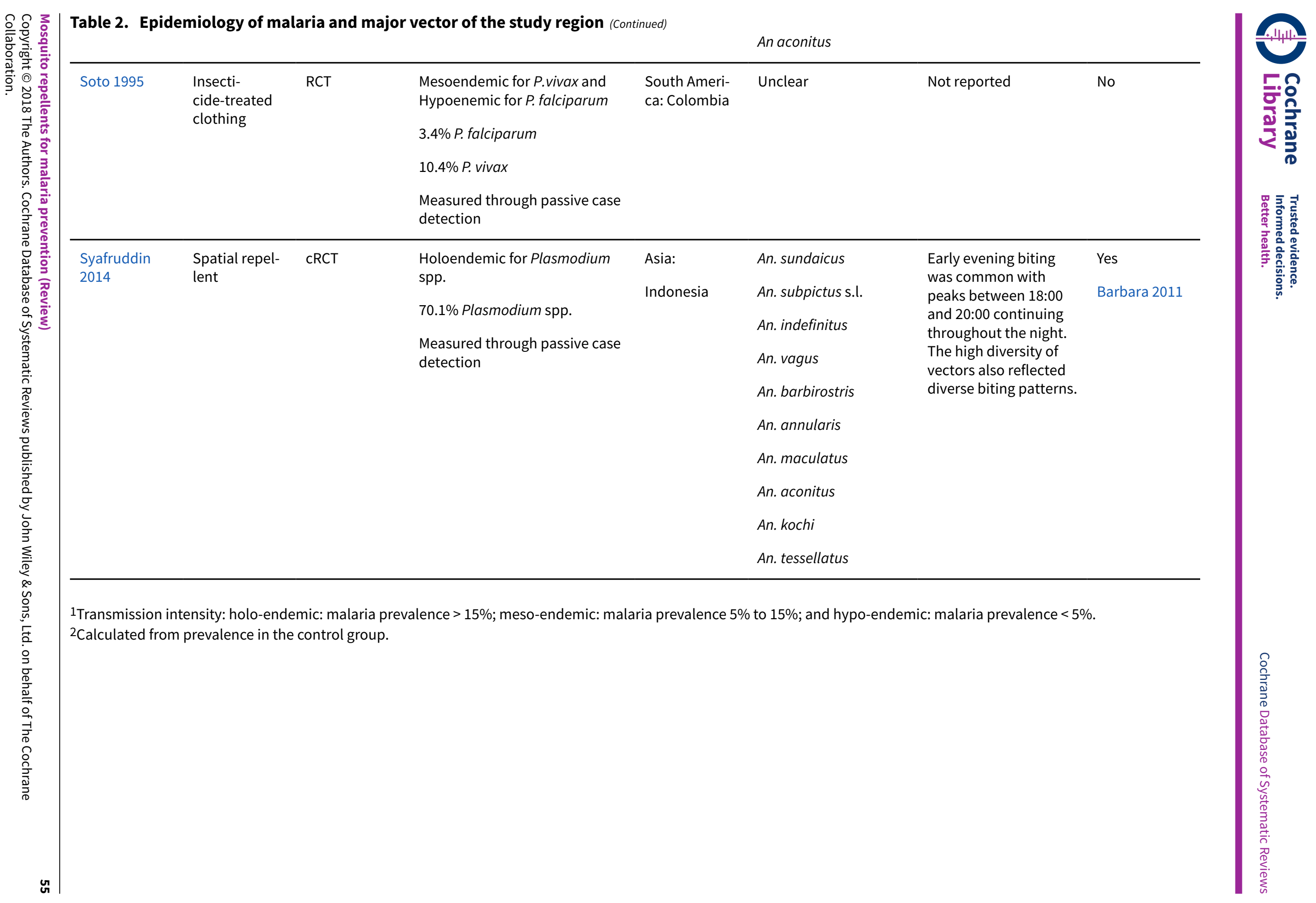


Table 3. Malaria diagnostic methods

\begin{tabular}{|c|c|c|c|c|c|c|}
\hline Study & Intervention & Design & $\begin{array}{l}\text { Diagnostic } \\
\text { method }\end{array}$ & Validated & $\begin{array}{l}\text { Plasmodium species in the } \\
\text { region }\end{array}$ & $\begin{array}{l}\text { Partic- } \\
\text { ipants } \\
\text { screened } \\
\text { and } \\
\text { cleared for } \\
\text { vivax }(\mathrm{Y} / \mathrm{N})\end{array}$ \\
\hline $\begin{array}{l}\text { Chen-Hussey } \\
2013\end{array}$ & Topical repellent & CRCT & $\mathrm{mRDT}$ & Yes, by PCR & $\begin{array}{l}80 \% \text { P. falciparum } \\
20 \% \text { P. vivax }\end{array}$ & No \\
\hline Hill 2007 & Topical repellent & CRCT & $\mathrm{mRDT}$ & No & $\begin{array}{l}\text { P. falciparum } \\
\text { P. vivax }\end{array}$ & $\mathrm{No}^{1}$ \\
\hline Hill 2014 & Spatial repellent & CRCT & mRDTs & $\begin{array}{l}\text { Yes, positive } \\
\text { RDTs were vali- } \\
\text { dated through } \\
\text { thick blood } \\
\text { slide. }\end{array}$ & $\begin{array}{l}32 \% \text { P. falciparum } \\
58 \% \text { P. vivax }\end{array}$ & Yes \\
\hline $\begin{array}{l}\text { McGready } \\
2001\end{array}$ & Topical repellent & $\mathrm{RCT}$ & $\begin{array}{l}\text { Blood } \\
\text { smear }\end{array}$ & No & $\begin{array}{l}\text { P. falciparum } \\
\text { P. vivax }\end{array}$ & No \\
\hline $\begin{array}{l}\text { Rowland } \\
1999\end{array}$ & $\begin{array}{l}\text { Insecticide-treated } \\
\text { clothing }\end{array}$ & CRCT & $\begin{array}{l}\text { Blood } \\
\text { smear }\end{array}$ & No & $\begin{array}{l}\text { P. falciparum } \\
\text { P. vivax }\end{array}$ & No \\
\hline $\begin{array}{l}\text { Rowland } \\
2004\end{array}$ & Topical repellent & CRCT & $\begin{array}{l}\text { Blood } \\
\text { smear }\end{array}$ & No & $\begin{array}{l}\text { P. falciparum } \\
\text { P. vivax }\end{array}$ & No \\
\hline $\begin{array}{l}\text { Sangoro } \\
2014 a\end{array}$ & Topical repellent & CRCT & $\mathrm{mRDT}$ & $\begin{array}{l}\text { Unclear if mi- } \\
\text { croscopy was } \\
\text { used for valida- } \\
\text { tion of positive } \\
\text { mRDTs }\end{array}$ & Mainly P. falciparum & No1 \\
\hline Sluydts 2016 & Topical repellent & CRCT & PCR & No & $\begin{array}{l}\text { P. falciparum } \\
\text { P. vivax }\end{array}$ & No \\
\hline Soto 1995 & $\begin{array}{l}\text { Insecticide-treated } \\
\text { clothing }\end{array}$ & $\mathrm{RCT}$ & $\begin{array}{l}\text { Blood } \\
\text { smear }\end{array}$ & No & $\begin{array}{l}\text { P. falciparum } \\
\text { P. vivax }\end{array}$ & No \\
\hline $\begin{array}{l}\text { Syafruddin } \\
2014\end{array}$ & Spatial repellent & CRCT & $\begin{array}{l}\text { Blood } \\
\text { smear }\end{array}$ & No & $\begin{array}{l}\text { P. falciparum } \\
\text { P. vivax }\end{array}$ & Yes \\
\hline
\end{tabular}

1 mRDT was only specific for P. falciparum. 


\section{APPEN DICES}

\section{Appendix 1. Search strategies \\ MEDLINE (PubMed)}

\begin{tabular}{|c|c|}
\hline Search & Query \\
\hline \#21 & Search (\#20) AND \#17 \\
\hline \#20 & Search (\#19) OR \#18 \\
\hline \#19 & $\begin{array}{l}\text { Search "Randomised Controlled Trial" [Publication Type] OR "Controlled Clinical Trial" [Publica- } \\
\text { tion Type] }\end{array}$ \\
\hline \#18 & Search randomised OR placebo OR randomly OR groups OR trial Field: Title/Abstract \\
\hline \#17 & Search (\#16) AND \#8 \\
\hline$\# 16$ & Search $((((((\# 9)$ OR \#10) OR \#11) OR \#12) OR \#13) OR \#14) OR \#15) \\
\hline \#15 & Search “vaporizer mat"” Field: Title/Abstract \\
\hline \#14 & Search "personal protection*” Field: Title/Abstract \\
\hline$\# 13$ & Search "impregnated cloth*" Field: Title/Abstract \\
\hline$\# 12$ & Search "electric emanator" Field: Title/Abstract \\
\hline$\# 11$ & Search Spray OR sprays OR lotion* OR gel OR gels OR roll-on* OR wipe* Field: Title/Abstract \\
\hline$\# 10$ & Search "insecticide treated clothing" OR ITC Field: Title/Abstract \\
\hline \#9 & Search repellen* Field: Title/Abstract \\
\hline \#8 & Search ((\#5) OR \#6) OR \#7 \\
\hline$\# \underline{7}$ & Search "Anopheles"[Mesh] \\
\hline \#6 & Search "Mosquito Control"[Mesh] \\
\hline \#5 & Search (\#4) AND \#1 \\
\hline \#4 & Search (\#2) OR \#3 \\
\hline \#3 & Search ("Insect Vectors"[Mesh]) \\
\hline \#2 & Search vector ${ }^{\star}$ OR mosquito* Field: Title/Abstract \\
\hline$\# 1$ & Search malaria Field: Title/Abstract \\
\hline
\end{tabular}

\section{Cochrane Library}

\#1 "malaria":ti,ab,kw (Word variations have been searched)

\#2 vector ${ }^{\star}$ or mosquito*:ti,ab,kw (Word variations have been searched) 
\#3 MeSH descriptor: [Insect Vectors] explode all trees

\#4 MeSH descriptor: [Anopheles] explode all trees

\#5 \#2 or \#3 or \#4

\#6 \#1 and \#5

\#7 MeSH descriptor: [Mosquito Control] explode all trees

\#8 \#6 or \#7

\#9 Spray or sprays or lotion* or gel or gels or roll-on* or wipe* or repellen* or coil*:ti,ab,kw

\#10 "insecticide treated clothing" or ITC:ti,ab,kw

\#11 "passive emanator " ti,ab,kw

\#12 "electric emanator*" ti,ab,kw

\#13 "vaporizer mat*" ti,ab,kw

\#14 "personal protection" ti,ab,kw

$\# 15 \# 9$ or \#10 or \#11 or \#12 or \#13 or or \#14

$\# 16$ \#8 and \#15

Embase (OVID)

\begin{tabular}{|c|c|}
\hline Results & Search Type \\
\hline 1 & malaria.mp. or malaria/ \\
\hline 2 & insect vectors.mp. or disease carrier/ \\
\hline 3 & mosquito/ or mosquito.mp. \\
\hline 4 & Anopheles/ \\
\hline 5 & 2 or 3 or 4 \\
\hline 6 & 1 and 5 \\
\hline 7 & mosquito control.mp. \\
\hline 8 & 6 or 7 \\
\hline 9 & insect repellent/ or insecticide treated clothing.mp. \\
\hline 10 & $\begin{array}{l}\text { (coil }{ }^{\star} \text { or spray or sprays or lotion* or gel or gels or roll-on* or wipe*).ab. or (coil }{ }^{\star} \text { or spray or sprays } \\
\text { or lotion* or gel or gels or roll-on }{ }^{\star} \text { or wipe }{ }^{\star} \text { ).ti. }\end{array}$ \\
\hline 11 & passive emanator $^{\star}$.ab. or passive emanator ${ }^{\star}$.ti. \\
\hline 12 & electric emanator ${ }^{\star}$.ab. or electric emanator ${ }^{\star}$.ti. \\
\hline 13 & vaporizer mat*.ab. or vaporizer mat*.ti. \\
\hline 14 & personal protection.ab. or personal protection.ti. \\
\hline
\end{tabular}


(Continued)

\begin{tabular}{ll}
15 & 9 or 10 or 11 or 12 or 13 or 14 \\
\hline 16 & 8 and 15 \\
\hline 18 & clinical trial/ \\
\hline 19 & randomised controlled trial/ \\
\hline 20 & 17 or 18 \\
\hline 21 & randomisation/ \\
\hline 22 & (single blind* or double blind $). \mathrm{mp}$. \\
\hline 23 & random allocation.mp. \\
\hline 24 & randomly allocated.mp. \\
\hline 25 & cluster randomised.mp. \\
\hline 26 & 17 or 18 or 20 or 21 or 22 or 23 or 24 \\
\hline
\end{tabular}

\section{CABI: CAB Abstracts ${ }^{\circledast}$}

\begin{tabular}{|c|c|}
\hline \multirow[t]{3}{*}{ \# 5} & \#4 AND \#3 \\
\hline & Timespan=All years \\
\hline & Search language=Auto \\
\hline \multirow[t]{3}{*}{ \# 4} & TOPIC: (randomised OR double-blind* or single-blindOR placebo OR randomly) \\
\hline & Timespan=All years \\
\hline & Search language $=$ Auto \\
\hline \multirow[t]{3}{*}{ \# 3} & \#2 AND \#1 \\
\hline & Timespan=All years \\
\hline & Search language $=$ Auto \\
\hline \multirow[t]{3}{*}{ \#2 } & $\begin{array}{l}\text { TOPIC: (Spray or sprays or lotion* or gel or gels or roll-on* or wipe* }{ }^{\star} \text { repellen* or coil*) OR TOPIC: } \\
\text { (insecticide treated clothing) OR TOPIC: (vaporizer mat }{ }^{\star} \text { ) OR TOPIC: (personal protection) }\end{array}$ \\
\hline & Timespan=All years \\
\hline & Search language $=$ Auto \\
\hline \multirow[t]{3}{*}{$\# 1$} & TOPIC: (malaria) AND TOPIC: (vector^ OR mosquito* OR anopheles) \\
\hline & Timespan=All years \\
\hline & Search language $=$ Auto \\
\hline
\end{tabular}




\begin{tabular}{ll}
\hline Database : & LILACS \\
\hline Search on : & $\begin{array}{l}\text { malaria and (mosquito } \$ \text { or vector\$) [Words] and repellent\$ or spray } \$ \text { or coils or emanator } \$ \text { or va- } \\
\text { porizer } \$ \text { or clothing [Words] and randomised or trial or controlled or placebo [Words] }\end{array}$ \\
\hline
\end{tabular}

\section{CONTRIBUTIONS OF AUTHORS}

MM, MV, and SJM developed the protocol with statistical input from MR. MM and MV screened search outputs, selected trials for inclusion, extracted the data, assessed risk of bias, analysed the data and prepared the draft manuscript. MR provided statistical support. CL and SJM critically engaged with the manuscript and provided comments.

SJM is an investigator on two of the studies included in this review; however the author was not involved in decisions regarding inclusion, assessment of risk of bias, data extraction or interpretation of the results of this trial. MM and MK evaluated the trials and conducted all tasks in regard to these studies with no input from SJM.

All review authors have seen and approved the final manuscript.

\section{DECLARATIONS OF INTEREST}

MM, MK, MR, and CL have no conflicts of interest in any way related to the content of the review. They have no financial interests in relation to repellents for mosquito avoidance, either in the form of participations or incomes from commercial activities, patents, or from any form of sponsorship.

SJM has received salary coverage from BMGF research grant and PSI for two studies included in this review. However she did not have any role in deciding inclusion, assessment of risk of bias, data extraction, or interpretation of the results of those trials. In addition, SJM currently holds a research grant funded by the Deployed War Fighters Protection Fund evaluating permethrin-treated clothing, which has been included in the review as an on-going study. SJM declares no further known conflicts of interest.

\section{SOURCES OF SUPPORT}

\section{Internal sources}

- Cochrane Infectious Diseases Group, UK.

- Liverpool School of Tropical Medicine, UK.

\section{External sources}

- University of Notre Dame, USA.

Award number 261655. Salary of MM and SM.

- Department of International Development (DFID), UK.

Grant: 5242

\section{DIFFERENCES BETWEEN PROTOCOL AND REVIEW}

With regard to $P$. vivax infections, we had originally described in the protocol that data on $P$. vivax from studies that had not cleared parasites at start would be excluded. However only two of the included studies, which both focused on spatial repellents, cleared parasites at start. If a study undertook a proper randomization, recrudescent infections would be similar between treatment arms. For this reason we decided to include data on $P$. vivax regardless of whether infections had been cleared at start or not.

We also decided to subgroup by use or not of LLINs as a co-intervention rather than by endemicity level, compliance and diagnostic methods, as described in the protocol. This was done because we believe there was heterogeneity between studies that included and did not include LLINs as co-interventions. Also, given that current malaria control programmes all incorporate LLINs, we believe policy makers are mostly interested in the combined effect of LLINs with topical repellents rather than these on their own. 


\section{N D EX TERMS}

\section{Medical Subject Headings (MeSH)}

${ }^{\star}$ Culicidae; *Insect Repellents; *Protective Clothing; Incidence; Insecticide-Treated Bednets; Malaria, Falciparum [epidemiology] ["prevention \& control]; Malaria, Vivax [epidemiology] [* prevention \& control]; Randomized Controlled Trials as Topic

\section{MeSH check words}

Animals 